\title{
From Multiple PAR1 Receptor/Protein Interactions to their Multiple Therapeutic Implications
}

\author{
Marta Gutiérrez-Rodríguez and Rosario Herranz*
}

Instituto de Química Médica (CSIC), Juan de la Cierva 3, E-28006 Madrid, Spain

Dedicated to Professor M. Teresa GarcíaŁópez, former supervisor and friend, on occasion of her retirement after a distinguished scientific career on Medicinal Chemistry

\begin{abstract}
PAR1, member of the family of protease-activated receptors, is a GPCR whose activation requires a proteolytic cleavage at its extracellular $\mathrm{N}$-terminus to unveil a tethered activating ligand. Although thrombin is the main activator of this receptor, diverse other proteases can also activate and disarm PAR1. Besides, tethered activating ligand-based peptides (PAR-APs) can also activate the receptor. PAR1 mainly signals via G proteins but, it can also signal using $\beta$-arrestin pathways and by transactivation of other receptors. This complex PAR1 interactome is completed with the receptor desensitization, trafficking, and degradation. PAR1 has shown species-, cellular-, and physiological or pathological state-dependent specificity. This review try to give an overview on the complex PAR1 interactome, its therapeutic impact upon the cardiovascular, immune and nervous systems, inflammation and cancer, as well as, on its modulation with agonists and antagonists.
\end{abstract}

Keywords: G-Protein signaling, Interactome, PAR1, PAR1 modulators, PPIs, Protease-activated receptors, Therapeutic target, Thrombin.

\section{INTRODUCTION}

The protease-activated receptor PAR1 was discovered in 1991 as the receptor responsible of thrombin signaling on cells. This receptor was cloned from human [1] and hamster [2] cells highly responsive to thrombin, in Xenopus oocytes. As other PARs, PAR1 is a member of the G-protein coupled receptor (GPCR) class A, which contains a central core of seven transmembrane hydrophobic helices connected by three extracellular and three intracellular loops (Fig. 1). Unlike most GPCRs that are reversibly activated by extracellular ligands, PAR activation requires a proteolytic cleavage at the $\mathrm{N}$-terminal extracellular domain, which unveils the recognition sequence, termed "tethered ligand". This tethered ligand remains attached to the receptor and its intramolecular binding to the extracellular loops triggers conformational changes and signaling. Although thrombin is the main physiological regulator of PAR1 activity, numerous other proteases also cleave and activate this receptor, such as factor $X a(F X a)$, activated protein $C(A P C)$, plasmin, granzyme $A$, kallikrein-related peptidases (KLKs), matrix metalloprotease-1 (MMP-1), neutrophil elastase (NE), and neutrophil protease-3 (PR3). Not all these proteases cleave PAR1 at the same site. Therefore, they can expose a variety of tethered ligands that can lead signaling through different pathways. PARs not only signal through $\mathrm{G}-$ proteins, they can also transmit signals through betaarrestins or by transactivation of other receptors. Finally, although there is little knowledge on the desensitization and trafficking of PAR1, its irreversible activation suggests a signal termination mechanism different from that of the classical GPCRs. In summary, as other PARs, PAR1 is part of a complex network of protein-protein interactions (PPIs) not completely deciphered, which needs to be cleared up for the validation of PAR 1 as a true therapeutic target. Modulators of PAR1 activity are essential tools to decoding its complex crosstalk system and, although some peptides, peptidomimetics and small molecules, agonists and antagonists, some of them in clinical trials, are known, their number is very limited and little is known about their binding sites. In the last years several good reviews have deal with different aspects of activation, signaling and therapeutic implications of PAR 1 [3-15]. This work is focused on aspects of PPIs, their modulation and therapeutic implications.

2. PRIMARY STRUCTURE, SPECIES AND CELLULAR SPECIFIC EXPRESSION

Human PAR1 has an extracellular amino terminal domain of 102 amino acids, comprising a signal peptide of 21 residues, followed by a propeptide that includes the serine protease cleavage recognition sequence, in the case of activation by thrombin up to residue 41 [1]. The proteolytic cleavage at this site, unmasks the tethered activating ligand (TAL), S $S^{42} F L L R N^{47}$ for thrombin, which interacts intramolecularly with the second extracellular loop (ECL2) and with the ligand binding site (LBS, $L^{84}$ PAFIS ${ }^{89}$ ), also localized at the $N$-terminal exodomain $[16,17]$. This domain also contains a hirudin-like sequence within residues $51-63\left(K^{51} Y_{E P F}{ }^{55}\right)$, which is essential for high affinity binding of thrombin. This serine protease is an extremely potent agonist of PAR1 $\left(E_{50}=50 \mathrm{pM}\right)$, whose activation is blocked by the thrombin inhibitors hirudin and hirugen [1]. Synthetic peptides derived from the tethered ligand, named "PAR1-activating peptides" (PAR1-APs), can activate the receptor without need of proteolytic activation. The pentapeptide SFLLR is the minimum sequence for full agonist activity but, in general, PAR-APs show much lower potency than thrombin $\left(E C_{50}\right.$ $>1 \mu \mathrm{M})$, low PAR selectivity, and their signaling can differ from that of the activating protease $[5,6,18,19]$. 
In spite of the high sequence homology, some differences across species have been found in the tethered ligand domain (SFLLRN human and SFFLRN rodent) [20]. These sequence discrepancies determine the affinities of their respective APs and, as these are used as receptor agonists in pharmacological studies, the affinity differences must be considered to choose the appropriate $A P$, depending on the animal species under study.

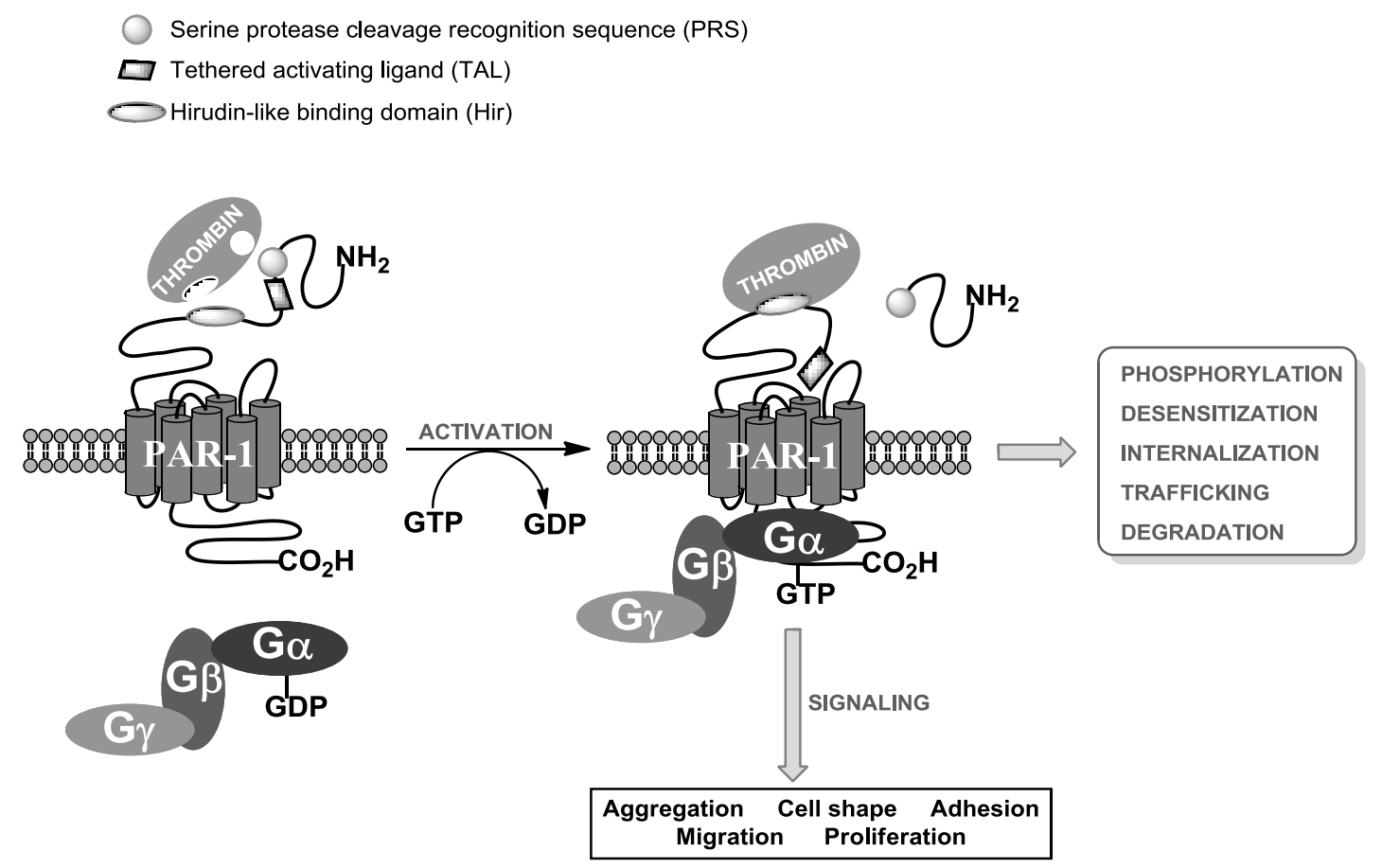

Fig. (1). Simplified representation of the PAR1 functional domains, thrombin-mediated activation, and G-protein signaling.

PARs present also animal species specificity in their cellular expression and signaling [10]. For example, human platelets express PAR1 and PAR4, which signal independently, whereas PAR3 and PAR4 are responsible of thrombin signaling in mouse platelets, and guinea-pig platelets express PAR1, PAR3, and PAR4. Noteworthy, key species of trial animals, such as mice, rats, and dogs, lack PAR1 on their platelets [21]. This species specificity complicates the development of modulators, as their in vivo studies must be realized in primates.

In mouse endothelial cells thrombin activates PAR1 and PAR4 [22]. However, human endothelial cells, not express PAR4. Depending on the type of blood vessel and animal species, different physiological and pathological effects of PAR1 activation have been reported $[9,23]$. The PAR profile in vascular smooth muscle cells and fibroblasts indicates that PAR1 is the main thrombin responsive receptor and PAR3 and PAR4 are not expressed in these cells [20]. PAR1 expression in normal vascular smooth muscle cells is limited, but it is considerably increased in cells localized in vascular lesions [10]. Thrombin and PAR1 agonist peptides have shown both vasodilating and vasoconstricting activity depending on the species and the experimental conditions employed.

PAR 1 is also expressed in neurons and astrocytes in the central nervous system (CNS), and in neurons of the peripheral nervous system, where they have important regulatory roles both in normal and disease states $[5,6,13$, 14]. In normal brain, thrombin is involved in the synaptic organization and plasticity, while in neurodegenerative disorders it has dual opposite effects [24, 25]. Thus, low concentrations of thrombin rescue neural cells from death after brain damage, whereas at high concentrations augments the brain damage. These dual effects are mediated by PAR1 activation.

Additionally, PAR1 is present in diverse inflammatory and immune cells, where it seems to play important roles regulating immune responses and inflammatory processes [19]. PAR1 is expressed in mast cells, monocytes, macrophages, T cells, and natural killer cells, but not in neutrophils [7]. 
3. PAR1 ACTIVATION, EXTRACELLULAR PROTEIN-PROTEIN INTERACTIONS

Although many proteases have been found to cleave and activate PARs in cultured cells (Table 1), the capacity of a protease to signal via PARs in intact tissues depends on many factors [6]. Proteases must be generated or released in the appropriate concentration to activate PARs. Although low concentrations of proteases could cleave PARs on the cell surface, it is the rate of hydrolysis which determines the magnitude of the signal [26]. Hydrolysis and activation of PARs may require the presence of cofactors. For example, the binding of $\alpha$-thrombin to the glycoprotein $\mid \beta \alpha$, a cell-surface platelet protein, accelerates the cleavage and activation of PAR1 [27]. The capacity of a protease to signal will depend on the availability of endogenous protease inhibitors which regulate the effects of many proteases in vivo. Although many proteases capable of activating PARs have been identified in cultured cells, the contribution of these activations to physiological and pathological processes is unknown.

Thrombin is the major physiological regulator of PAR1, which unveils the tethered ligand $S^{42} F L L R N^{47}$, by cleaving the $N$-terminal domain of PAR1 at the $R^{41^{\prime}}-S^{42}$ peptide bond. However, other coagulation enzymes can also activate this receptor. Thus, during coagulation, factor VIla (FVIIa) binds tissue factor (TF), and the complex TFFVIla signals, in part, through PAR1 and PAR2 [28, 29]. Although FVIla, even at high concentrations, does not activate PAR1 or PAR2 expressed in Xenopus oocytes, when these receptors are coexpressed together with TF, FVIla efficiently activates PAR2 and, to a lesser degree, PAR1. Similarly, soluble factor $X a(F X a)$ weakly activates PAR1, PAR2, and PAR4, but when it is associated in the complex TFFVIla-FXa potently activates PAR1 and PAR2 [28, 30-32]. The receptor responsible of FXa signaling depends on the cell and its cofactor expression. In endothelial cells and human vascular smooth muscle cells, this signaling is mainly due to PAR2 [33, 34], while in lung fibroblasts [35] and human atrial tissue slices [36], FXa mainly signals via PAR1. These FVIla and FXa signaling mechanisms may have particular importance during septic shock, when expression of TF is upregulated on several cell types [6]

The anticoagulant activated protein C (APC) also induces cellular responses through the activation of PAR1 [37]. Low levels of thrombin are usually present in the blood and they participate in the anticoagulant APC process when vessels remain intact. Under these circumstances, thrombomodulin binds thrombin to the endothelial cell surface, where thrombin transforms protein $C$, bound to the endothelial protein $C$ receptor (EPCR), into APC. Then, APC is released from the EPCR and, as a circulating anticoagulant protein, degrades FVa and FVIla. However, when retained at the cell surface, the EPCR APC complex induces activation of PAR1 [38]. This APC-induced PAR1 activation mediates, in large part, the anti-inflammatory and neuroprotective effects of APC [39]. Studies analyzing the hydrolysis of synthetic peptides corresponding to the $\mathrm{N}$-terminal exodomain of PAR1 have demonstrated that APC hydrolyses PAR1 at the same position that thrombin $\left(R^{41}-S^{42}\right)$. However, the activation of this receptor on the endothelial cell surface by the APC-EPCR complex is 100-1000-fold less efficient than by thrombin and dependent on the expression level of EPCR [37]. By contrast, as the half live of thrombin is estimated to be only a few seconds and the half live of APC is significantly longer ( 10-30 min), the APC concentration relative to thrombin may be high enough to allow significant activation of PAR1 by APC. This protease concentration influence could explain some responses of PAR1, dependent on the kinetics of its activation [38]. Recent studies have also shown that, whereas thrombin activation of PAR 1 causes endothelial disruptive, pro-inflammatory effects, mediated through Gprotein signaling, APC exerts endothelial cytoprotective actions via PAR 1 activation, through $\beta$-arrestin 2 signaling [40]. This activation is mediated by the "noncanonical" cleavage of the $\mathrm{N}$-terminal domain at the $\mathrm{R}^{46} \mathrm{~N}^{47}$ peptide bond $[40,41]$, with a different tethered ligand to that of the unveiled by thrombin. A synthetic peptide comprising PAR1 residues 47-66, named TR47, stimulated the protective signaling in endothelial cells, as reflected in Akt and GSK $3 \beta$ phosphorylation and endothelial barrier stabilization [40]. In mice, TR47 reduced vascular endothelial growth factor (VEGF)-induced vascular leakage.

Plasmin can also affect PAR1. The effects are complex, since this enzyme can both activate and deactivate PAR1 [19]. It has been shown that plasmin can both activate and inhibit platelets, depending on its concentration. Low concentrations of plasmin inhibit platelets by truncating the PAR1 exodomain at the $\mathrm{R}^{70} / \mathrm{K}^{76} / \mathrm{K}^{82}$ sites, inactivating and desensitizing the receptor. Whereas higher concentrations of plasmin activate PAR 1 by the cleavage at the $\mathrm{R}^{41}$ site (the same as thrombin) [42]. In astrocytes and neuronal cultures plasmin activates PAR1, while in CA1 pyramidal neurons it potentiates NMDA receptor synaptic currents [43].

Amongst the immune cell-derived proteases, granzymes $A, B$, and $K$ induce neurotoxicity via activation of PAR1. In neuronal cells and astrocytes, granzyme A causes morphological changes, as neurite retraction, mediated through activation of PAR1 by cleavage at the same site that thrombin [44]. In cultured human neuronal cells, gramzyme B induce neurotoxicity by interacting with PAR1, followed by increased expression and activation of the potassium channel Kv1.3 and Notch-1 [45]. Granzyme K activates PAR1, inducing fibroblast cytokine secretion and proliferation [46].

Several tumor-derived proteases also activate PAR1, such as the kallikrein-related peptidases (KLKs), which have received significant attention. Although the targets of $K L K$ s are not clear, it has been proposed that these serine proteases could signal by regulating PAR activity [19]. Depending on its concentration, KLK14 could both activate (high concentration) and disarm (low concentration) PAR1 [19]. Recent data suggest that, by activating PARs, tumor-related $K L K s$, such as $K L K 4$, $K L K 6$, and $K L K 14$, may play active roles in setting carcinogenesis [47-49].. A question to resolve is whether or not the high levels of KLKs in tumor-derived or body fluid samples represent enzymatically active species. The data suggest that, although the proportion of enzymatically active KLKs is low, the amount of active enzyme 
produced by tumors could be sufficient to participate in the regulation of PAR activity [47].

Matrix metalloproteases MMP-1 and MMP-13, two proteases produced in the setting of tumorigenesis also regulate PAR activity $[50,51]$. These metalloproteases are tumor-cell-derived enzymes that can promote the invasive activity of cancer cells by PAR1 activation [52-54] Furthermore, these zinc-dependent metalloproteases, members of the family of collagenases, are expressed in most human tissues, including the majority of cell types in the blood vessel wall, inflammatory cells, and platelets.
Recently, it has been shown that both MMP-1 and MMP13 activate PAR1 through cleavage at "noncanonical" sites distinct from thrombin. MMP-1 cleaves PAR1 at the $D^{39}$ $\mathrm{P}^{40}$ peptide bond, unmasking a two amino acid longer tethered ligand $\left(P^{40} R S F L L R N^{47}\right)$. This cleavage activates a biased signaling cascade in human platelets, by preferential activation of $G \alpha_{12 / 13}$ proteins, while thrombin preferentially activates Gaq [51, 55, 56]. MMP-13 activates PARl through the cleavage of the $S^{42} F^{43}$, although there is little knowledge about its signaling cascade [57]

Table 1. PAR1 activating proteases and their participation in PAR1 inactivation

\begin{tabular}{|c|c|c|c|}
\hline Activating protease & Cleavage site & PAR1-APs & PAR1 inactivation \\
\hline Thrombin & $R^{41} \downarrow S^{42}$ & \multirow{4}{*}{$\begin{array}{c}\text { SFLLRN } \\
\text { TFRRRL [58] } \\
\text { TFLLR-NH }{ }_{2} \text { [59] } \\
\text { YFLLRNP [60] }\end{array}$} & No \\
\hline TF/FVIIa & $R^{41} \downarrow S^{42}$ & & No \\
\hline TF/FVIla/FXa & $R^{41} \downarrow S^{42}$ & & No \\
\hline \multirow{2}{*}{ APC } & $R^{41} \downarrow S^{42}$ & & \multirow{2}{*}{ No } \\
\hline & $R^{46} \downarrow N^{47}$ & $N^{47} P N D K Y E P F W E D E E K N E S G L^{66} a$ & \\
\hline Plasmin & $R^{41} \downarrow S^{42}$ & \multirow{2}{*}{$\begin{array}{l}\text { SFLLRN } \\
\text { TFRRRL } \\
\text { TFLLR-NH } 2 \\
\text { YFLLRNP }\end{array}$} & Yes \\
\hline Granzymes A, B, K & $R^{41} \downarrow S^{42}$ & & No \\
\hline KLK4, KLK6, KLK14 & Unknown & Unknown & Yes \\
\hline MMP-1 & $D^{39} \downarrow P^{40}$ & $P^{40}$ RSFLLRN ${ }^{47 b}$ & No \\
\hline MMP-13 & $S^{42} \downarrow F^{43}$ & Unknown & No \\
\hline NE & $L^{45} \downarrow R^{46}$ & $R^{46} N P N D K Y E^{53 c}$ & Yes \\
\hline PR3 & $A^{36} \downarrow T^{37}$ & $T^{37} L D P R S F L L R^{46 c}$ & Yes \\
\hline Gingipains HRgpA and RgpB & Unknown & Unknown & Unknown \\
\hline Streptokinase-plasminogen & Unknown & Unknown & Unknown \\
\hline
\end{tabular}

${ }^{a}$ Reference [40]. ${ }^{b}$ References [51,55 and 56]. ${ }^{c}$ Reference [61]

Recently, it has been described that the neutrophilderived proteases neutrophil elastase (NE) and proteinase3 (PR3) also trigger signaling through PAR1, but in a different manner to thrombin [61]. These serine proteases unmask two different "noncanonical" tethered ligands that lead to activation of Gai coupled to p42/44 MAPK signaling, but not Gaq-coupled calcium signaling. Thus, in an inflammatory setting, enzymes released by infiltrating neutrophils would modulate PAR1 signaling by silencing its calcium signaling and activating MAPK pathways. NE cleavages the PAR1 exodomain at the $L^{45}-R^{46}$ peptide bond, while PR3 cleavages the $A^{36}-T^{37}$ peptide bond. The corresponding activating tethered ligand sequences have been identified and each of these sequences appear to be capable of triggering distinct subsets of PAR1 signals, presumably, by inducing unique conformational changes in the receptor [61]. In human kidney glomerular endothelial cells, PR3, but not NE, activates PAR1, although the precise cleavage site has not been identified [62]. Besides, both proteases cleavage and inactivate PAR1 in a time- and concentration-dependent manner, disarming the receptor.

Some bacterial proteases can also signal through mammalian PARs. Among them, the bacterial argininespecific gingipains-R (HRgpA and RgpB), produced by Porphyromonas gingivallis, main origin of human periodontitis, have been implicated in this disease. It has been described that HRgpA and RgpB induce platelet 
aggregation with a similar potency to thrombin and that this effect is mediated by PAR1 and PAR4 [63]. These results have revealed a novel mechanism by which bacteria influence mammalian cells. This mechanism could explain the relation between periodontitis and cardiovascular disorders. In human oral epithelial cells, RgpB activates both PAR1 and PAR2, induces interleukin-6 secretion [64] and upregulates expression of the pro-inflammatory cytokines IL-1 $\alpha, \mid L-1 \beta$, IL-6 and TNF- $\alpha$ [65]. In human gingival fibroblasts Rgps induce the production of hepatocyte growth factor (HGF) through activation of PAR1 and PAR2 [66]. In human monocytic cells, gingipains also trigger the production of pro-inflammatory cytokines (IL-8, $\mid L-6$, and MCP-1) through activation of PAR1, PAR2 and PAR3 [67].

Finally, it has been reported that platelet activation by the bacterial proteins streptokinase-plasminogen involves PAR1 activation and antistreptokinase antibodies [68].

\section{PAR1 SIGNALING, INTRACELLULAR PROTEIN-PROTEIN INTERACTIONS}

In general, PAR signaling activates several complex signal pathways for which, presently, there is limited information regarding their molecular determinants. First, as GPCRs, they signal mainly via G proteins; second, they can signal through $\beta$-arrestin pathways, as above commented for the activation of PAR 1 by APC; and third, they also signal by transactivation of a variety of receptors (Fig. 2) [15]. Due to the complexity of signal transduction networks of PAR1, most of their molecular crosstalk remains undefined. As an example of this complexity, a recent quantitative phosphoproteomic study of the thrombin signaling in human endothelial cells has identified 2224 thrombin-regulated phosphorylation sites, many of them related to its signaling through PAR1 [69].

\subsection{Signaling via $G$ proteins}

PAR1 activation induces conformational changes in the transmembrane domains, the intracellular loops (i1-i3), and in the C-terminal domain, also termed i4. These conformational changes favor the interaction of the receptor with heterotrimeric $G$ proteins through its intracellular loops. In the inactive state, a $G \alpha$ subunit is bound to guanosine diphosphate (GDP) and a G $\beta \gamma$ subunit complex. Activated GPCRs induce a conformational change in the G $\alpha \beta \gamma$ trimeric complex that provokes the exchange of GDP for GTP in the Ga subunit. With this exchange $G \alpha$ is released from the complex with $G \beta \gamma$. Then, both $G$ protein moieties ( $G \alpha-G T P$ and $G \beta \gamma$ ) independently interact with downstream signaling effectors. It seems that in the PAR1/G protein interaction, the N-terminal $\alpha$-helix of the $G \alpha$ subunit interacts both with PAR1 and the $G \beta$ subunit [70].

Although a complete knowledge of the PAR1 Gprotein signaling mechanisms lacks, it seems that they are cell-specific and may depend on the PAR1 localization within the plasma membrane [71]. Besides, it is known that cross-talk between diverse $G$ protein-linked pathways exists $[72,73]$. PAR1 signals through three of the four $G \alpha$ protein subfamilies, $G_{i / 0}, G_{q}$, and $G_{12 / 13}$.
Coupling to $G \alpha_{i / 0}$ inactivates adenylate cyclase, suppressing the formation of CAMP, and activates pertussis toxin (PTX)-sensitive MAPK signaling, resulting in the activation of phosphatidylinositol 3 -kinase $\left(\mathrm{PI}_{3} \mathrm{~K}\right)$ [74] and the phosphorylation of ERK1/2 [71]. These signaling pathways have been implicated in PAR 1mediated platelet activation [4, 71]. A recent study has indicated that, in platelets, PAR 1 -mediated $\mathrm{PI}_{3} \mathrm{~K}$ activation induces activation and cytoskeletal translocation of the protein kinase $C K 2$, which is associated with activation of GPIIb/IIla and platelet aggregation [75]. Another report has shown that PAR1 activates the tumor progression locus 2 (Tp/2), a kinase required for downstream activation of the MAPKs extracellular kinases ERK1/2. This activation is via $G \alpha_{i 2}$, through the activation of phospholipase $\mathrm{C} \beta_{3} \quad\left(\mathrm{PLC} \beta_{3}\right)$, which generates inositol triphosphate $\left(\mathrm{IP}_{3}\right)$ that promotes the release of $\mathrm{Ca}^{2+}$ and $\mathrm{Ca}^{2+}$-dependent cell migration [76].

The coupling of PAR1 to $\mathrm{G} \alpha_{12}$ and $\mathrm{G} \alpha_{13}$ controls cell shape and migration [6]. These G-protein subunits interact with Rho guanine-nucleotide exchange factors (GEFs) [18, 77, 78], allowing Rho-mediated control of cell shape and migration, as well as with serum response elements (SRE) [79]. In platelets, this $\mathrm{G \alpha}_{12 / 13}$ induced activation of Rhokinases is involved in thrombin-induced shape changes $[80,81]$, while, in fibroblasts and endothelial cells, it is involved in permeability and migration [18, 78, 82, 83]. RhoA is involved in the PAR1-mediated reorganization and cell growth of cardiomyocytes [84]. PAR1-mediated activation of Rho-kinases is also involved in the cytoskeleton reorganization, cell migration and invasion in tumor cells $[77,85,86]$. PAR1 regulates the activity of endothelial nitric oxide synthase (eNOS), by inhibition of the enzyme upon activation of the Rho/Rho-kinase (ROCK) pathway and activation via Gaq/protein kinase C (PKC) $\delta$ [87]. $G \alpha_{13}$ has been involved in the PAR1induced stabilization of $\beta$-catenin and in cancer [88].

The main coupling of PAR1 to G-proteins is via $G \alpha_{a}$ $[6,18]$. This coupling activates phospholipase C $\beta$ (PLC $\beta)$ [89], to generate inositol triphosphate $\left(I P_{3}\right)$, which produces calcium mobilization, and diacylglycerol (DAG) that activates protein kinase C (PKC). This pathway leads to activation of calcium-and PKC-regulated kinases, such as mitogen-activated protein kinases (MAPKs), and phosphatases [90]. Given the important mitogenic role of thrombin, there has been considerable interest in PAR1 coupling to the MAPK cascades $[5,6]$. In particular, the MAPK ERK $1 / 2$ module is important in cell proliferation and differentiation. Most information about the regulation of this module comes from the study of tyrosine kinase receptors, such as the epidermal growth factor receptor (EGFR). Activation of this receptor opens the cascade of phosphorylation from protein Ras to ERK1/2. This cascade can be activated via PKC [91] or by PAR1-induced transactivation of EGFR [6, 90, 92-94]. In fibroblasts, PAR1 activation induces production of the chemokine CCL2 by coupling to $\mathrm{G} \alpha_{a}$ in cooperation with the Rho signaling pathways through $\mathrm{Ga}_{12 / 13}$ [73]. Coupling of neuronal PAR1 to $\mathrm{G} \alpha_{\mathrm{a}}$ regulates endocannabinoid 2arachidonoylglycerol signaling, which activates presynaptic $\mathrm{CB}_{1}$ receptors and suppresses transmitter release at hippocampal inhibitory synapses [95]. 


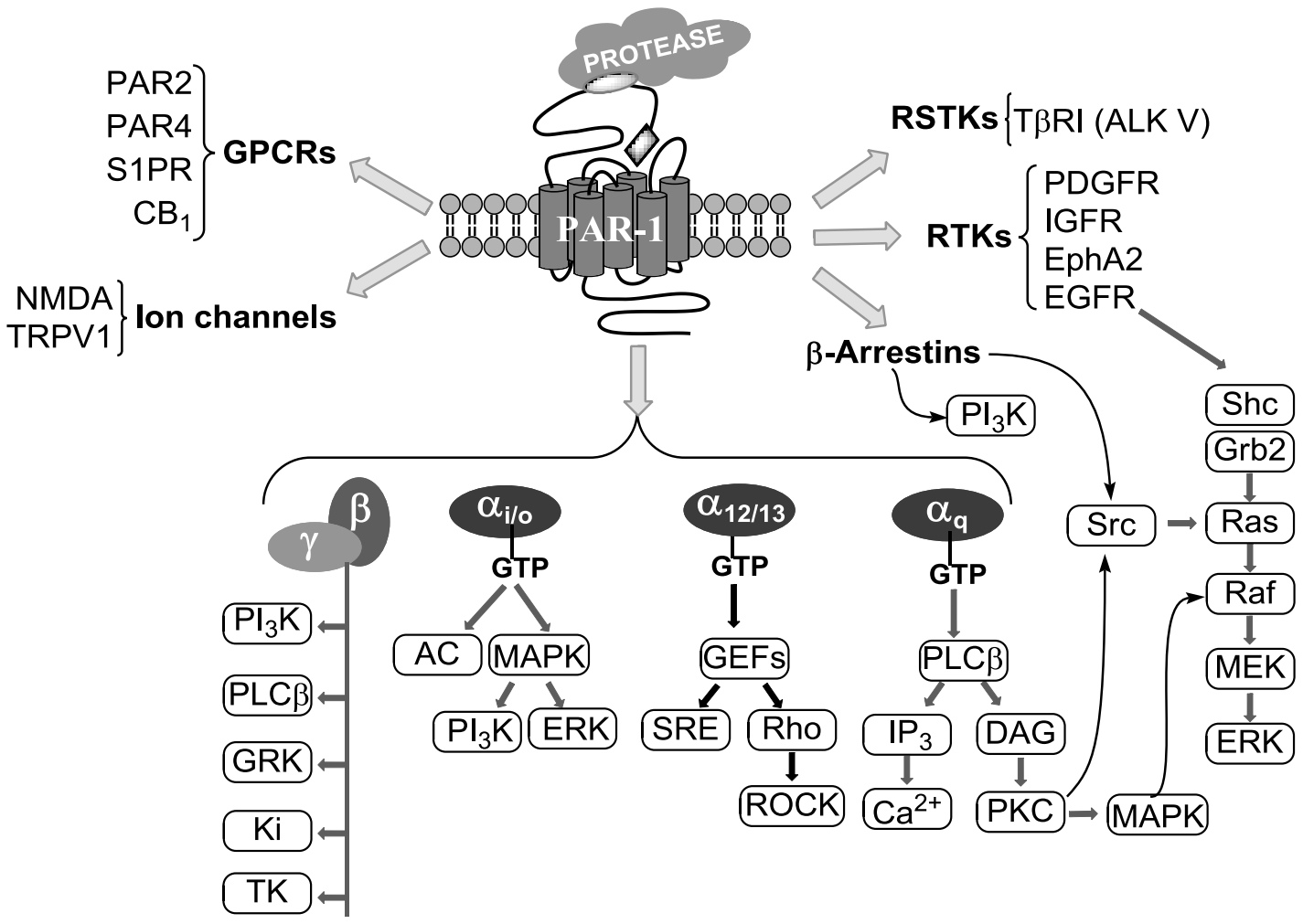

Fig. (2). Simplified scheme of the complex PAR1 interactome.

G $\beta \gamma$-Subunits couple PAR1 to many other pathways $[4,6,96]$, including phosphatidylinositol-3-kinase $\left(\mathrm{Pl}_{3} \mathrm{~K}\right)$, lipid-modifying enzymes (PLC $\beta$ ), G protein receptor kinases (GRK), potassium channels $(\mathrm{Ki})$, and non-receptor tyrosine kinases (TKs). As already commented, $\mathrm{PI}_{3} \mathrm{~K}$ is involved in PAR1-mediated regulation of cytoskeletal structure, cell motility, cell survival, and mitogenesis and, in some cell types, it acts as an intermediate in the activation of ERKs $[4,5,89,97]$.

PAR1-APs have shown different functional selectivity in PAR1 activation from thrombin due to biased signaling through G-proteins [98]. Thus, thrombin via PAR1 induces higher increase in endothelial permeability, which reflects $\mathrm{Ga}_{12 / 13}$ activation, that in $\mathrm{Ca}^{2+}$ mobilization through activation of $\mathrm{G} \alpha_{\mathrm{a}}$. The opposite order of activation was observed for the PAR1APs, which favor $\mathrm{G} \alpha_{a}$ activation [18]. As commented in the previous section, different activating endogenous proteases can also activate biased signaling cascades by their "non-canonical" tethered activating ligands. MMP-1 preferentially activates $\mathrm{G} \alpha_{12 / 13}$-Rho-dependent pathways, chemotaxis, and MAPK signaling $[51,55]$. NE and PR3 also with "non-canonical" TALs selectively activate PAR 1 -mediated MAPKs via $G \alpha_{i}$ signaling [61]. Selective signaling may also be dependent on the receptor location. For example, the endothelial barrier protective effects and selective signaling of APC are mediated through the compartmentalization of PAR1 in caveolae [99]. Furthermore, the cytoprotective effects of APC are mediated by signaling through $\beta$-arrestin 2 via the mentioned non-canonical activation of PAR1 [40]. With respect to PAR1 antagonists, most of them have been investigated based on their pharmacological activity as antiaggregant agents and there is scarce information on their action upon the PAR1 signaling cascade. However, three different families of small-molecule antagonists have been reported in the last years that seem to selectively inhibit the $\mathrm{G} \alpha_{0}$-mediated PAR1 signaling [100-102].

Very little is known regarding the mechanisms of PAR $1 \rightarrow$ G-protein signal transference and about the structural elements of these macromolecular interactions. Several unsolved question have been raised respect to these signaling mechanisms. 1) Does PAR1 form preassembled complexes with different $G \alpha$ subunits previously to the agonist binding or is the agonist-induced activation necessary for the PAR1-G-protein coupling? The existence of, at least, two distinct receptor populations has been suggested. In one of them PAR1 could preassemble $G \alpha_{i 1}$, and receptor activation would induce rapid and transient $G \alpha_{i 1}$ activation and stable recruitment of $\beta$-arrestin 1. In the other population, PAR1 would not be preassembled and, after ligand binding, $\mathrm{G} \alpha_{12}$ or $\beta$-arrestin 1 would be recruited to form a complex with the receptor and to initiate the signaling cascade. These alternative modes of PAR 1-G-protein assembly and signaling appear to depend on the G $\alpha$ C-terminus [103]. 2) Does PAR1 include specific recognition sites for each G-protein or do different G-proteins dock at overlapping recognition sites? First studies trying to answer this question with experiments of chimeric receptors indicated that the 
second intracellular loop (i2) of PAR1 is involved in its coupling to $G \alpha_{q}$ [104]. Subsequent studies implicated key roles for i2, i3, and the C-tail [105]. A more recent study has found that the $8^{\text {th }}$ helix region at the PAR 1 C-terminus is critical for activation of the $\mathrm{G} \alpha_{q}$-dependent signaling branches [106]. Furthermore, a network of $\mathrm{H}$-bond and ionic interactions was found to connect the $\mathrm{N}$-terminal portion of the $8^{\text {th }}$ helix, through the hydrophilic residues $E^{377}, Q^{379}$, and $R^{380}$, to the nearby $N^{367} P L \mid Y^{371}$ motif in transmembrane helix 7 and to the il loop. Disruption of these interactions cause additive defects in the coupling to G-protein. A recent work has identified five amino acids within PAR1 i2 loop $\left(R^{205}, V^{209}, P^{212}, I^{213}\right.$, and $\left.L^{216}\right)$ that markedly reduced signaling via $\mathrm{G} \alpha_{\mathrm{q} / 11}$ when individually mutated. Among these mutations, only $\mathrm{R}^{205}$ completely abolished the direct binding of $G \alpha_{\mathrm{g} / 11}$ to PAR1. None of these mutations affected the direct binding of PAR1 to either $G \alpha_{i / 0}$ or $G \alpha_{12 / 13}$ and their respective signaling [107].

\subsection{Signaling via $\boldsymbol{\beta}$-arrestins}

$\beta$-Arrestins ( $\beta$-arrestin 1 and 2 ) were originally identified as terminators of G-protein coupling and mediators of endocytosis, but later, they were shown to function as scaffolds linking receptor activation to several signaling cascades [108], mainly to MAPK and $\mathrm{PI}_{3} \mathrm{~K}$ signaling. A large body of work has demonstrated that diverse parameters, such as agonist structure, agonist concentration, receptor clustering and prevalence of signaling components can switch the receptor signal from a G-protein-dependent to a $G$-independent one. $\beta$-Arrestins can work both in opposition and in synergy with the $\mathrm{G}-$ protein signaling. In other cases, $\beta$-arrestins and $G$-proteins can activate the same downstream protein, but through different mechanisms, leading to distinct cellular outcomes [109]. The availability of these diverse downstream signaling possibilities through specific G-proteins or $\beta$ arrestins is cell-type-specific. Up to now, most of the studies on receptor signaling have been based on measuring G-protein second messengers. As a consequence, other signaling pathways have been disregarded, as in the case of PAR1, where there is very limited information on the contribution of $\beta$-arrestins to its signaling cascade. It has been described that $\beta$-arrestin 1 couples PAR1 to the rapid and sustained activation of $\mathrm{PI}_{3} \mathrm{~K} / \mathrm{Akt}$ signaling pathways that are essential for the cell progression through the $G_{1}$ phase $[110,111]$. On the other hand, $\beta$-arrestin 1 and $\beta$-arrestin 2 have shown opposing effects on the activation and degradation of Src induced by PAR1 [112]. PAR1-mediated activation of Src and ERK1/2 was increased with overexpression of $\beta$-arrestin 1 or depletion of $\beta$-arrestin 2. This $\beta$-arrestin also appears to promote the PAR1 induced degradation of Src. Finally, as abovementioned, the PAR1-mediated endothelial cytoprotective actions of APC are induced through $\beta-$ arrestin 2 signaling $[40,113]$

\subsection{Signaling via receptor transactivation}

GPCRs can signal through other receptors by a process known as transactivation, which is defined as "GPCR activation which leads to the activation of a second cell surface receptor in a relatively short time and in absence of de novo protein synthesis" [114]. This transactivation includes intra- and extra-cellular mechanisms and may involve a direct interaction between the two receptors, or not. By transactivation PAR1 can activate receptor tyrosine kinases (RTKs), receptor serine/threonine kinases (RSTKs), other GPCRs, and ion channels [15]. Among the transactivation of RTKs, besides the transactivation of EGFR, already commented, it has been reported that the crosstalk between PAR1 and the platelet-derived growth factor receptor (PDGFR) in spinal cord neurons is implicated in neuropathic pain after nerve injury [115]. It has also been reported the implication of PAR 1-mediated transactivation of the insulin-like growth factor receptor (IGFR) in the regulation of aortic smooth muscle cell proliferation [116, 117]. In endothelial cells, PAR 1 transactivates, in a Src-dependent manner, the RTK of ephrin A1, EphA2 [1 18]

Recent works suggest that PAR1 can also transactivate RSTKs, concretely, the transforming growth factor beta $(T G F-\beta)$ receptor $(T \beta R I)$, also known as activin-like kinase $\vee(A L K V)$. The thrombin stimulation of proteoglycan synthesis in vascular smooth muscle is mediated by PAR1 transactivation of T $\beta R I$ [119]. Overstimulation of PAR1-mediated activation of ALK $V$ can promote acute lung injury [120].

Growing pharmacological and biochemical data indicate that most GPCRs, including PARs, form functional homo- and heterodimeric complexes. These processes increase the diversity of receptor functions and lead to synergic signaling. During the past few years distinct PARPAR interactions, including co- and transactivation have been proposed in different cell types. However, only limited data exist about homo- and heterodimer complex formation and their impact in cells. Most of the work has been done with expression systems, in which higher than normal receptor concentrations may force dimer and oligomer formation not observed in naturally occurring cells. Signaling crosstalk between endothelial PAR1 and PAR2 in vivo has been demonstrated in a sepsis mouse model, where the protective effect of PAR1 agonistic activity, mediated by $A P C$, on the endothelial barrier and mice survival required the presence of PAR2. FRET studies suggested the formation of PAR1-PAR2 heterodimers [121]. PAR1 transactivation of PAR2 has also been demonstrated on human umbilical vein endothelial cells (HUVECs) [122]. The cooperative signaling between PAR1 and PAR2 observed on carcinoma cells suggests a role of PAR1PAR2 dimerization in carcinogenesis [123-125]. On the other hand, the known cooperative participation of the PAR1/PAR4 receptor system in human platelet signaling and aggregation indicated the possible formation of heteromeric complexes. This suggestion has been demonstrated in human platelets [126]. The data provided evidence for a mechanism by which thrombin first docks to and cleaves PAR1, then, reaches over and cleaves PAR4 while still bound to PAR1. This PAR1-PAR4 interaction was further supported by co-immunoprecipitation and FRET studies, demonstrating the ability of both receptors to form heterodimers in COS-7 fibroblasts transfected with PAR1 and PAR4. There are also results suggesting the formation of PAR1-PAR4 heterodimers in other cell types, including those from epithelial cancers, such as 
astrocytoma [127] and hepatocellular carcinoma cells [128].

PAR1 can also transactivate non-PAR GPCRs. Thus, it seems that the endothelial barrier protection and neuroprotective effects of APC are mediated through the PAR1 crossactivation of sphingosine 1-phosphate receptors $\left(\mathrm{SIPR}_{1}\right.$ and $\mathrm{S} 1 \mathrm{PR}_{3}$ ) [129-131]. Also activation of neuronal PAR1 transactivates presynaptic cannabinoid receptors $\left(C B_{1}\right)$, through retrograde signaling mediated by 2-arachinoylglycerol, and suppresses transmitter release at hippocampal synapses [95]

Finally, some reports have shown the implication of PAR1 activation in ion channel receptor signaling. Thus, several lines of evidence indicated that both plasmin and thrombin can regulate neuronal functions of NMDA receptors through activation of PAR1. Concretely, it has been suggested that plasmin regulation of NMDA activity, via PAR1, is relevant for synaptic plasticity and behaviour [43, 132], while, thrombin/PAR1-induced neurodegenerative effects under pathological conditions, such as ischemia or hemorrhage, seems to be induced through activation of NMDA [133, 134]. In astrocytes PAR1 activation can tune synaptic NMDA receptor responses by stimulating glutamate release [135]. Also, it seems that PAR1 activation can sensitize the transient receptor potential ion channel TRPV 1 in nociceptive neurons [136]

\section{PAR1 DESENSITIZATION, TRAFFICKING, AND DEGRADATION}

Due to its irreversible proteolytic activation, PAR1 signaling is controlled by rapid desensitization and receptor trafficking $[6,10,13]$. The irreversible activation suggests that PARl might require a signal termination mechanism different from that of classical GPCRs. Activated and uncleaved PAR1 receptors internalize through two different pathways. Protease activation induces rapid internalization and degradation of PAR 1 in an agonist-dependent manner $[13,137]$. Internalization is preceded by receptor desensitization via rapid GRKmediated C-terminal phosphorylation and phosphorylation-independent binding of $\beta$-arrestins. PAR1 is mainly phosphorylated by GRK3 and GRK5 on serine and threonine residues located at the i3 or the C-terminal cytoplasmatic tail $[138,139]$. Although internalization of PAR1 does not require $\beta$-arrestins, receptor desensitization is $\beta$-arrestin 1 dependent [140], which physically interacts with both phosphorylated and unphosphorylated PAR1 [141]. G-Protein signalling of PAR1 is also regulated by regulator of G-protein signalling (RGS) proteins, which function as GTPase-activating proteins to inhibit GPCR/Gprotein signaling [142]. It seems that RGS2 and RGS4 directly interact with PAR1 in a G $\alpha$-dependent manner to modulate PAR $1 / G \alpha$ signaling. It also seems that the recruitment of these RGS to the G-proteins is regulated by the binding of the clathrin adaptor protein complex-2 (AP2) to PAR1 through a C-tail tyrosine-based motif $\left(Y^{420} \mathrm{KKAA}^{424}\right)[143]$.

PAR1 is basally ubiquitinated at highly conserved lysine residues localized within the cytoplasmic tail tyrosine-based motif of binding AP-2 [144]. This ubiquitylation may preclude AP-2 binding. Consequently, internalization of PAR1 involves firstly deubiquitylation, followed by interaction with AP-2 [144] and epsin 1 [145]. These processes result in clathrin-and dynamin-dependent endocytosis to early endosomes. The adapter protein bicaudal D1 (BicD1) is involved in the transport of PAR1 from the plasma membrane to endosomes [146]. BicD1, through its CC3 domain, directly interacts with the Cterminal $8^{\text {th }}$ helix of PAR1, inhibiting its signaling to $G \alpha_{a}$ PLC $\beta$. Silencing BicDl expression impairs PAR1 transport to endosomes and this adapter protein has been found to be a potent suppressor of PAR1-driven proliferation of breast carcinoma cells [146]. PAR1 is translocated from endosomes to lysosomes for degradation [147]. This traslocation requires physical interaction with sorting nexin 1 (SNX1) [148]. Other endocytic adaptor proteins may mediate the sorting of PAR1 to lysosomes, but have not been identified yet.

There is little information on the Iysosomal degradation of PAR1. A recent report has suggested the participation of prohibitin $(\mathrm{PHB})$, a regulatory protein in the maintenance of mitochondrial functions, in the internalization and degradation of PAR1 [149]. In cancer cells, the absence of plasma membrane PHB induces persistent PAR1 signaling, while, upregulation of intracellular PHB decreases PAR1 degradation, which may render cancer cells highly invasive. As already commented in section 3, PAR1 can also be disarmed by extracellular protease-mediated degradation of the extracellular $\mathrm{N}$ terminus downstream to the tethered ligand. This is the case of the PAR1 inactivation by plasmin $[19,150], K L K s$ [19], neutrophil elastase, proteinase-3 and thermolysin [62, 151, 152], trypsin [153], tryptase and chymase [154], and cathepsin G [155]. Receptor disarming by trypsin, thermolysin, elastase and proteinase-3 is governed by PAR 1 glycosylation at the $\mathrm{N}$-terminus downstream to the tethered ligand, mainly at $\mathrm{Asn}^{75}$ [152]. Receptors inactivated by extracellular proteases remain at the cell surface, but are not longer available for protease-mediated activation, although they can be activated by PAR 1 APs.

Uncleaved PAR1 is internalized by constitutive clathrin-coated pit, AP-2, and dynamin-dependent endocytosis, negatively regulated by ubiquitination. This constitutive internalization modulates cell surface expression of uncleaved PAR 1, which can recycle between endosomes and the cell surface and lead to fast resensitization, independent of de novo receptor synthesis $[10,13,156]$

\section{PAR1 THERAPEUTIC IMPLICATIONS}

The complex interactome of PAR1 and its wide cellular expression give an idea of the multiple physiological functions of this receptor and of the pathological implications of its dysfunctions, mainly in the cardiovascular [9, 11, 157, 158], immune [7, 159], and nervous $[24,25,160,161]$ systems, inflammation [7, 162164] and cancer $[12,165,166]$, that are summarized in Table 2. Many of these pleiotropic actions are PAR1mediated in combination with PAR2 or PAR4. 


\subsection{Cardiovascular system}

In the cardiovascular system, PAR1 is mainly expressed in platelets, endothelial and vascular smooth muscle cells. The effects of PAR 1 activation are cell typedependent and its cellular expression varies from physiological to pathological conditions [157]. Depending on cell expression, PAR1 activation causes platelet activation and aggregation, arterial vasodilation, venoconstriction, and release of coagulant and fibrinolytic factors [167].

Human platelets express PAR1 and PAR4, and activation of each of them induces platelet secretion and aggregation [168]. Both receptors account for most thrombin signaling in platelets. PAR1 mediates fast platelet responses at low thrombin concentrations, while PAR4 mediates slow and prolonged platelet activation at high thrombin concentrations. Once PAR1 is activated, its rapid signaling through G-proteins causes changes in platelet shape, synthesis and release of thromboxane $A_{2}$, mobilization of $\mathrm{P}$-selectin, rapid increase in intracellular calcium, and activation of the GPIlb-flla fibrinogen receptor, which culminates in platelet aggregation. PAR1 and PAR4 do not signal simultaneously during platelet activation, instead they complement each other by evoking two distinct waves of intracellular calcium [169]. The signal of PAR1 is fast and quickly shut off. This is followed by a slow and prolonged signaling of PAR4. Unlike PAR1, PAR4 leads to irreversible platelet aggregation. Studies on human platelets have provided evidence that the high affinity PAR 1 receptor forms stable complexes with PAR4, which enables thrombin to act as a bivalent functional agonist [126]. Platelet activation is important in haemostasis, but platelet activation and aggregation also play a critical role in thrombosis, which is responsible for the acute clinical manifestations of vascular atherothrombotic diseases, such as acute coronary syndromes (ACS), myocardial infarction (MI), ischemic stroke/transient ischemic attack, and symptomatic peripheral artery disease (PAD). Despite improvements in the management of ACS with established anti-platelet and anticoagulant therapies and revascularization techniques, many patients continue to suffer recurrent ischemic events, and bleeding rates are increased. However, inhibition of PAR1 is considered an attractive approach to antiplatelet therapy, because it may provide incremental ischemic protection without increasing bleeding. So, as below commented, several PAR1 antagonists have been developed and tested in clinical trials as antiplatelet drugs for cardiovascular diseases [170-173].

Endothelial cells (ECs) express PAR1, PAR2, PAR3 and PAR4, but, PAR1 is the major mediator of thrombin signaling in these cells $[9,11]$. In normal pig and human coronary arteries, the activation of PAR1 induces endothelium-dependent vasodilation [174, 175]. However, in renal artery, thrombin elicits a biphasic response with initial endothelium-dependent relaxation, followed by endothelium-dependent contraction [176]. Therefore, PAR1 activation causes endothelium-dependent vasodilation and contraction depending on the vessel type. Vasorelaxation is due to PAR 1 -induced $\mathrm{NO}$ production by eNOS, while, contraction is mediated by thromboxane $A_{2}$ (TX $\left.\mathrm{A}_{2}\right)$ and prostaglandin $\mathrm{H}_{2}\left(\mathrm{PGH}_{2}\right)$ [176]. Besides the effects on the modulation of the vessel tone, PAR1 activation causes changes in vascular permeability in ECs [177-179], release of endothelium-derived coagulant and fibrinolytic factors, such as the endothelial tissue plasmiminogen activator [167], and mobilization of the von Willebrand factor (VWF) and P-selectin from WeibelPalade bodies [180, 181]. On the other hand, as commented in section 3, activation of PAR1 by APC induces anti-inflammatory, cytoprotective and barrierstabilizing effects in ECS [38]. Also in ECs, thrombin modulates, mainly via PAR1, the expression of genes related to haemostasis, cell growth and angiogenesis, cytokines, and cell adhesion [180, 182]. Under vascular pathologic conditions, thrombin upregulates these genes and their expression alterations may be linked to phenotypic conversion of endothelial cells into the proinflammatory phenotype [182].

Under pathological conditions, such as tissue damage, thrombosis, hemorrhage and inflammation, proteases of the coagulation-fibrinolytic system and proteases-derived from immune and inflammatory cells are activated. This activation induces acute activation of PAR1, which, due to direct endothelial cell contraction, causes an increase in vascular permeability, resulting in plasma extravasation and edema [183]. Additionally, the endothelial activation of PAR1 accounts for the proinflammatory responses to tissue injury, which include release of pro-inflammatory cytokines, increased surface expression of adhesion molecules, and platelet and leucocyte adhesion [184, 185]. Constitutive endothelial PAR1 activation seems to play a key role in vasculogenesis [186] and PAR1 signaling in ECs is necessary for proper vessel development [187, 188]. It has also been suggested that PAR1 activation may induce proliferation and migration of endothelial progenitor cells by an angiopoietin-dependent mechanism [189]. Furthermore, as below commented, thrombin is a potent angiogenic factor dependent on PAR1 activation and independent on fibribrin formation [190, 191]. These PAR1 effects on neovascularization and angiogenesis may contribute to the pathophysiology of vascular lesions.

In contrast to ECS, the expression of PARs, particularly PAR1 and PAR2, is quite limited in normal vascular smooth muscle cells (VSMCs). However, both receptors are upregulated in VSMCs and macrophages of the vessel wall after vascular lesions [192, 193]. This higher expression suggests that PAR1 and PAR2 play an important role under vascular pathological conditions. In the presence of atherosclerotic lesions, the PAR 1 -induced endothelium-dependent relaxation is attenuated and, in advanced lesions associated with vessel wall thickening, the vasorelaxing response eventually disappears, becoming predominant the PAR1-induced and VSMC-mediated wall contraction response [194]. As a consequence, PAR1mediated effects on VSMC, such as contraction, proliferation, migration, hypertrophy, release of cytokines, and production of extracellular matrix are predominant in vascular lesions. In addition to atherosclerosis, angiotensin Il-induced hypertension has been associated with upregulation of PAR1 in VSMCs [195]. A rapid and marked increase of PAR1 expression in VSMCs has also been associated with the proliferative and pro- 
inflammatory effects of thrombin in vascular remodeling and restenosis [196, 197].

In the heart, PAR1 is also expressed in ventricular myocytes [198] and cardiac fibroblasts [199]. Increased PARl expression has been found in the hearts of patients with ischemic and idiopathic dilated cardiomyopathy [200] and in the left ventricle of a mouse model of chronic heart failure [201]. In ventricular myocytes, PAR1 activation induces hypertrophy, with cytoskeletal reorganization, through activation of PKC- and RhoA/ROCK-dependent signaling pathways, presumably, via $G \alpha_{q}$ and $G \alpha_{12 / 13}$ proteins [84]. It has been suggested that this activation pathway is triggered by activation of MMP-9 [200]. Thrombin-mediated PAR1 activation induces atrial natriuretic factor expression [202] and activates the $\mathrm{Na}^{+} / \mathrm{H}^{+}$ exchanger [203], increasing the persistent component of the $\mathrm{Na}^{+}$current, which results in an uncontrollable sodium influx into cardiomyocytes [204] that may contribute to the cellular damage observed during cardiac ischemia.

PAR1 is the most highly expressed GPCR in adult cardiac fibroblasts [199], where they promote the adverse left ventricular (LV) remodeling that underlines the development of ischemic cardiomyopathy. It has been shown that the PAR1 antagonist SCH79797 inhibits thrombin-mediated ERK1/2 phosphorylation, TGF- $\beta$ and type I procollagen production, MMP-2 and -9 activation, and myofibroblast transformation in vitro. Furthermore, this PAR 1 antagonist attenuated LV dilation and improved systolic function of the reperfused myocardium after myocardial ischemia [205].

\subsection{Inflammation and immune system}

As aforementioned, thrombin, through activation of PAR1, triggers many responses associated with inflammation, including endothelial cell activation, mast cell degranulation, increased adhesion of neutrophils to the endothelium, platelet aggregation and chemotaxis of neutrophils, and induction of cytokine release from epithelial cells, VSMCs, and ECs [19]. These effects may be responsible for the hallmarks of inflammation, such as increased blood flow and temperature, pain, edema, and loss of function. Immune cells are highly involved in the inflammatory responses to PARs activation, although the mechanisms by which these receptors exert their effects on these cells related to inflammation are still poorly understood $[7,19,206]$. Most of the studies related to the actions of PARs in inflammation and the immune system have been carried out in vitro or in animal models from different species. Taking into account the species and cellular specific expression of these receptors, the comparison of results is difficult.

PAR1 signaling in inflammation is complex since, depending on the type and stage of the inflammatory disease $[207,208]$, the activating protease can be different and the response to activation may be either inflammatory or anti-inflammatory $[14,19,206]$. In general, thrombin triggers inflammatory responses, while APC triggers the anti-inflammatory ones.

PAR1 plays a pivotal role in sepsis, an exaggerated and acute inflammatory response that can have several etiologies, also known as systemic inflammatory response syndrome (SIRS), with high incidence and mortality in
ICU patients and, currently, with few and low response treatments $[209,210]$. This syndrome develops when an initial appropriate innate immune response, usually to a microbial infection, becomes amplified and then dysregulated. Under these conditions, high levels of pathogen-associated molecular mediators, such as endotoxin, lipopolysaccharide (LPS) or other microbial components, can initiate a massive release of host-derived mediators, including cytokines, chemokines and products of the complement system that activate ECs. As a consequence, the endothelial barrier is disrupted causing fluid leakage from the intravascular space. This contributes to hypovolemia and hypotension and to the septic shock. Coagulation is activated by the induction of TF on monocytes and ECs, where PAR1 plays important roles in the crosstalk between coagulation and inflammation, and may further contribute to organ failure and death. In this regard, based on its PAR1-mediated protective antiinflammatory and endothelial barrier-stabilizing properties, APC is the only approved agent for the treatment of severe sepsis, although it has shown only modest mortality rate reduction [211]. On the other hand, in a recent study in human sepsis patients, a highly significant correlation has been found between elevated plasma levels of MMP-1 and deaths at 7 and 28 days after diagnosis [212]. Moreover, in septic mice, blockage of MMP-1 activity suppressed endothelial barrier disruption, disseminated intravascular coagulation, lung vascular permeability, as well as the cytokine storm, and improved survival. These effects were lost in PAR1 deficient mice.

Studies in animal models have shown contradictory results on the role of PAR1 in the gut, that is, both proinflammatory and anti-inflammatory [14, 213]. The results depended on the cell, animal species and time frame of the assays. Further studies are needed to clarify the potential roles of PAR1 in gut diseases. PAR1 are highly expressed in the gastrointestinal (GI) tract, where it has been detected in ECs of the lamina propria, epithelial cells, SMCs, enteric neurons, fibroblasts and some immune cells (neutrophils, mast cells, lymphocytes, monocytes, and macrophages) [213]. Activation of this receptor has been involved in several aspects related to the gut physiology, such as: ion transport, inflammation, permeability, motility, sensory functions, and proliferation. Activation of PAR1 in neurons of mouse colon inhibits chloride secretion, suggesting that PAR1 activation on enteric nerves might modulate ion transport across the epithelium [214]. PAR1 increases intestinal permeability by direct activation on epithelial cells [215] and it is involved in the modulation of Gl motility [216]. Thus, PAR1 activation induces contraction in mouse and rat gastric smooth muscle in a prostaglandin dependent manner [217], while in longitudinal and circular muscles of the colon inhibits contractile effects $[218,219]$. Concerning inflammation, PAR1 appears to play both pro-inflammatory and antiinflammatory roles in different models of inflammatory bowel diseases (IBD). In mouse models of colitis, PAR1 activation enhanced and prolonged inflammation, whereas PAR1 antagonists decreased mortality and severity of colitis [207]. PAR1 induced colitis was partly due to an increase in intestinal barrier permeability, but also to direct activation of $\mathrm{B}$ and $\mathrm{T}$ lymphocytes. 
Table 2. Summary of cell PAR1 expression and main physiological functions and dysfunction pathologies

\begin{tabular}{|c|c|c|c|}
\hline & Cell expression & Physiological function & Dysfunction pathologies \\
\hline \multirow{5}{*}{$\begin{array}{l}\text { Cardiovascular } \\
\text { system }\end{array}$} & Platelets & Secretion and aggregation in hemostasis & Thrombosis, ACS, MI, PAD \\
\hline & ECs & $\begin{array}{l}\text { Coronary artery vasodilatation } \\
\text { APC-mediated anti-inflammation, } \\
\text { cytoprotection and barrier stabilization }\end{array}$ & $\begin{array}{l}\text { Increased vascular permeability, edema, } \\
\text { inflammation, neovascularization and angiogenesis }\end{array}$ \\
\hline & VSMCs & Low expression & $\begin{array}{l}\text { Increased expression in vascular lesions, wall } \\
\text { contraction, cell proliferation, migration and } \\
\text { hypertrophy }\end{array}$ \\
\hline & $\begin{array}{l}\text { Ventricular } \\
\text { myocytes }\end{array}$ & Low expression & $\begin{array}{l}\text { Increased expression in ischemic and idiopathic } \\
\text { cardiomyopaties, hypertrophy, cellular damage }\end{array}$ \\
\hline & $\begin{array}{l}\text { Cardiac } \\
\text { fibroblasts }\end{array}$ & Low expression & Increased expression in ischemic cardiomyopaties \\
\hline \multirow{13}{*}{$\begin{array}{l}\text { Inflammation and } \\
\text { immune system }\end{array}$} & ECs & Cell activation, cytokine release & \multirow{13}{*}{$\begin{array}{l}\text { Sepsis (Inflammation, endothelial barrier } \\
\text { disruption, hypovolemia, hypotension, coagulation) } \\
\text { In the gut: alteration of ion transport, inflammation, } \\
\text { permeability, motility, and proliferation. Involved } \\
\text { in IBD, colitis, and IBS } \\
\text { Bladder inflammation } \\
\text { In the respiratory system: pulmonary diseases } \\
\text { coupled to inflammation and coagulation (ALI, } \\
\text { pulmonary fibrosis, asthma, and bronchitis) } \\
\text { Involved in allergy processes and delayed immune } \\
\text { responses }\end{array}$} \\
\hline & Mast cells & Degranulation & \\
\hline & Platelet & Aggregation & \\
\hline & VSMCs & Cytokine release & \\
\hline & SMCs & $\begin{array}{l}\text { Cytokine release, contraction of bronchial } \\
\text { rings }\end{array}$ & \\
\hline & Enteric neurons & Activation of chloride secretion & \\
\hline & \multirow{2}{*}{ Lung fibroblasts } & \multirow{2}{*}{$\begin{array}{l}\text { Synthesis and release of extracellular matrix } \\
\text { proteins, growth factors, and } \\
\text { proinflammatory agents }\end{array}$} & \\
\hline & & & \\
\hline & Neutrophils & $\begin{array}{l}\text { Increased adhesion to endothelium, } \\
\text { chemotaxis }\end{array}$ & \\
\hline & Eosinophils & Eosinophil chemotaxis & \\
\hline & Monocytes & $\begin{array}{l}\text { Increase of }\left[\mathrm{Ca}^{2+}\right] \text { level, modulation of } \\
\text { cytokine release, enhancement of kill } \\
\text { bacteria ability }\end{array}$ & \\
\hline & Macrophages & $\begin{array}{l}\text { Increase of }\left[\mathrm{Ca}^{2+}\right] \text { level, modulation of } \\
\text { cytokine release }\end{array}$ & \\
\hline & hMCs & Enhancement of chemokine secretion & \\
\hline \multirow{6}{*}{ Nervous system } & & Induction of cell morphological changes & \multirow{6}{*}{$\begin{array}{l}\text { Epileptic seizure onset } \\
\text { Neuroinflammation and neurodegeneration (stroke, } \\
\text { Alzheimer's and Parkinson's diseases, HIV- } \\
\text { associated dementia and MS) }\end{array}$} \\
\hline & & $\begin{array}{l}\text { Neuronal development and plasticity, } \\
\text { learning and memory }\end{array}$ & \\
\hline & Neurons & $\begin{array}{l}\text { Thrombin concentration dependent cell } \\
\text { protection/damage }\end{array}$ & \\
\hline & & $\begin{array}{l}\text { APC-mediated stabilization of BBB and } \\
\text { neuroprotection }\end{array}$ & \\
\hline & Astrocytes & $\begin{array}{l}\text { Induction of cell morphological changes, } \\
\text { cell proliferation, glutamate release, } \\
\text { activation of NMDA receptors in neurons }\end{array}$ & \\
\hline & Microglia & $\begin{array}{l}\text { Modulation of inducible iNOS expression } \\
\text { and proinflammatory cytokines, activation } \\
\text { of NADPH }\end{array}$ & \\
\hline \multirow[b]{2}{*}{$\begin{array}{l}\text { Cancer and } \\
\text { angiogenesis }\end{array}$} & Platelets & Secretion and aggregation in hemostasis & Hipercoagulation-cancer association \\
\hline & Cancer cells & Activation of PAR1 signaling cascade & $\begin{array}{l}\text { Overexpression in melanoma, breast, prostate, } \\
\text { pancreas, ovarian, colon, head and neck, and lung } \\
\text { cancers, endometrial carcinoma, and aggressive } \\
\text { leukemias } \\
\text { Secretion of cell growth and angiogenesis factors } \\
\text { Activation of cell growth, invasion, and metastasis } \\
\text { Activation of oncogenes }\end{array}$ \\
\hline
\end{tabular}


PAR1 expression was upregulated in biopsies from Crohn's disease or ulcerative colitis patients. On the other hand, a protective role has been ascribed to PAR1 during the course of the Helicobacter pylori infection in the gut, where PAR 1 activation suppressed the production of proinflammatory cytokines and lowered the host inflammatory response [220]. A potential role of PAR1 activation has been suggested in the initial inflammatory events for the development of irritable bowel syndrome (IBS) [213], often associated with a previous history of infectious colitis. As already commented, PAR1 has been associated with many of the pathogenic symptoms of IBS, such as inflammation, altered Gl motility, and increased permeability. Interestingly, since functional PAR1 is expressed on afferent sensory fibers in the gut, a role for this receptor in nociception, activating opioid pathways, has been suggested [221, 222], which could contribute to inhibit pain symptoms associated with IBS.

PAR1 is expressed in kidney eurothelial cells, where its activation, by locally generated thrombin or other proteases present in the urine, may mediate bladder inflammation by inducing the release and expression of the macrophage migration inhibitory factor (MIF), a pivotal mediator of acute and chronic inflammation [223]. On the other hand, based on the fact that PAR1 is upregulated in glomeruli from diabetic mice, it has been suggested that PAR1 upregulation may play a role in the progression of glomerulosclerosis and abnormal urinary excretion of urinary albumin in diabetic nephropathy [224]

In the respiratory system, PAR1 is abundantly expressed in various cell types in the airways, such as epithelial cells, SMCs, fibroblasts and immune cells and its expression is upregulated during development of pulmonary diseases, which are coupled to inflammation and procoagulant activity, such as pulmonary fibrosis, asthma, and bronchitis [7, 163, 164]. In the normal uninjured lung, the alveolar haemostatic balance is generally antithrombotic and profibrinolytic. However, in both acute lung injury (ALI) and chronic lung diseases, such as pulmonary fibrosis, the balance seems to be shifted in favor of pro-coagulant and anti-fibrinolytic activity [164]. These pathologies are characterized by diffuse alveolar damage, disruption of the alveolar capillary barrier, pulmonary edema, neutrophilic inflammation, and extravascular intra-alveolar accumulation of fibrin in pulmonary fibrosis [225]. PAR1 is the main protease receptor in lung fibroblasts, where it induces synthesis and release of extracellular matrix proteins (collagen, tenascin) $[163,226]$, growth factors (CTGF, PDGF) [227, 228], and the proinflammatory agents $I L-6$ and $I L-8$ [163]. PARI activation also induces cell proliferation [229] and differentiation of fibroblasts to myofibroblasts [230], which are the key effector cells in pulmonary fibrosis. Furthermore, PAR 1 exerts a contraction effect on human bronchial rings [231], while, in mouse tracheal SMCs it exerts a dual role of constriction and relaxation [232, 233]. It seems that this last effect is mediated by the release of the anti-inflammatory and relaxant prostaglandin $E_{2}$ $\left(P G E_{2}\right)$ after PAR1 activation.

Many of the commented inflammatory responses to PAR1 activation are mediated by immune cells. This receptor is expressed in neutrophils, eosinophils, monocytes, macrophages, lymphocytes, dendritic cells, and mast cells, although its functionality in some of these cells remains to be verified $[159,206]$. Thus human neutrophils isolated from male or nonpregnant female healthy volunteers do not express PAR1, but it is expressed in neutrophils from normal or preclamptic pregnant female donors [234]. Human eosinophils express PAR 1 and its activation by thrombin stimulates eosinophil chemotaxis [235, 236]. Thrombin and PAR1-APs stimulate and increase the levels of $\left[\mathrm{Ca}^{2+}\right]$ in human monocytes [237]. The activation of the receptor in these cells upregulates the expression and release of monocyte chemoattractant protein-1 (MCP-1) [237], and the plasmin-mediated activation induces the anti-apoptotic effect of plasminogen observed in these cells [238]. Also in monocytes, thrombin and PAR1 APs modulate the production and release of cytokines, including $I L-6, I L-8$, platelet factor-4, platelet basic protein, and RANTES [206]. Additionally, treatment of human monocytes with thrombin or PAR1 APs enhances the ability of these cells to kill bacteria [239].

Human macrophages express a similar PAR1 pattern to that of their monocyte precursors. A higher expression of PAR1 has been shown in alveolar macrophages of smokers than nonsmokers [240]. Activation with PAR1APs increases intracellular $\left[\mathrm{Ca}^{2+}\right]$, upregulates the expression and release of MCP-1 [206], and stimulates elastase secretion from macrophages [241]. In fibrotic liver diseases PAR1 is upregulated and a recent report has associated the effect of PAR 1 signaling on the induction of chemotaxis on bone marrow derived macrophages with a fibrotic response of the liver to a recurrent injury [242].

$T$ lymphocytes expresses PAR1 [243] and its thrombin-mediated activation increases intracellular $\left[\mathrm{Ca}^{2+}\right]$, activates PKC $[244,245]$ and increases IL-6 secretion [246], whereas PAR1 is absent in B lymphocytes. However, there is lack of information concerning the involvement of PARl signaling in the regulation of $T$ cell functions and $T$ cell-mediated diseases, as well as, in those of dendritic and mast cell functions. Although human dendritic cells express PAR1, little is known on its physiological and pathophysiological significance $[206,247]$. It seems that the PAR1-S1PR signaling in dendritic cells plays a critical role in regulating the amplification of inflammation in the sepsis syndrome [130]. Human mast cells (hMCs) are recognized as key players in the initiation of allergic diseases and also as participants in the host response to certain parasitic infections [206]. Skin hMCs expresses PAR1 [248] and PAR1 activation in mouse MCs enhances IL-6 secretion [249] and induces the adhesion of bone marrow-derived MCs to fibronectin and laminin [250]. The potent chomoattractant RANTES, crucial player in the pathogenesis of allergy, upregulates the expression of PAR1 in mouse MCs and induces the production of $1 \mathrm{~L}-13$ [251]. In human oral keratinocytes PAR1, along with PAR2, triggers innate immune responses signaling via $p 38$ and ERK1/2 MAP kinases. PI3K exerts a negative regulatory role in this signaling through the inhibition of p38 signaling. In this way, both PAR1 and PAR2 keep the innate immune responses of human oral keratinocytes in balance [252].

Although most pathogens trigger a delayed immune response, in some situations, pathogen-derived proteases 
can trigger an immediate innate immune response, in part by regulating the activity of PAR 1. This regulation can be mediated through both receptor activation or disarm. This is the case, already commented in section 3, of the gingipains, implicated in human periodontitis produced by Porphyromonas gingivallis, which activate both PAR1 and PAR2 [63-67]. In Leishmania infection, Leishmania promastigotes, through their surface protease, leishmanolysin or gp63, activates PAR1 in the host macrophages. This activation raises the cytosolic $\left[\mathrm{Ca}^{2+}\right]$, activating the $\mathrm{Ca}^{2+}$-dependent protease $\mu$-calpain. The virulence of Leishmania has been related to the expression of surface gp63 [253]. PAR1 has also been related with the pathogenicity of influenza $A$ virus in mice. PAR1 expression is increased in infected mice [254], and it seems that PAR1 activation decreased survival and increased lung inflammation after influenza infection in a plasminogen-dependent manner, while both PAR1 antagonist administration or PAR1 deficiency protected mice from infection [255]. However, the signaling mechanism of this PAR1 pathogenic role in virus infection is unknown.

\subsection{Nervous system}

PAR1 expression is widespread, but with low intensity, in the late embryonic and early postnatal nervous system, becoming more pronounced and confined to particular neuronal cells in adult animals [256]. This receptor is abundant in the hippocampus, particularly in the pyramidal layers of the CA2 and CA3 regions, and low level of expression has been observed in the cortex, thalamus, hypothalamus, striatum, and amygdala [25]. PAR1 is expressed in neurons, astrocytes, microglia, and oligodendrocytes [257-262]. These cells also express PAR 1 -activating serine proteases [8, 24, 160]. The local expression of these proteases and PAR1 indicates that this receptor plays an important role in physiological functions in the brain related to neuronal development and plasticity. On the other hand, the expression of both PAR1 and its activating proteases is increased in the brain of patients with neurodegenerative diseases, such as stroke, Alzheimer's disease, Parkinson's disease, and HIVassociated dementia [25]. The level of signaling of PAR1 is also altered during disease due to the extravasation of plasma proteases through a perturbed blood-brain barrier (BBB), such as in acute injuries (for example, in trauma or stroke). In injured brains, thrombin mediates, via PAR1, dual opposite effects. Low concentrations of thrombin rescue neuronal cells from death after brain insults, while, high concentrations of this protease exacerbate brain damage [25]. Oh the other hand, APC signaling through PARl can favorably regulate diverse pathways in the neurovascular unity in non-neuronal cells and neurons during acute or chronic CNS insults, leading to stabilization of BBB, neuroprotection and control of neuroinflammation [160]

During neuronal development, thrombin signaling through PAR1 has a direct effect on cell morphology of astrocytes, fetal neurons, and neuroblastoma cells. Low concentrations of thrombin induce neurite retraction in neurons and reverse the stellation in astrocytes [25]. The protein RhoA, via PAR1 signaling through $\mathrm{G}_{12 / 13}$, has been implicated in the thrombin-induced morphological changes in neurons and astrocytes. This signaling requires the interaction of PAR1 with creatinine kinase and heat shock protein 90 (Hsp90) [263-265]. Thrombin, also via PAR1, induces cell proliferation in astrocytes, signaling through $G \alpha_{i / 0}$ [25], and regulates synaptogenesis in the peripheral nervous system $[266,267]$. PAR1 has also been implicated in synaptic plasticity and learning and memory in the brain $[25,268]$. PAR 1 activation induces glutamate release from astrocytes, which activates NMDA receptors on adjacent neurons of the hippocampus $[135,269]$. PAR 1 deficiency in mice impairs learning, passive avoidance behavior, and fear-eonditioning freezing [270]. Both thrombin and APC, via PAR1, participates in the NMDAmediated regulation of long term potentiation (LTP) of synaptic transmission. Thrombin induces a slow onset LTP, while APC shifts the threshold of LTP towards further potentiation and, besides PAR 1, requires activation of S1PR 1 and intracellular $\mathrm{Ca}^{2+}$ stores [271]. Plasmin may also participate in the potentiation of NMDA synaptic currents in CAl pyramidal neurons through PAR1 activation in astrocytes [43]. It has been suggested that the potentiation of NMDA receptor function by PAR1 activation may also increase the excitability of dentate granule neurons of hippocampus [272] and underlie the PAR 1-dependent neuronal damage after brain injury [133]. On the other hand, thrombin and PAR1 have been implicated in the onset of seizures. Thrombin causes an increase in spontaneous action potential discharges of $\mathrm{C} 3$ and $\mathrm{Cl}$ pyramidal neurons that is blocked by selective PAR1 antagonists. These results, along with the higher expression of PAR1 in striatum lucidum of C3, suggest that thrombin, via PAR1, is implicated in epileptic seizure onset [161]

Microglia cells are the major immune effectors in the brain, and activated microglia participates in neuroinflammation around injured areas in the brain. In microglia, thrombin mediates the expression of inducible iNOS and several proinflammatory cytokines [25]. Thrombin also activates, via PAR1, NADPH oxidase, an important source of reactive oxygen species (ROS) during inflammation in microglia in the hippocampus. So, several neurodegenerative disorders have been associated with thrombin-induced neuroinflammation in microglia, such as stroke, Alzheimer's disease, Parkinson's disease, and HIVassociated dementia. PAR1-mediated activation of astrocytes also contributes to neuroinflammation in the brain [25]. On the other hand, several studies in astrocytes have indicated that thrombin, in a concentration dependent manner, induces, via PAR1 activation, the release of cytokine-induced neutrophil chemoattractants (CINCs) that enhance cell survival in astrocytes [273, 274]. These chemokines, released from astrocytes upon thrombin stimulation, protect cortical neurons from apoptosis and might be responsible, in part, of the protective actions of low concentrations of thrombin after brain injury [275].

Thrombin is responsible for brain edema formation after intracerebral hemorrhage or after focal cerebral ischemia. Under these conditions, a variety of proimflammatory mediators are generated in the brain and thrombin-induced neuroinflammation seems to be involved into neurodegeneration in stroke [25]. In vivo studies have demonstrated that PAR1 activation 
significantly increases infarct volume in the brain after transient focal cerebral ischemia [276]. PAR1 activation by thrombin induces apoptosis in hippocampal neurons through activation of RhoA and the MAPKs cascade [97, 277]. Both signaling molecules are involved in neurodegeneration and neuroprotection in stroke. Thus, cell death and cell survival may share initial signaling proteins, but differences in amplitude, as well as in duration of signal may result in opposite final consequences [278]. On the other hand, MMP-9 is increased in brain after intracerebral hemorrhage and contributes to the thrombin-mediated PAR1 neurotoxicity $[279,280]$, as this metalloprotease can degrade extracellular matrix and cause BBB disruption.

In Alzheimer's disease, thrombin plays an important role in its pathogenesis. Thus, oxidative stress and neuroinflammation is present in this disease [281]. On the other hand, as already commented, thrombin and PAR 1 are upregulated in the brains of patients suffering this disease. Both proteins are accumulated in extracellular and intracellular neurofibrillary tangles, senile plaques, and reactive microglia cells $[282,283]$. There is evidence that thrombin, through activation of PAR1 and PAR4 induces hyperphosphorylation and aggregation of tau protein in hippocampal neurons. This effect seems to be mediated by activation of ERK1/2 [284]. Conversely, thrombin attenuates $A \beta$ toxicity via PAR1, but this effect is not clear and needs further investigations [285]. High levels of expression of the transcription factor $\mathrm{HIF}-1 \alpha$, which regulates proinflammatory gene expression, and of MMP1 have been detected in Alzheimer's disease brains. Besides, thrombin induces upregulation of $\mathrm{HIF-l} \alpha$ and MMP-1 in brain endothelial cells [283, 286]. Taking into account these results, it has been suggested that thrombininduced alterations in brain microcirculation might also contribute to the pathological processes of Alzheimer's disease [25]

Oxidative stress and neuroinflammation are the most significant features of Parkinson's disease. Both thrombin and PAR1 are upregulated in the vessel wall in the substantia nigra pars compacta of Parkinson's disease patients [287]. However the role of PAR1 in Parkinson's disease is not clear, as both neurodegenerative and neuroprotective effects of the thrombin-mediated PAR1 activation on Parkinson's disease models have been reported. Thus, PAR1 deficiency, as well as administration of PAR1 antagonists, reduced dopaminergic neuron damage and microgliosis in a model of induced Parkinson's disease [288]. In another model, PAR1specific antagonists diminished the expression of microgliar inflammatory cytokines induced by $\alpha$ synuclein, a protein with a key role in the pathogenesis of Parkinson's disease [289]. In contrast, it has been found that PAR1, activated by thrombin, mediates neuroprotection in the rat 6-hydroxydopamine model of Parkinson's disease and reduces dopaminergic terminal cell loss [290].

Activation of the coagulation cascade has been associated with inflammation in the experimental autoimmune encephalomyelitis model of multiple sclerosis (MS) [291]. Considering the key role of thrombin in coagulation, it has been suggested that this protease may play an important role in MS [25]. Besides, the predominant expression of PAR1 in oligodendrocytes also indicated an important role of this receptor in MS [261]. On the other hand, it has also been reported that APCmediated activation of PAR1 results in neuroprotection in animal models of MS and amyotrophic lateral sclerosis (ALS) [160].

\subsection{Cancer and angiogenesis}

Over the last years, abundant evidences have contributed to associate dysregulation of PAR 1 activity with cancer, including: i) high correlation between hypercoagulation disorders and cancer, ii) overexpression of PAR1 in cancer patients, iii) relationship between dysregulation in the PAR1 signaling cascade with cancer development pathways, and iv) strong involvement of PAR1 in angiogenesis processes.

\subsubsection{Hypercoagulation-cancer association}

The relationship between thrombosis and cancer [292], which was first described by Armand Trousseau in 1865 [293], Venous thromboembolism (VTE) is frequenly observed in cancer patients and its incidence depends on the cancer type. Clinical symptoms of VTE vary from asymptomatic deep vein thrombosis (DVT) to fatal pulmonary embolism (PE). It is considered that 10-20\% of cancer deaths could be due to PE, rather than to the cancer itself [294], and it seems that tumor histology is related to the risk of developing PE. In necropsy studies, ovarian cancers had the highest percentage (34.6\%), whereas cancers of the oesophagus and larynx, and lymphomas had the lowest rates (0.5-6\%) [295]. VTE is the second most common cause of death in cancer patients [296]. On the other hand, cancer is a well-known predictor for VTE and patients with cancer undergoing surgery have increased risk of developing post-operative DVT [297].Often, thrombosis is the first clinical manifestation of cancer. It has been reported that approximately $10 \%$ of patients who developed spontaneous thrombosis develop cancer several years later [298]. In addition, cancer patients who develop thrombosis have worse prognosis [299, 300]. A recent report shows that patients with digestive tract cancers tend to form less permeable, and more resistant to lysis, fibrin clots than controls [301]

Increasing data from prospective randomized clinical trials indicate important benefits of anticoagulants on cancer patient survival [292, 297, 302, 303]. This suggestion is supported by diverse results, which includes the use of heparin or low-molecular weight heparin (LMWH) instead of warfarin, [304-307]. Comparative clinical trials of $L M W H$ versus warfarin and heparin point out increases in survival indices of the patients treated with LMWH [308, 309]. Additionally, it has been described that anticoagulants are able to raise the functional activity of natural killer cells in cancer patients, and in an animal model of lung cancer [310]. Furthermore, it has been reported that platelets from anticoagulated patients have decreased VEGF release and angiogenic potential [311]. These data have been considered to suggest that antithrombotic agents can increase survival and decrease metastasis in cancer patients through attenuation of platelet angiogenic potential. 
Recent studies show that diverse oncogenic events link haemostasis and cancer, mainly through the crossroads between TF and PAR1 [312]. It seems that TF may act as molecular switch that controls the transition between dormant, latent, and progressive/metastatic disease [312-314]. TF initiates the coagulation cascade, which, through thrombin and PAR1, activates platelets Thrombin/PAR1 signaling has been associated with the upregulation of TF in diverse cancer cell lines [297], increase in tumor production of VEGF and decrease in the antiangiogenic regulatory protein thrombospodin [314]

\subsubsection{Overexpression of PAR1 in cancer}

The association of PAR1 expression with cancer has been recognized for an numerous group of tumors [166, 315]. Thus, overexpression of PAR 1 has been observed in biopsy samples from patients with melanoma [316], endometrial carcinoma [317], cancers from breast [318, 319], prostate [320-322], pancreas [323], ovarian [324], and colon [325], squamous cell carcinoma of the head and neck [326], and in lymphocytes and granulocytes from aggressive human leukemias [327]. A analysis of a group of mammary carcinoma cell lines showed high levels of expression of the gene hParl in aggressive metastatic cells (MDA-435 or MCF10AT3B), lower levels in moderately metastatic cells (MDA-231 or MCF10T), and very low levels to none in non-metastatic breast cancer cells (MCF7, ZR-75, or MCF10A) [318]. Recent studies indicate that in breast cancer cells the expression of the hParl gene is controlled by estrogen [319] and progesterone [328], and overall survival is shorter in breast cancer patients that are positive for the estrogen receptor (ER) and PAR1 [319] [329]. PAR1 expression is also increased in patients with non-small-cell lung cancer, mainly in patients with adenocarcinomas [330, 331], and in stromal fibroblasts of malignant tissues in comparison to fibroblasts from normal or benign breast tissue samples [332]. In these patients, PAR1 was an independent prognostic factor for reduced survival, and it has been shown that it is a potential risk factor for recurrence in prostate cancer [266]. Recent studies have demonstrated that the PAR1-506 I/D polymorphism might be an important prognostic factor for breast cancer, esophagus adenocarcinoma, and gastric cancer patients [333-335]. Experimental studies on animal models and cancer cell lines also support the relationship between PARlexpression and tumor growth and metastasis. Thus, PAR1 induces oncogenic transformation of NIH 3T3 fibroblasts [336]. Knocking down PAR1 expression in metastatic MDA-MB-231 breast cancer cells reduces significantly their metastatic potential, whereas PAR1 overexpression in low metastatic MCF-7 breast cancer cells activates growth and invasion in a mouse model [50]. Similarly, knocking down the PAR1 expression in lung adenocarcinoma cells inhibited cell progression [337]. Stable PAR1 antisense melanoma cells showed reduced cell proliferation and invasion in vitro [338]. Injection of these cells into nude mice afforded very few and occasional small tumors, while advanced and vascularized tumors were detected with injection of the highly metastatic human melanoma cells A375SM.Likewise, systemic administration of PAR1 small interfering RNA (siRNA), enclosed in neutral liposomes, significantly reduced tumor growth, weight, and metastatic lung colonies in nude mice with subcutaneous implants of melanoma cells A375-SM [339]. The immunohistochemistry study of the tumor samples indicated a parallel reduction in VEGF, interleukin-8, and matrix metalloprotease-2 (MMP-2) expression levels, as well as in blood vessel density. These results suggest that PAR1 regulates tumor cell growth and metastasis by its action upon angiogenic and invasive factors. Most human cancers derive from epithelial cells, and it has been observed that although hParl is overexpressed in many malignant tumors, the levels of this gene in physiological invasion processes are high only in the placenta during the first trimester of pregnancy [166].

\subsubsection{PARI Activation and signaling related to cancer}

PAR1 is responsible for the direct downstream mitogenic effects of thrombin on tumor cells and for its indirect effects through platelet-tumor interactions. Among these later activities, it has been proposed that thrombin can increase tumor growth indirectly by activating platelets and activating platelet-tumor cell interaction [165]. Platelet activation induces the release of tumor cell growth and angiogenesis factors, such as platelet-derived growth factor (PDGF) [340], VEGF [341], and angiopoietin-1 [342]. It has also been described that platelets produce lysophosphatidic acid (LPA), which stimulates tumor cell growth, by binding to its LPA1 receptor in breast (MDA-BO2) and ovarian $(\mathrm{CHO})$ cancer cells [343]. Besides to its contribution to the adhesion of endothelial cells and the development of collateral vessels, platelet-tumor aggregates protect tumor cells from natural killer cells [344]. These aggregates embolize, leading to ischemia and endothelial cell damage [302]. As a result, tumor cells and platelets bind more strongly to the subendothelial basement membrane and matrix [345]. Finally, tumor cells are released into the parenchyma leading to neoangiogenesis [302]

Besides thrombin, other PAR1 activating proteases are involved in tumor cell survival, motility, migration and invasion, at least in experimental in vitro studies. Thus, it has been reported that APC increases invasion and chemotaxis of breast cancer cells by activating specific signaling pathways through activation of PAR 1 and EPCR [346-348]. As indicated in section 3, the activation of PAR1 by either KLKs $[19,48]$ or MMPs $[54,349]$ has also been related to cancer.

With respect to MMPs, it is well-known that these metalloproteases are important in growth, invasion, and metastasis of malignant tumors [350]. In particular, tumor expression of MMP-1 is associated with bad prognosis in melanoma, breast, ovarian, colorectal, pancreatic and gastric cancers [351]. Expression of MMP-1 is also related to increased angiogenesis in xenograft models of melanoma, breast, and prostate tumors [53]. Although the collagenolitic activity of MMP-1 may help angiogenesis by clarifying extracellular space to enable vessel branching [352], recent works have suggested that the angiogenic activity of tumor produced MMP-1 could also be due to the activation of PAR1 expressed in endothelial cells [50, 53, 353, 354]. On the other hand, although MMP-9, an inductor of tumor cell invasion, does not activate PAR1, this protease is induced by the activation of this receptor by thrombin [355]. PAR1 and MMP-9 are coexpressed in 
osteosarcomas and it has been shown that activation of U2-OS osteosarcoma cells with thrombin or a PAR1 AP induces pro-MMP-9 release, as well as its surfaceassociated expression and proteolytic activity. The stimulation of MMP -9 by thrombin also produces a $\mathrm{PI}_{3} \mathrm{~K}-$ mediated increase in $\beta 1$-integrin expression on the cell surface, which is required for invasion [355].

Several PAR1 signaling pathways also have a clear implication in cancer and angiogenesis, such as transactivation of EGFR. A study on the PAR1 transactivation cascade of EGFR in HT-29 colon cancer cells [356] revealed the following activation sequence: (a) a MMP-dependent release of the transforming growth factor- $\alpha$ (TGF- $\alpha$ ); (b) TGF- $\alpha$-mediated activation of EGFR and EGFR phosphorylation; (c) activation of ERK1/2 and cell proliferation. The association between these actions was proved by the fact that stimulation of cell proliferation and ERK1/2 by activation of PAR1 was reversed by the MMP inhibitor batimastat, TGF- $\alpha$ neutralizing antibodies, EGFR binding domain blocking antibodies, and EGFR tyrosine kinase inhibitors. It has been also proved that activation of PAR1 by thrombin induces persistent transactivation of EGFR and ErbB2/HER2, via prolonged ERK1/2 signaling, in invasive breast carcinoma, but not in normal mammary epithelial cells [93]. Transactivation of EGFR by thrombin-mediated activation of PAR1 has also been associated with the aggressiveness of inflammatory breast cancer, a very aggressive form of epithelial breast cancer [357]

Aberrant PAR1 trafficking, resulting in receptorpopulated cell surfaces and prolonged and persistent signaling has also been shown in breast cancer. The PAR1 C-tail is responsible for this persistent signaling. It has been demonstrated that, in breast cancer cells, there is an association of the proteins Etk/Bmx and Shc to form a physical complex with the PAR1 C-tail via its $\mathrm{PH}$ domain [358].

It has been reported that thrombin stimulates the expression and secretion of VEGF and interleukin-8, via activation of PAR1, in melanoma [339] and prostate cancer cells [359]. This upregulation was reversed by inhibitors of ERK or $\mathrm{PI}_{3} \mathrm{~K}$ kinase pathways, and completely deactivated by PAR1 specific siRNA. In human endometrial stromal cells, the activation of PAR 1 by thrombin or PAR1 APs also promoted the production of VEGF, MMP-1 and active MMP-2 [360]. On the other hand, PAR1 can stimulate cell migration, via Rac and focal adhesion kinase (FAK), by activation of the tumor progression locus 2, tumor necrosis factor $\alpha$ and CD40 signals [86].

Different groups have reported that overexpression of the gene hParl in mice mammary glands rises the expression levels of Wnt-4 and Wnt-7b, both linked to a $\beta$ catenin nuclear stabilization [166, 361, 362]. This enhancement of $\beta$-catenin stabilization has been noted only throughout pregnancy and in stabilized epithelial tumor cell lines.

PAR1 expression has also been related to some transcriptional factors associated with cancer [166]. For instance, analysis of the hParlpromoter showed the presence of androgen response elements (ARE), and androgens regulate hParl expression in prostate cancer biopsy specimens. After hormone ablation treatment, tumor tissues from the same individuals presented very little to none hParl expression and significantly reduced tumor size [363]. Also in prostate cancers, the early growth response-1 (Egr-1) gene induces overexpression of hParl, and a direct correlation between the degree of cancer malignancy, PAR1 expression, and EGR-1 expression has been observed in prostate biopsy samples. Expression of PAR1 and EGR-1 was not observed in noncancerous cells. However, a high distribution and colocalization of both receptors were detected in neoplastic tissues [364]. Finally, the tumor suppressor p53 also acts on hParl as one of its targets genes, regulating its expression [166]. It has been observed that hParl expression is low in cancer cell lines expressing wild-type p53, whereas it is overexpressed in cell lines lacking p53 expression or expressing mutant forms [365]

\subsubsection{PAR 1 and angiogenesis}

Angiogenesis is an essential process in tumor growth $[165,191]$, which is affected by potent angiogenic factor thrombin, whose effect is dependent on PAR1 activation and independent of fibrin formation [190]. Thrombin and the PAR1-AP SFLLRNPNDKYEPF enhance neoangiogenesis 2-3fold in the chick CAM angiogenesis model [366]. This angiogenesis is associated with induction of VEGF and angiopoietin-2 (Ang-2) mRNAs, and is inhibited by the angiogenesis inhibitors KDR-Fc (vs. VEGF) and Tie-2-Fc (Vs. Ang-1 and Ang-2), as well as by inhibitors of the PAR1 signaling cascade, such as the protein kinase $C$ inhibitor bisindolylmaleimide, the MAPK inhibitor PD980598, and the $\mathrm{PI}_{3} \mathrm{~K}$ inhibitor LY294002 [366]. Thrombin also promotes angiogenesis in tumor cells by activating VEGF production [165]. In endothelial cells, thrombin induces the expression of VEGFR2 [367] and the production of Ang-2 [368]. Thrombin also induces liberation of VEGF and Ang-1 in platelets [341, 342]. The PAR1 activation of angiogenesis is associated with upregulation of the growth-regulated oncogene- $\alpha$ (GRO- $\alpha$ ) [369].

In the CAM angiogenesis model the PARlantagonists SCH79797 and RWJ56110 have shown very potent antiangiogenic activity [370], which correlated with their inhibitory effect both in endothelial cell proliferation and DNA synthesis. This inhibitory effect was only evident when endothelial cells were at the fastgrowing state. However, when cells were in the quiescent state, the effect upon the DNA synthesis was much less evident. Both PAR1 antagonists also inhibited thrombin induced ERK1/2 activity in endothelial cells. This inhibition was specific for thrombin-mediated activation, as PAR1 antagonists did not have any effect on bFGF-, VEGF-, or EGF-induced ERK1/2 phosphorylation. Besides, the growth inhibition of endothelial cells by the PAR1 antagonists induced apoptosis, and this effect was due, at least in part, to caspase activation. The $\mathrm{N}$-terminal peptide of PAR1 (1-41), which has been designated as "parstatin", has shown potent angiogenesis inhibition [371-373], although its target receptor has not been identified. 


\section{MOLECULAR ACTIVATION \\ MAPPING OF PAR1}

The elucidation of the molecular mechanisms and structural points relevant for the protein/PAR1 interactions is crucial to ascertain the numerous cellular actions exerted via activation and signaling of PAR1. The master physiological regulator of PAR1 activation is thrombin and, in the last years, different works have been carried out to decipher the pivotal residues involved in thrombin/PAR1 interactions. The key residues of PAR1 for interacting with thrombin are localized in six domains (Table 3), namely protease recognition site, tethered activating ligand, hirudin-like binding domain, ligand binding site 1, and the second and third extracellular loops. The relevance of each of these domains for the activation of PAR1 via thrombin is discussed in detailed in this section. Regarding the intracellular signaling exerted by PAR1, the scarce structural information has been commented above (Section 4).

\subsection{Protease recognition domain (PRS, $L^{38} D P R^{41}$ )}

Initial site-directed mutagenesis studies revealed that the $\mathrm{R} 41$ residue is critical for receptor activation, suggesting that the information necessary for thrombinmediated PAR1 activation is afforded by the breakdown of the receptor at the R41-S42 peptide bond [1, 374]. Later, studies using a library of PAR1 N-terminus exodomains with single-amino acid alanine substitutions disclosed that L38 and P40 PAR1 residues are key for the adequate breakdown of PAR1 by thrombin, and indicated, by the first time, the essential role of $L 38$ of PAR1 in the thrombin binding and cleavage [375]. Furthermore, modeling studies of PAR1/thrombin interaction supported this finding and indicated that the leucine L38 takes up the cavity shaped by the residues L99, 1174 and W215 of thrombin [376]. The crystal structure of thrombin S195A bounded to an uncleaved extracellular PAR1 fragment confirmed the findings suggested in the modeling studies [377]. Besides, this crystal structure has also shown that the residue D39 of PAR1 binds to G216 and G219 of thrombin [377]. Additionally, the 3D structure showed that PAR1 P40 snugly fits into a hydrophobic pocket shaped by the residues Y60a, W60d, H57, and L99 of thrombin [377]. Regarding the PAR1 R41, this residue is implicated in widespread interactions with the thrombin F227, A190, E192, G219, S214, A195 and G193 residues.

\subsection{Tethered activating ligand domain (TAL, $S^{42} F L L R N^{47}$ )}

A loosely binding between R46 of PAR1 and E39 of thrombin was proposed by mutagenesis studies [376]. Besides, these studies also suggested the interaction between the amino acids P40, F43 and L45 of PAR 1 and the amino acid S195 and H57 of thrombin. [376]. On the other hand, the crystal structure of thrombin bound to the uncleaved $\mathrm{N}$-terminal extracellular fragment of PAR1 showed important interactions between PAR1 S42 and thrombin L41 and K60f. The benzyl ring of PAR1 F43 interacts with thrombin E192; PAR1 L44 stacks against thrombin L41; PAR1 R46 interacts with the Q38 in the 30-toop of thrombin; and PAR1 N47 makes a polar contact with the K149w in the autolysis loop of thrombin [377].

\subsection{Hirudin-like binding domain (Hir, $K^{51} Y E P F^{55}$ )}

This domain resembles the C-tail of the leech anticoagulant protein hirudin and it has been stablished that its presence is crucial for thrombin recognition [378]. Additionally, the interaction of this sequence with thrombin increases in an allosteric fashion the cleavage induced by thrombin $[374,376,378]$. Different studies have disclosed that the receptor residues Y52, E53, and F55 are crucial to establish specific interactions with thrombin. Especially, the residue Y52 appears to have a key role [17, 374, 379]. Receptor based peptides studies point out a bidentate interaction of PAR1 with thrombin. To evaluate this bidentate binding, Mathews et al. crystallized thrombin with the PARI sequence L38-E60, where the S42 residue had been mutated to Pro. [379]. Nevertheless, the bidentate interaction was not detected in a single crystal. In its place, the $L^{38} \mathrm{DPR}^{41}$ domain binds at the active site of one thrombin molecule in an unexpected nonproductive interaction, while, the $K^{51} Y_{E P F}^{55}$ domain of the same peptide engages at the fibrinogen recognition site of an additional thrombin molecule. This novel interaction between PAR1 peptides and thrombin seems to be related to the crystallization conditions [378]. The abovementioned 3D models of thrombin bound to PAR 1 identified a ionic interaction between the PAR 1 amino acid E53, at the hirudin-like domain, and the thrombin amino acid R67 [376], in agreement with the data obtained from $X$ ray analysis [379] and the previous mutagenesis studies [380], which identified the residue R67 of thrombin as a crucial point of recognition.

Crystal structures of the thrombin mutant D102N with the extracellular S42-N62 domain of PAR1 indicated that the binding of this PAR1 domain to the exosite I of thrombin triggers an important conformational change in thrombin as consequence of a long-range allosteric communication between the exosite I and the active site of this protease [381]. The N-terminal extracellular PAR1 fragment interacts with the exosite I through polar and hydrophobic bonds, essentially in a similar conformation as commented above.

Furthermore, for the first time, this crystal structure pointed out the crucial role of the PAR1 D50 residue in the PAR1/thrombin interaction. In addition, a crystal structure of thrombin bound to the uncleaved N-terminal extracellular fragment of PAR1 showed an interaction network for the hirudin-like binding domain of PAR1 [377] in which the PAR1 Y52 interacts with the thrombin $\mathrm{R} 73$ and Q38; the PAR1 residue E53 is engaged by the side chain of the thrombin R75 and the backbone $\mathrm{N}$ of the Y76 in exosite I, also interacting with the T74 and R67 of thrombin. Finally, it was shown that the F55 of PAR1 has a weak $\pi$-cation interaction with the $\mathrm{R} 67$ residue of thrombin [377]. 
Table 3. Key residues for thrombin/PAR1 binding drawn from structural studies

\begin{tabular}{|c|c|c|c|c|c|}
\hline & \multicolumn{2}{|c|}{ Mutagenesis $^{a}$} & \multicolumn{2}{|r|}{$X-$ Ray $^{b}$} & \multirow{2}{*}{$\begin{array}{l}\mathrm{NMR}^{c} \\
\mathrm{PAR} 1\end{array}$} \\
\hline PAR1 domain & PAR 1 & Thrombin & PAR1 & Thrombin & \\
\hline \multirow{4}{*}{ Protease recognition domain $\left(\mathrm{L}^{38} \mathrm{DPR}{ }^{41}\right)$} & L38 & L99, I174, W215 & L38 & L99, I174, W215 & \\
\hline & & & D39 & G216 & \\
\hline & P40 & $\mathrm{S} 195, \mathrm{H} 57$ & P40 & Y60a, W60d, H57, L99 & \\
\hline & & & R41 & F227, A190, E192, A195, S214, G219, G193 & \\
\hline \multirow{6}{*}{$\begin{array}{l}\text { Tethered activating ligand domain } \\
\left(S^{42} F L L R N^{47}\right)\end{array}$} & & & S42 & $\llcorner 41, \mathrm{~K} 60 f$ & \\
\hline & F43 & $\mathrm{S} 195, \mathrm{H} 57$ & F43 & E192 & \\
\hline & & & $\llcorner 44$ & $\llcorner 41$ & \\
\hline & $\llcorner 45$ & $\mathrm{S} 195, \mathrm{H} 57$ & & & F43, L44, R46 \\
\hline & R46 & E39 & R46 & Q38 & \\
\hline & & & N47 & K149w & \\
\hline \multirow{4}{*}{$\begin{array}{l}\text { Hirudin-like binding domain } \\
\left(D^{50} K_{Y} \text { PPF }^{55}\right)\end{array}$} & D50 & $\mathrm{R} 73, \mathrm{~K} 149$ & D50 & $\mathrm{R} 73, \mathrm{~K} 149$ & \\
\hline & Y52 & & Y52 & $\mathrm{R} 73, \mathrm{Q} 38$ & $\mathrm{D} 50, \mathrm{~K} 51$ \\
\hline & E53 & R67 & E53 & $\mathrm{R} 67, \mathrm{~T} 74, \mathrm{R} 75, \mathrm{Y} 76$ & \\
\hline & F55 & $182, Y 76$ & F55 & R67, F34, 182 & \\
\hline Ligand binding site domain $1\left(L^{84} P A F I S^{89}\right)$ & F87 & & & & $\mathrm{P} 85, \mathrm{~A} 86, \mathrm{~S} 89,188$ \\
\hline \multirow{2}{*}{$\begin{array}{l}\text { Second extracellular loop } \\
\left(\mathrm{Q}^{242} \mathrm{G}^{265}\right)\end{array}$} & D256 & & & & \\
\hline & E260 & & & & \\
\hline Third extracellular loop $\left(A^{335} \ldots E^{350}\right)$ & E347 & & & & \\
\hline
\end{tabular}

${ }^{a}$ References [1, 16, 169, 374-376, 378, 380, 382, 383]. ${ }^{b}$ References [377, 379,381]. ${ }^{c}$ NMR studies were carried out using a PAR1 A26Hse103 fragment. Reference [17]

\subsection{Ligand binding site domain 1 (LBS-1, $L^{84} \mathrm{PAFIS}^{89}$ )}

This site is necessary for initiation of the transduction of signals. LBS-1 was identified by using a polyclonal antibody, anti-PAR ${ }^{1-160}$, which inhibited peptide ligandinduced receptor activation in various cell types expressing PAR1 [382]. Furthermore, it was confirmed that this domain is an authentic ligand binding site in the full-Hength receptor [17].

The NMR study of the PAR1 N-terminal exodomain identified, as a significant characteristic, the docking of the TAL domain onto the LBS-1 surface [17]. In this study, F43 and S89 display eight NOES, revealing a broad intramolecular interaction. [17]. Besides, the PAR1 188 residue has hydrophobic intramolecular interactions with the $L 44$ residue of thrombin An unexpected interaction was identified between $P^{85} A^{86}$ and $D^{50}-K^{51}$ peptide backbones, indicating that the length of the intramolecular ligand is greater than previously estimated. Notably, the TAL forms a tight turn in R46, whose guanidine group projects away from the LBS-1 [17].

\subsection{Second and third extracellular loops (ECL2 and ECL3)}

With the aim of identifying the domains or specific residues of PAR1 involved in its activation by PARAPS or thrombin, Blackhart et al. carried out mutations on specific residues of ECL2 (D256A) and ECL3 (E347A)
[16]. These mutations displayed deep changes on the functional responses of PAR 1 to the PAR-APs or thrombin activation [16]. Furthermore, the substitution of D256 and E347 residues with asparagine and glutamine, respectively, pointed out the relevance of the negative charge of E347 in receptor activation, while the negative charge of the D256 seems to be less critical. However, changes in amino acids involved in the response to synthetic peptides have little effect on the PARl activation by thrombin. Furthermore, these changes were capable of dissociating receptor specific agonist binding from functional activity. This agonist-dependent selectivity of PAR1 binding could explain the agonist-based biased signaling commented in Section 4.1. This result has not been described for other GPCRs, pointing out that it may be an exceptional characteristic of receptors whose activation is mediated by a tethered ligand [16]. On the other hand, a potential role for an electrostatic interaction between R46 of the PAR1AP and E260 of ECL2 has been suggested [383].

\section{PARI MODULATORS}

Considering that the activation of PAR1 triggers multiple physiological and pathophysiological effects, compounds able to interfere the PAR1/protein interactions, specifically PAR1/thrombin interactions, could be drug candidates to treat numerous disorders, such as those related to cardiovascular, immune, and nervous systems, 
inflammation and cancer. Additionally, PAR1-specific agonist and antagonists could be used as pharmacological tools to study their individual physiological functions. Nevertheless, the discovery of PAR 1 modulators has been a demanding task because the intramolecular tethered ligand-binding mechanism is energetically favored. To overcome this matter, the key starting point was the structure-activity relationship (SAR) studies on diverse synthetic analogues of the tethered ligand capable of activating the receptor (PAR1-APs). In this sense, it is worth noting, the 14-mer peptide SFLLRNPNDKYEPF$\mathrm{NH}_{2}$, which resembles the 42-55 sequence of the $\mathrm{N}-$ terminus of PAR1, and is a potent agonist for both thrombin receptor activation and platelet activation [1]. Deletions in the $\mathrm{C}$ - terminus of the 14-mer PAR1 AP guided the identification of the 6 -mer SFLLRN-NH$H_{2}$ as the PAR 1 AP with full agonist activity and the 5-mer SFLLR$\mathrm{NH}_{2}$ as the minimum sequence for this activity. [5, 384, 385]. The structural requirements for PAR1/thrombin interactions have been delineated by extensive modifications of these PAR1 activating peptides, which have delineated the basis for antagonists rational design. In this regard, the SAR studies in the 5-mer PAR 1 AP have allowed the identification of the Phe, Leu and Arg side chains as key points, along with the need of the free $\mathrm{N}$-terminal amine [384-390]. These and other modifications, including the incorporation of heterocyclic and macrocyclic moieties into the PAR1 APs, have provided several peptide PAR1 ligands with agonist, antagonist and mixed agonist-antagonist activity, but often with low potency and selectivity [21, 391]. The peptide TFRRRLSRATR derived from the C-terminal sequence of the human platelet $\mathrm{P} 2 \mathrm{Y} 1$ receptor has been characterized as a peptide PAR1 agonist in which the pentapeptide TFRRRL is the minimum fragment able to directly activate human platelets through the PAR1 receptor [58].

Various pharmaceutical companies have dedicated efforts to provide powerful and selective PAR1 antagonists with therapeutic application, especially in the thrombosis and atherosclerosis/restenosis field [21, 392, 393]. In this sense, a rational design of peptidomimetics and a random high throughput screening (HTS) of small-molecules were chosen as strategies.

The rational design strategy led to a family of potent PAR1 antagonists by modification of the most potent 5mer peptide with full agonist activity, $\mathrm{SF}(f) \mathrm{F}(\mathrm{G} n)\left\llcorner\mathrm{R}-\mathrm{NH}_{2}\right.$ ( $f=p$-fluoro; $G n=p$-guanidino). The substitution of the serine residue by a trans-cynnamoyl or phenylpropynoyl moiety, along with the incorporation of basic residues at the C-terminus, gave rise to the identification of BMS200261 (1) as the most potent antagonist of the synthesized analogues [394] (Fig. 3). This derivative was a selective PAR1 antagonist relative to PAR-2 [122] and PAR-4 $[395,396]$.<smiles>CC(C)C[C@H](NC(=O)[C@H](Cc1ccc(NC(=N)N)cc1)NC(=O)[C@H](CCCNC(=N)N)NC(=O)/C=C/c1ccccc1)C(=O)N[C@@H](CCCNC(=N)N)C(=O)N[C@@H](CCCNC(=N)N)C(N)=O</smiles>

SFLLR-NH

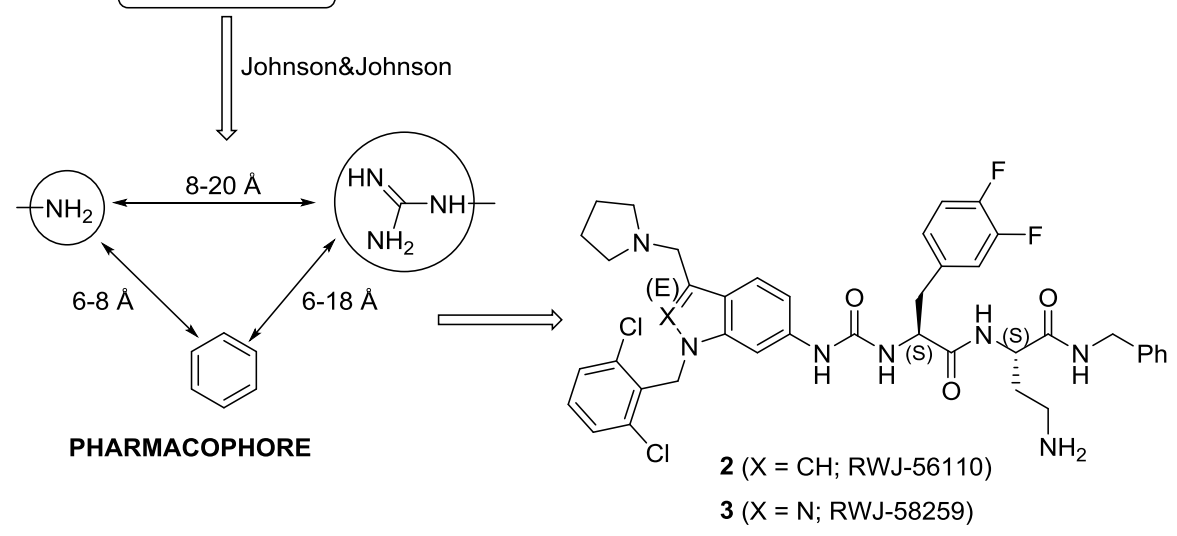

Fig. (3). PAR1 antagonists obtained following a rational design. 
The de novo design of PAR1 peptidomimetic antagonists was a successful strategy to obtain potent PAR1 antagonists. Hence, based on the widespread SAR knowledge on PAR1 APs and the 5-mer peptide as the minimum sequence necessary for the full agonist activity, the Maryanoff group from Johnson and Johnson defined a "three-point model", in which the N-terminal amine, the benzene ring of the Phe residue and the central carbon of the Arg guanidine moiety were the key residues [385, 393] (Fig. 3). In accordance with the peptidomimetic definition, this pharmacophore model was combined with rigid scaffolds to obtain several PAR1 antagonists [21, 392, 393]. Therefore, the 6-aminoindole moiety was initially chosen as scaffold to suitably orient the three key functional groups of SFLLR providing a first series of PAR1 antagonists. In an attempt to avoid undesirable cardiovascular effects, these series were further optimized, by replacing the guanidine moiety, leading to the compound RWJ-56110 (2) (Fig. 3). The antagonist potency, PAR1 selectivity, lack of cytotoxicity, and minimal effect on collagen-induced platelet aggregation showed by RWJ-56110, made this compound attractive to carry out further biological evaluations [370, 397-399]. The first results showed by RWJ-56110 prompted the idea that PARl could be an important target to develop antiangiogenic drugs for cancer and other angiogenesisrelated diseases. However, RWJ-56110 showed hypotensive effects therefore, with the aim to improve the cardiovascular safety profile of the indole-based peptidomimetics, the indole template was substituted by the bioisostere indazole moiety. From this new series, a potent and selective indazole-based PAR1 antagonist named RWJ-58259 (3) was found [397]. Furthermore, RWJ-58259 is used as a standard reference in pharmacological evaluations. [400]. This derivative displayed protection against thrombus formation in nonhuman primates giving the earliest in vivo evidence to support the potential clinical benefit of PAR1 antagonists in humans [401, 402].

Additional changes in the template of peptidomimetics based on an indole scaffold comprise the introduction of a 2-methyl group into the 5- and 6aminoindole scaffold and the substitution of this heterocyclic skeleton with the 1,4-benzodiazepine privileged scaffold [403] or different small bifunctional templates (piperidine, azetidine, cyclohexane and indole) [404]. The capacity of these derivatives to suppress SFLLRN- $\mathrm{NH}_{2}$ induced platelet aggregation-and thrombinmediated calcium signaling was moderated. Additionally, the synthesis of diverse small directed libraries of different scaffolds able to assemble, at least, one or two aromatic groups and one or two basic groups at variable distances and orientation have recently been described, as well as their evaluation as human PAR1 antagonists in a platelet aggregation assay and as cytotoxic agents in human cancer cell lines [405-408]. Some of the compounds displayed moderate PAR1 antagonist activity, while, others were cytotoxic at $\mu \mathrm{M}$ concentration. No correlation was observed between both types of activities.

Moreover, different researches have provided numerous series of structurally diverse potent PARlantagonists found by HTS of combinatorial libraries of non-peptide small molecules followed by optimization.
Representative molecules obtaining following this strategy are summarize in Fig. 4 and reviewed below.

The first non-peptide PAR1 antagonists described was the 1,3-thiazolidinone derivative named FR171113 (4). This compound, discovered by Kato et al. from Fujisawa Pharmaceutical as specific antagonist of PAR1, inhibited arterial thrombosis in guinea pigs inhibit arterial thrombosis in guinea pigs $[409,410]$.

Barrow et al. from Merck first identified a tris-urea analogue with PAR1 antagonist activity, which was structurally modified and optimized to obtain more potent mono-tureas, such as 5 (Fig. 4) [411]. Additionally, directed screening followed by lead optimization provided a second family of non-peptide PAR1 antagonists, exemplified by the phenylisoxazole derivative 6 [412]. The $I_{50}$ values of these two compounds, in the PAR1 radioligand binding assay and in a $\left[{ }^{3} \mathrm{H}\right]$ serotonin assay, were in the submicromolar range.

The next series of thrombin receptor antagonists were four series of compounds patented by Eisai Company [413-415]. Among them, E-5555 (7) showed the most promising profile and oral bioavailability. This compound is an emerging oral antithrombotic drug that is undergoing Phase II clinical trials for coronary artery disease in Japanese population [416]. Nevertheless, scarce preclinical data on this drug have been reported [21]

Researches from Schering Plough, first, described the pyrroloquinazoline SCH-79797 (8) and its N-methyl analogue SCH-203099 (9) as potent and selective PAR1 antagonists in human platelets and human coronary artery SMCs [417, 418]. SCH-79797 and the previously commented RWJ-56110, are the only two PAR1 antagonists that have showed potent antiangiogenic activity in in vivo models $[370,399]$. Besides, the Schering Plough derivative displayed antiproliferative activity, inhibited cell migration and reduced myocardial ischemiareperfusion injury $[128,419,420]$. Moreover, SCH-79797 inhibited the growth of different human and mouse cell lines, although this antiproliferative activity is likely not related to PAR1 antagonism [421].

The same pharmaceutical company developed a fruitful and unexpected family of non-peptide PAR1 antagonist based on the central scaffold of the natural product himbacine. In a HTS campaign focused on the search of muscarinic receptor ligands, it was found an himbacine derivative containing a pyridine ring that later was identified as a selective PAR1 antagonist vs muscarinic receptor [392, 422]. Extensive structural modifications on the pyridine ring, the himbacine tricycle moiety and the stereochemistry allowed the identification of $\mathrm{SCH}-530348$ (10), called vorapaxar [21]. This himbacine analogue exhibits excellent oral bioavailability and is currently undergoing Phase $\mid \mathrm{II}$ clinical trials in patients with acute coronary syndrome and in patients with atherosclerosis [423-426].

In 2012, the crystal structure of vorapaxar (10) bound to human PAR1 was obtained, opening new avenues to the design of improved PAR1 antagonist [427]. Vorapaxar binds to PAR1 in a region very close to the extracellular surface of PAR1 showing an unusual mode of drug binding, in which vorapaxar is surrounded by residues from TM3, TM4, TM5, TM6 and TM7, as well as ECL2 and ECL3, shielding this antagonist from the solvent 
[427]. This structure is a good example of the irreversible binding of a small molecule to inhibit receptor activation by the tethered ligand of PAR1 and provides a model, as a starting point, for the development of PAR1 antagonists. In this sense, this model has been used to guide and explain the structure-activity relationships of a series of spirocyclic analogues of vorapaxar (11) that showed activity and rat plasma levels comparable to vorapaxar [428]. Based on the crystal structure of the complex vorapaxar-PAR1, a recent virtual screening study, aimed to identify phytochemicals with antagonist activity against PAR1, has been carried out. This study has led to the identification of phytochemicals as PAR1 antagonists, which showed interaction with, at least, one residue of the vorapaxar binding site. Nevertheless, further experimental studies are necessary to validate their antagonistic activity against PAR1 [429].<smiles>COC(=O)/C=C1\S/C(=N\C(=O)c2ccc(Cl)cc2Cl)N(c2ccc(Cl)cc2)C1=O</smiles><smiles>CC[C@H](C)N(C[C@H](O)c1ccc(Cl)c(Cl)c1)C(=O)Nc1ccc(CNC(=O)CC(C)C)cc1</smiles><smiles>Fc1cc(F)cc(-c2cc(N(CCCN3CCCCCC3)Cc3ccc4c(c3)OCO4)on2)c1</smiles>

4 (FR171113)<smiles>CCOc1cc2c(c(F)c1OCC)C(=N)N(CC(=O)c1cc(N3CCOCC3)c(OC)c(C(C)(C)C)c1)C2</smiles><smiles>CC1OC(=O)[C@H]2C[C@@H]3C[C@]4(CC[C@@H]3[C@@H]1/C=C/c1ccc(-c3cccc(F)c3)cn1)COC(=O)N24</smiles>

11<smiles>[R]N(c1nc(N)c2c(ccc3c2ccn3Cc2ccc(C(C)C)cc2)n1)C1CC1</smiles>

$8(\mathrm{R}=\mathrm{H} ; \mathrm{SCH}-79797)$

$9(\mathrm{R}=\mathrm{Me} ; \mathrm{SCH}-203099)$

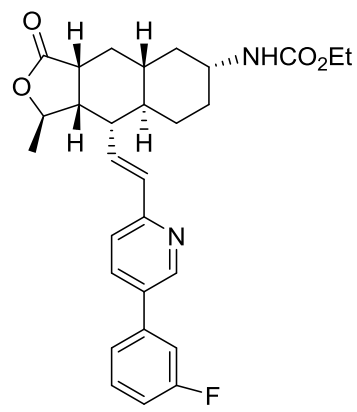

10 (SCH-530348, vorapaxar)<smiles>[X]C(OCCC)C([Al]C(C)(C)C)n1cnc(C)c1</smiles>

12: $X=O, S$<smiles>N#Cc1ccccc1/C=C/C=C/C(=O)N1CCN(c2ccccn2)CC1</smiles>

Fig. (4). Non-peptide PAR1 antagonists

On the other hand, the tricyclic ring of vorapaxar was substituted by an octahydroindene core, providing PAR1 antagonists with comparable potency to vorapaxar, although these compounds were not metabolically stable in human and mouse liver microsomes [430].

In a search for novel structures, Pierre Fabre laboratories carried out a HTS campaign and described two new series of PAR1 antagonists not structurally related, among them the imidazole derivative 12 [431] and the piperazine-derived amides, represented by 13 (F 16618) [432, 433] were selected. The last one, the most advanced PAR1 antagonist of these series, has shown potent antithrombotic activity in vivo and a reduction of the restenosis in the carotid artery of rats without affecting clotting time [434-436]
The modulation of PAR1 activation in an allosteric fashion opens new ways to obtain PAR1 modulators with an improved therapeutic window and increased selectivity. However, up to now, this approach has been poorly investigated and only three examples have been described following this approach (Fig. 5) [100, 101, 437]. Thus, the screening of a small-molecule library for inhibitors of platelet activation led to a new family of molecules, which, by binding to the PAR $18^{\text {th }}$ helix, modify PAR 1 -mediated granule secretion [100]. Among them, the quinoline derivative 14 was identified as a potent allosteric PAR1 antagonist. This antagonist was inactive in a PAR 1 mutant, where the $8^{\text {th }}$ helix was deleted, supporting the important role of this helix for activity. Evaluation of downstream signaling showed that 14 was selective with regard to $G$ protein coupling, blocking signaling mediated by $G_{\alpha q}$ but 
not by $G_{\alpha 12}$. Later, Astereti et al. identified two benzimidazole derivatives $(15,16)$ as selective negative modulators of PAR1 $G_{\alpha q}$ signaling and positive allosteric agonists of PAR1 $G_{\alpha i}$ signaling [437]. Finally, from a HTS of the National Institute of Health Molecular Libraries Small Molecule Repository (NIHALSMR) and further optimization, the 1,3-diaminobenzene 17 was described as an allosteric antagonist of PAR1. This compound inhibited platelet aggregation induced by a PAR1 peptide agonist or by thrombin but not by several other platelet agonists [101].<smiles>CCCCCn1c2c(c(=N)c3ccccc31)CCC2</smiles>

14

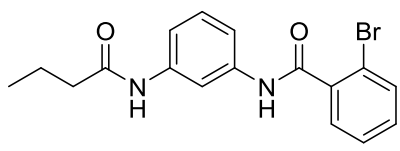

17
Fig. (5). Allosteric PAR1 modulators.

Apart from the aforementioned PAR1 inhibitors, a new strategy to obtain PAR1 antagonist based on lipidated cell-permeable peptides, which mimic intracellular loop sequences, has shown promising effects in the prevention of blood clotting and in animal models of breast cancer $[438,439]$. These antagonists, named pepducins, interfere with PAR1/G protein binding on the inside surface of the receptor, in contrast to classical ligands [105, 440]. The design of pepducins was carried out on the basis of the mutagenesis studies that allowed identifying that the third intracellular loop (i3) of a GPCR is responsible of the coupling between the receptor and its corresponding $G-$ protein [441]. Furthermore, the i3 domain based pepducins, which contains intracellular residues from the adjacent TM5 of PAR1, provoked a fast intracellular calcium influx rather than the inhibition of platelet activation [105, 440]. From these findings, succeeding shortening and N-palmitoylation yielded Plpal12pepducin (Palmitoyl-NH-RCLSSSAVANRS $-\mathrm{NH}_{2}$ ), as a full PAR1 antagonist, capable of preventing SFLLRN$\mathrm{NH}_{2}$-induced platelet aggregation and blocking thrombininduced calcium response [105, 440]. This pepducin together with the smaller heptapeptide derivative P1pal-7 (Palmitoyl-NH-KKSRALF-NH$H_{2}$ ), also a full antagonist, reduced in a significant way the tumor growth and the angiogenesis of breast cancer xenografts in nude mice[442] and in primary lung cancer cells [443].

Apart from the aforementioned PAR1 inhibitors, a new strategy to obtain PAR1 antagonist based on lipidated cell-permeable peptides, which mimic intracellular loop sequences, has shown promising effects in the prevention of blood clotting and in animal models of breast cancer $[438,439]$. These antagonists, named pepducins, interfere with PAR1/G protein binding on the inside surface of the receptor, in contrast to classical ligands [105, 440]. The design of pepducins was carried out on the basis of the mutagenesis studies that allowed identifying that the third intracellular loop (i3) of a GPCR is responsible of the coupling between the receptor and its corresponding $G$ protein [441]. Furthermore, the i3 domain based pepducins, which contains intracellular residues from the adjacent TM5 of PAR1, provoked a fast intracellular calcium influx rather than the inhibition of platelet activation [105, 440]. From these findings, succeeding shortening and N-palmitoylation yielded Plpal12 pepducin (Palmitoyl-NH-RCLSSSAVANRS $-\mathrm{NH}_{2}$ ), as a full PAR1 antagonist, capable of preventing SFLLRN$\mathrm{NH}_{2}$-induced platelet aggregation and blocking thrombininduced calcium response $[105,440]$. This pepducin together with the smaller heptapeptide derivative P1pal-7 (Palmitoyl- $\mathrm{NH}-\mathrm{KKSRALF}-\mathrm{NH}_{2}$ ), also a full antagonist, reduced in a significant way the tumor growth and the angiogenesis of breast cancer xenografts in nude mice[442] and in primary lung cancer cells [443]

\section{CONCLUSIONS AND PERSPECTIVES}

The plethora of clinical and experimental evidences that associate PAR1 expression and activation with diverse disease conditions strongly supports the interest of this receptor as a promising therapeutic target. However, there are several challenges that should be resolved before considering PAR1 a validated drug target. (a) Targeting PAR1 and developing PAR1-targeted therapeutic agents, particularly to the CNS, represents a substantial hurdle, due to its bimodal actions (inflammatory/antiinflammatory; relaxation/contraction; endothelial barrier disruption/stabilization; neuronal damage/protection; neurodegeneration/neuroprotection), depending on the protease agonist, the agonist concentration, the cell-, animal species-, and disease stage-expression specificity, which are still poorly understood. (b) Due to the animal species specific PAR1 expression, the development of a humanized mice model is urgently needed for in vivo assays, to avoid the use of primates in the first preclinical studies. (c) In spite of the advances in the last years in the knowledge of the complex network of the PAR1 interactome, fundamental questions regarding the mechanisms that control signaling selectivity in this multiliganded and multifunctional receptor wait for an answer and further research is needed to fully fathom the molecular basis of the role of PAR 1 in pathology and of its pharmacological control. (d) Structural studies to determine the binding sites of agonists and antagonists at PAR1 are necessary for a structure-based design of more potent and selective PAR1 modulators. In this point, it is noteworthy the recent report on the $X$-ray structure of the complex of PAR1 with its antagonist vorapaxar [427], as well as, the reports on the $G$ protein selective allosteric antagonists [100, 101, 437]. These reports open the door to the structure-based design of selective and potent PAR1 modulators as invaluable pharmacological tools to better unravel the PAR1 interactome and validate it as 
therapeutic target and as drugs in a near future. Taking into account that PAR1 not only signals through $G$ protein, the signaling studies should not be limit to those based on $G$ protein second messengers that would miss other signaling pathways.

\section{ACKNOWLEDGMENTS}

The work was supported by the Spanish Ministerio de Economia y Competividad grant SAF2012-32209. Authors acknowledge Professor M. Teresa Garcíatoópez for reading the manuscript and making valuable suggestions.

$$
\begin{aligned}
& \text { ABBREVIATIONS } \\
& \text { AC = Adenylate Cyclase } \\
& \text { ACS = Acute Coronary Syndromes } \\
& \text { ALI } \quad \text { Acute Lung Injury } \\
& A L K V=\text { Activin } \_ \text {ike Kinase } V \\
& \text { ALS = Amyotrophic Lateral Sclerosis } \\
& \mathrm{C}-\mathrm{AMP}=\text { cyclic Adenosine Monophosphate } \\
& \text { Ang-2 = angiopoietin-2 } \\
& \text { AP-2 = Clathrin adaptor Protein complex } 2 \\
& \text { APC }=\text { Activated Protein C } \\
& \text { ARE = Androgen Response Elements } \\
& \mathrm{BBB}=\text { Blood-Brain Barrier } \\
& \text { bFGF = basic Fibroblast Growth Factor } \\
& \text { BicD1= Bicaudal D1 } \\
& \text { CAM = ChorioAllantoic Membrane } \\
& \text { CB1 = Cannabinoid receptor } 1 \\
& \text { CCL2 = Cc Chemokine Ligand } 2 \\
& \text { CINCs = Cytokine-Induced Neutrophil } \\
& \text { CK2 }=\text { Casein Kinase } 2 \\
& \text { CNS = Central Nervous System } \\
& \text { CTGF = Connective Tissue Growth Factor } \\
& \mathrm{DAG}=\text { Diacylglycerol } \\
& \text { DVT = Deep Vein Thrombosis } \\
& \text { ECL2 = Extracellular Loop } 2 \\
& \text { ECs = Endothelial Cells } \\
& \text { EGR-1 = Early Growth Response-1 } \\
& \text { ELISA = Enzyme-Linked Immunosorbent Assay } \\
& \text { eNOS = endothelial Nitric Oxide Synthase } \\
& \text { EPCR = Endothelial Protein C Receptor } \\
& \text { ERK = Extracellular Regulated Kinase } \\
& \text { Etk/Bmx = Bone marrow tyrosine kinase in } \\
& \text { chromosome } X \\
& \text { FAK = Focal Adhesion Kinase } \\
& \text { FVIla = Factor VIla } \\
& \mathrm{FXa}=\text { Factor } \mathrm{Xa} \\
& \text { FRET = Fluorescence Resonance Energy Transfer } \\
& \text { GDP = Guanosine Diphosphate } \\
& \text { GEFs = Guanine-nucleotide Exchange Factors } \\
& \text { Gl = Gastrointestinal } \\
& \text { GPIIb/lla= Glycoprotein } \mid l b / \| l a \\
& \text { GPCRs = GProtein Coupled Receptors } \\
& \text { GRK = G protein Receptor Kinase } \\
& \text { GRO- } \alpha=\text { Growth-Regulated Oncogene- } \alpha \\
& \text { GSK = Glycogen Synthase Kinase }
\end{aligned}
$$

GTP = Guanosine Triphosphate

hCASMC $=$ Human Coronary Artery Smooth Muscle Cells

HER2 = Human Epidermal growth factor Receptor 2

HGF = Hepatocyte Growth Factor

HMVEC = Human Microvessel Endothelial Cells

HIF-l $\alpha=$ Hypoxia-Inducible Factor $1-\alpha$

$\mathrm{HIV}=$ Human Immunodeficiency Virus

hMCs = human Mast Cells

Hsp = Heat shock protein

HUVECs = Human Umbilical Vein Endothelial Cells

i $\quad=$ intracellular loop (1-3)

$\mathrm{IBD} \quad=$ Inflammatory Bowel Diseases

IBS = Irritable Bowel Syndrome

ICU = Intensive Care Unit

IGFR = InsulinŁike Growth Factor Receptor

$\mathrm{IP}_{3} \quad=$ Phosphoinositide

IL $\quad=$ Interleukin

$\mathrm{Ki} \quad=$ Potassium Channels

KLK $=$ Kallikrein-Related Peptidases

LBS $\quad=$ Ligand Binding Site

$L M W H=$ Low-Molecular Weight Heparin

LPA = LysoPhosphatidic Acid

LPS $=$ Lipopolysaccharide

LTP = Long Term Potentiation

LV $\quad=$ Left Ventricular

MAPKs = Mitogen Activated Protein Kinases

MCP-1 = Monocyte Chemoattractant Protein-1

MEK = Mitogen-activated protein Kinase Kinase

$\mathrm{MI} \quad=$ Myocardial Infarction

MIF = Macrophage migration Inhibitory Factor

MMP-1 = Matrix Metalloprotease-1

MMP-13 = Matrix Metalloprotease-13

MS $=$ Multiple Sclerosis

MT-SP1 = Membrane-Type-Serine Protease 1

$\mathrm{NADPH}=$ Nicotinamide Adenine Dinucleotide Phosphate

NE $\quad=$ Neutrophil Elastase

NMDA $=$ NAlethyl-DAspartate

NMR = Nuclear Magnetic Resonance

NOE = Nuclear Overhauser Effect

NOS = Nitric Oxide Synthase

PAD = Peripheral Artery Disease

PARs = Protease-Activated Receptors

PARAPs = PAR_Activating Peptides

PDGF = Platelet-Derived Growth Factor

PDGFR = Platelet-Derived Growth Factor Receptor

$\mathrm{PE} \quad=$ Pulmonary Embolism

$\mathrm{PGE}_{2}=$ Prostaglandin E2

$\mathrm{PHB}=$ Prohibitin

$\mathrm{PI}_{3} \mathrm{~K}=$ Phosphatidylinositol-3-Kinase

$\mathrm{PKC}=$ Protein Kinase $\mathrm{C}$

PLC $\beta=$ Phospholipase $C \beta$

PR3 = Neutrophil Protease-3

PRS = Protease Recognition Sequence

PTX = Pertussis Toxin

RANTES $=$ Regulated on Activation Normal T cell Expressed and Secreted

RGS = Regulator of G-protein Signalling

RNA = Ribonucleic Acid

mRNA = messenger Ribonucleic Acid

ROCK = Rho-Kinase

ROS $=$ Reactive Oxygen Species 


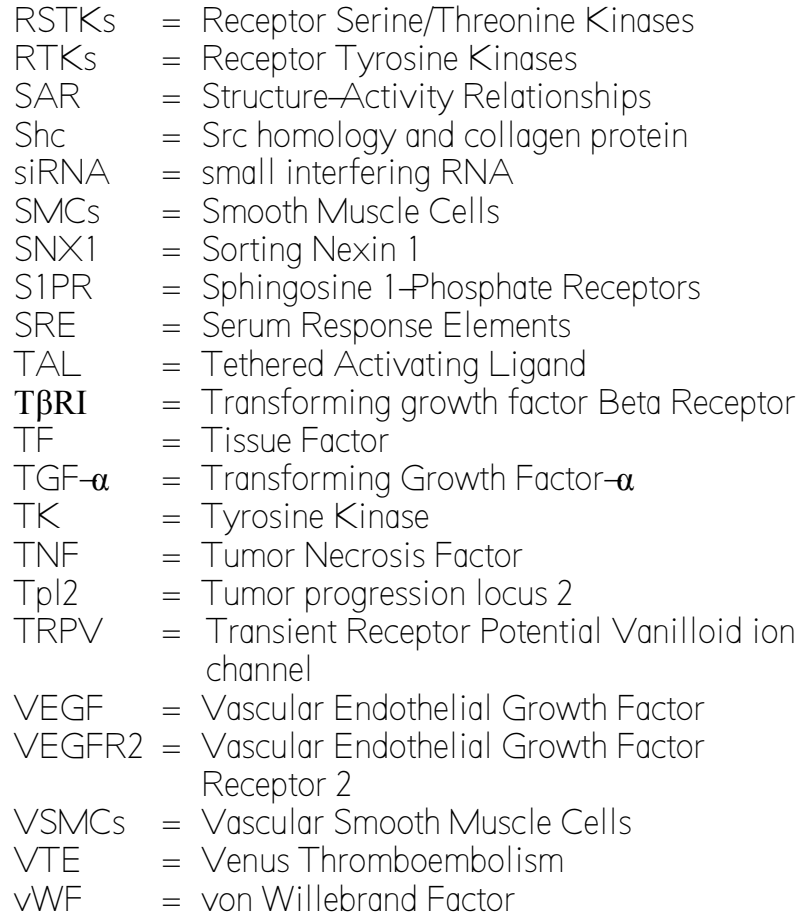

\section{REFERENCES}

[1] Vu, T.K.; Hung, D.T.; Wheaton, V.I.; Coughlin, S.R. Molecular cloning of a functional thrombin receptor reveals a novel proteolytic mechanism of receptor activation. Cell, 1991, 64, 1057-1068.

[2] Rasmussen, U.B.; Vouret-Craviari, V.; Jallat, S.; Schlesinger, $Y$.; Pagès, G.; Pavirani, A.; Lecoca, J..P.; Pouysségur, J.; Van Obberghen-Schilling, E. cDNA cloning and expression of a hamster $\alpha$-thrombin receptor coupled to Ca2+ mobilization. FEBS Lett., 1991, 288, 123128.

[3] Grand, R.J.; Turnell, A.S.; Grabham, P.W. Cellular consequences of thrombin-receptor activation. Biochem. J., 1996, 313, 353-368.

[4] Coughlin, S.R. Thrombin signalling and protease-activated receptors. Nature, 2000, 407, 258-264.

[5] Macfarlane, S.R.; Seatter, M.J.; Kanke, T.; Hunter, G.D.; Plevin, R. Proteinase-activated receptors. Pharmacol. Rev., 2001, 53, 245-282.

[6] Ossovskaya, V.S.; Bunnett, N.W. Protease-activated receptors: contribution to physiology and disease. Physiol. Rev., 2004, 84, 579-621.

[7] Steinhoff, M.; Buddenkotte, J.; Shpacovitch, V.; Rattenholl, A.; Moormann, C.; Vergnolle, N.; Luger, T.A.; Hollenberg, M.D. Proteinase-activated receptors: transducers of proteinase-mediated signaling in inflammation and immune response. Endocr. Rev., 2005, $26,1-43$

[8] Ramachandran, R.; Hollenberg, M.D. Proteinases and signalling: pathophysiological and therapeutic implications via PARs and more. Br. J. Pharmacol., 2008, 153, S263S282.

[9] Martorell, L.; Martínez-González, J.; Rodríguez, C.; Gentile, M.; Calvayrac, O.; Badimon, L. Thrombin and protease-activated receptors (PARs) in atherothrombosis. Thromb. Haemostasis, 2008, 99, 305-315.

[10] Trejo, J. Regulation of thrombin receptor signaling. In Thrombin: Physiology and Disease. Maragoudakis, M.E.;
Tsopanoglou, N.E., Eds.; Springer: New York, 2009, pp $47-61$.

[11] Shah, R. Protease-activated receptors in cardiovascular health and diseases. Am. Heart J., 2009, 157, 253-262.

[12] García-López, M.T.; Gutiérrez-Rodríguez, M.; Herranz, R. Thrombin-Activated Receptors: Promising Targets for Cancer Therapy? Curr. Med. Chem., 2010, 17, 109-128.

[13] Adams, M.N.; Ramachandran, R.; Yau, M.-K.; Suen, J.Y.; Fairlie, D.P.; Hollenberg, M.D.; Hooper, J.D. Structure, function and pathophysiology of protease activated receptors. Pharmacol. Ther., 2011, 130, 248-282.

[14] Ramachandran, R.; Noorbakhsh, F.; DeFea, K.; Hollenberg, M.D. Targeting proteinase-activated receptors: therapeutic potential and challenges. Nat. Rev. Drug Discovery, 2012, 11, 69-86.

[15] Gieseler, F.; Ungefroren, H.; Settmacher, U.; Hollenberg, M.D.; Kaufmann, R. Proteinase-activated receptors (PARs) - focus on receptor-receptor-interactions and their physiological and pathophysiological impact. Cell Commun. Signaling, 2013, 11, 86

[16] Blackhart, B.D.; Ruslim_itrus, L.; Lu, C.C.; Alves, V.L.; Teng, W.; Scarborough, R.M.; Reynolds, E.E.; Oksenberg, D. Extracellular mutations of protease-activated receptor-1 result in differential activation by thrombin and thrombin receptor agonist peptide. Mol. Pharmacol., 2000, 58, 1178 1187.

[17] Seeley, S.; Covic, L.; Jacques, S.L.; Sudmeier, J.; Baleja, J.D.; Kuliopulos, A. Structural basis for thrombin activation of a protease-activated receptor: inhibition of intramolecular liganding. Chem. Biol., 2003, 10, 10331041

[18] McLaughlin, J.N.; Shen, L.; Holinstat, M.; Brooks, J.D.; Dibenedetto, E.; Hamm, H.E. Functional selectivity of $G$ protein signaling by agonist peptides and thrombin for the protease-activated receptor-1. J. Biol. Chem., 2005, 280, 25048-25059

[19] Ramachandran, R.; El-Daly, M.; Saifeddine, M.; Hollenberg, M.D. Thrombin: To PAR or not to PAR, and the regulation of inflamation. In Thrombin: Physiology and Disease

Maragoudakis, M.E.; Tsopanoglou, N.E., Eds.; Springer: New York, 2009, pp 19-46.

[20] Derian, C.K.; Maryanoff, B.E.; Zhang, H.C.; AndradeGordon, P. Therapeutic potential of protease-activated receptor-1 antagonists. Expert Opin. Investig. Drugs, 2003, 12, 209-221

[21] Chen, C.; Maryanoff, B.E.; Andrade-Gordon, P. Thrombin receptor modulators: Medicinal chemistry, biological evaluation, and clinical applications. In Thrombin: Physiology and Disease. Maragoudakis, M.E.; Tsopanoglou, N.E., Eds.; Springer: New York, 2009, pp 205-236.

[22] Kataoka, H.; Hamilton, J.R.; McKemy, D.D.; Camerer, E.; Zheng, Y.-W.; Cheng, A.; Griffin, C.; Coughlin, S.R. Protease-activated receptors 1 and 4 mediate thrombin signaling in endothelial cells. Blood, 2003, 102, 32243231

[23] Gudmundsdóttir, I.J.; Megson, I.L.; Kell, J.S.; Ludlam, C.A.; Fox, K.A.A.; Webb, D.J.; Newby, D.E. Direct vascular effects of protease-activated receptor type 1 agonism in vivo in humans. Circulation, 2006, 114, 16251632.

[24] Sokolova, E; Reiser, G. Prothrombin/thrombin and the thrombin receptors PAR-1 and PAR-4 in the brain: localization, expression and participation in neurodegenerative diseases. Thromb. Haemost., 2008, 100, 576-581. 
[25] Luo, W.; Wang, Y.; Reiser, G. The role of thrombin and thrombin receptors in the brain. In Thrombin: Physiology and Disease. Maragoudakis, M.E.; Tsopanoglou, N.E., Eds.; Springer: New York, 2009, pp 133-159.

[26] Ishii, K.; Hein, L.; Kobilka, B.; Coughlin, S.R. Kinetics of thrombin receptor cleavage on intact cells. Relation to signaling. J. Biol. Chem., 1993, 268, 9780-9786.

[27] De Candia, E.; Hall, S.W.; Rutella, S.; Landolfi, R.; Andrews, R.K.; De Cristofaro, R. Binding of thrombin to glycoprotein Ib accelerates the hydrolysis of Par-1 on intact platelets. J. Biol. Chem., 2001, 276, 4692-4698.

[28] Camerer, E.; Huang, W.; Coughlin, S.R. Tissue factor-and factor $X$-dependent activation of protease-activated receptor 2 by factor VIla. Proc. Natl. Acad. Sci., 2000, 97, $5255-5260$

[29] Schaffner, F.; Ruf, W. Tissue factor and protease-activated receptor signaling in cancer. Semin. Thromb. Hemost., 2008, 34, 147-153.

[30] Riewald, M.; Ruf, W. Mechanistic coupling of protease signaling and initiation of coagulation by tissue factor. Proc. Natl. Acad. Sci., 2001, 98, 7742-7747.

[31] Riewald, M.; Kravchenko, V.V.; Petrovan, R.J.; O'Brien, P.J.; Brass, L.F.; Ulevitch, R.J.; Ruf, W. Gene induction by coagulation factor $\mathrm{Xa}$ is mediated by activation of protease-activated receptor 1. Blood, 2001, 97, 3109-3116.

[32] Borensztajn, K.; Peppelenbosch, M.P.; Spek, C.A. Factor $X \mathrm{a}$ : at the crossroads between coagulation and signaling in physiology and disease. Trends Mol. Med., 14, 429-440.

[33] Rana, S.; Yang, L.; Hassanian, S.M.; Rezaie, A.R. Determinants of the specificity of protease-activated receptors 1 and 2 signaling by factor $X a$ and thrombin. J. Cell. Biochem., 2012, 113, 977-984.

[34] Jobi, K.; Rauch, B.H.; Dangwal, S.; Freidel, K.; Doller, A.; Eberhardt, W.; Fischer, J.W.; Schroer, K.; Rosenkranz, A.C. Redox regulation of human protease-activated receptor-2 by activated factor $X$. Free Radical Biol. Med., $2011,51,1758-1764$.

[35] Scotton, C.J.; Krupiczojc, M.A.; Konigshoff, M.; Mercer, P.F.; Lee, Y.C.G.; Kaminski, N.; Morser, J.; Post, J.M.; Maher, T.M.; Nicholson, A.G.; Moffatt, J.D.; Laurent, G.J.; Derian, C.K.; Eickelberg, O.; Chambers, R.C. Increased local expression of coagulation factor $X$ contributes to the fibrotic response in human and murine lung injury. J. Clin. Invest., 2009, 119, 2550-2563.

[36] Bukowska, A.; Zacharias, I.; Weinert, S.; Skopp, K.; Hartmann, C.; Huth, C.; Goette, A. Coagulation factor Xa induces an inflammatory signalling by activation of protease-activated receptors in human atrial tissue. Eur. J. Pharmacol., 2013, 718, 114-123.

[37] Riewald, M. Thrombin and activated protein C: Integrated to regulate vascular physiology. In Thrombin: Physiology and Disease

Maragoudakis, M.E.; Tsopanoglou, N.E., Eds.; Springer: New York, 2009, pp 63-80.

[38] Riewald, M.; Petrovan, R.J.; Donner, A.; Mueller, B.M.; Ruf, W. Activation of endothelial cell protease activated receptor 1 by the protein C pathway. Science, 2002, 296, 1880-1882.

[39] Cheng, T.; Liu, D.; Griffin, J.H.; Fernandez, J.A.; Castellino, F.; Rosen, E.D.; Fukudome, K.; Zlokovic, B.V. Activated protein C blocks p53-mediated apoptosis in ischemic human brain endothelium and is neuroprotective. Nat. Med., 2003, 9, 338-342.

[40] Mosnier, L.O.; Sinha, R.K.; Burnier, L.; Bouwens, E.A.; Griffin, J.H. Biased agonism of protease-activated receptor 1 by activated protein $C$ caused by noncanonical cleavage at Arg46. Blood, 2012, 120, 5237-5246.
[41] Schuepbach, R.A.; Madon, J.; Ender, M.; Galli, P.; Riewald, M. Protease-activated receptor-1 cleaved at R46 mediates cytoprotective effects. J. Thromb. Haemost., 2012, 10, 1675-1684.

[42] Kuliopulos, A.; Covic, L.; Seeley, S.K.; Sheridan, P.J.; Helin, J.; Costello, C.E. Plasmin desensitization of the PAR1 thrombin receptor: Kinetics, sites of truncation, and implications for thrombolytic therapy. Biochemistry, 1999, 38, 4572-4585.

[43] Mannaioni, G.; Orr, A.G.; Hamill, C.E.; Yuan, H.; Pedone, K.H.; McCoy, K.L.; Palmini, R.B.; Junge, C.E.; Lee, C.J.; Yepes, M.; Hepler, J.R.; Traynelis, S.F. Plasmin potentiates synaptic NAMthyl-D-aspartate receptor function in hippocampal neurons through activation of protease-activated receptor-1. J. Biol. Chem., 2008, 283, 20600-20611.

[44] Suidan, H.S.; Bouvier, J.; Schaerer, E.; Stone, S.R.; Monard, D.; Tschopp, J. Granzyme A released upon stimulation of cytotoxic $T$ lymphocytes activates the thrombin receptor on neuronal cells and astrocytes. Proc. Natl. Acad. Sci. USA, 1994, 91, 8112-8116.

[45] Wang, T.; Lee, M.H.; Choi, E.; Pardo-Villamizar, C.A.; Lee, S.B.; Yang, I.H.; Calabresi, P.A.; Nath, A. Granzyme $B$ induced neurotoxicity is mediated via activation of PAR1 receptor and Kv1.3 channel. PLoS One, 2012, 7, e43950.

[46] Cooper, D.M.; Petchkovsky, D.V.; Hackett, T.L.; Knight, D.A.; Granville, D.J. Granzyme $K$ activates proteaseactivated receptor-1. PLoS One, 2011, 6, e21484.

[47] Hollenberg, M.D.; Oikonomopoulou, K.; Hansen, K.K.; Saifeddine, M.; Ramachandran, R.; Diamandis, E.P. Kallikreins and proteinase-mediated signaling: proteinaseactivated receptors (PARs) and the pathophysiology of inflammatory diseases and cancer. Biol. Chem., 2008, 389, 643-651.

[48] Oikonomopoulou, K.; Diamandis, E.P.; Hollenberg, M.D. Kallikrein-related peptidases: proteolysis and signaling in cancer, the new frontier. Biol. Chem., 2010, 391, 299-310.

[49] Gratio, V.; Beaufort, N.; Seiz, L.; Maier, J.; Virca, G.D.; Debela, M.; Grebenchtchikov, N.; Magdolen, V.; Darmoul, D. Kallikrein-related peptidase 4: a new activator of the aberrantly expressed protease-activated receptor 1 in colon cancer cells. Am. J. Pathol., 2010, 176, 1452-1461.

[50] Boire, A.; Covic, L.; Agarwal, A.; Jacques, S.; Sherifi, S.; Kuliopulos, A. PAR1 is a matrix metalloprotease-1 receptor that promotes invasion and tumorigenesis of breast cancer cells. Cell, 2005, 120, 303-313.

[51] Austin, K.M.; Covic, L.; Kuliopulos, A. Matrix metalloproteases and PAR1 activation. Blood, 2013, 121, $431-439$

[52] Blackburn, J.S.; Liu, I.; Coon, C.I.; Brinckerhoff, C.E. A matrix metalloproteinase-1/protease activated receptor-1 signaling axis promotes melanoma invasion and metastasis. Oncogene, 2009, 28, 4237-4248.

[53] Blackburn, J.S.; Brinckerhoff, C.E. Matrix metalloproteinase-1 and thrombin differentially activate gene expression in endothelial cells via PAR-1 and promote angiogenesis. Am. J. Pathol., 2008, 173, 17361746.

[54] Pei, D. Matrix metalloproteinases target protease-activated receptors on the tumor cell surface. Cancer Cell, 7, 207208.

[55] Trivedi, V.; Boire, A.; Tchernychev, B.; Kaneider, N.C.; Leger, A.J.; O'Callaghan, K.; Covic, L.; Kuliopulos, A. Platelet matrix metalloprotease-1 mediates thrombogenesis by activating PAR1 at a cryptic ligand site. Cell, 2009, 137, 332-343. 
[56] Austin, K.M.; Nguyen, N.; Javid, G.; Covic, L.; Kuliopulos, A. Noncanonical matrix metalloprotease-1protease-activated receptor-1 signaling triggers vascular smooth muscle cell dedifferentiation and arterial stenosis. J. Biol. Chem., 2013, 288, 23105-23115

[57] Jaffré, F.; Friedman, A.E.; Hu, Z.; Mackman, N.; Blaxall, B.C. $\beta$-Adrenergic receptor stimulation transactivates protease-activated receptor 1 via matrix metalloproteinase 13 in cardiac cells. Circulation, 2012, 125, 2993-3003.

[58] Mao, Y.; Jin, J.; Kunapuli, S.P. Characterization of a new peptide agonist of the protease-activated receptor-1. Biochem. Pharmacol., 2008, 75, 438-447.

[59] Hollenberg, M.D.; Saifeddine, M.; Al-Ani, B.; Kawabata, A. Proteinase-activated receptors: structural requirements for activity, receptor cross-reactivity, and receptor selectivity of receptor-activating peptides. Can. J. Physiol. Pharmacol., 1997, 75, 832-841.

[60] Rasmussen, U.B.; Gachet, C.; Schlesinger, Y.; Hanau, D.; Ohlmann, P.; Van Obberghen-Schilling, E.; Pouysségur, J.; Cazenave, J.P.; Pavirani, A. A peptide ligand of the human thrombin receptor antagonizes alpha-thrombin and partially activates platelets. J. Biol. Chem., 1993, 268, 14322-14328.

[61] Mihara, K.; Ramachandran, R.; Renaux, B.; Saifeddine, M.; Hollenberg, M.D. Neutrophil elastase and proteinase-3 trigger $G$ protein-biased signaling through proteinaseactivated receptor-1 (PAR1). J. Biol. Chem., 2013, 288, 32979-32990.

[62] Tull, S.P.; Bevins, A.; Kuravi, S.J.; Satchell, S.C.; Al-Ani, B.; Young, S.P.; Harper, L.; Williams, J.M.; Rainger, G.E.; Savage, C.O. PR3 and elastase alter PAR1 signaling and trigger $v W F$ release via a calcium-independent mechanism from glomerular endothelial cells. PLoS One, 2012, 7, e43916.

[63] Lourbakos, A.; Yuan, Y.; Jenkins, A.L.; Travis, J.; Andrade-Gordon, P.; Santulli, R.; Potempa, J.; Pike, R.N. Activation of protease-activated receptors by gingipains from Porphyromonas gingivalis leads to platelet aggregation: a new trait in microbial pathogenicity. Blood, 2001, 97, 3790-3797.

[64] Lourbakos, A.; Potempa, J.; Travis, J.; D'Andrea, M.R.; Andrade-Gordon, P.; Santulli, R.; Mackie, E.J.; Pike, R.N. Arginine-specific protease from Porphyromonas gingivalis activates protease-activated receptors on human oral epithelial cells and induces interleukin-6 secretion. Infect. Immun., 2001, 69, 5121-5130

[65] Giacaman, R.A.; Asrani, A.C.; Ross, K.F.; Herzberg, M.C. Cleavage of protease-activated receptors on an immortalized oral epithelial cell line by Porphyromonas gingivalis gingipains. Microbiology, 2009, 155, 32383246.

[66] Uehara, A.; Muramoto, K.; Imamura, T.; Nakayama, K.; Potempa, J.; Travis, J.; Sugawara, S.; Takada, H. Argininespecific gingipains from Porphyromonas gingivalis stimulate production of hepatocyte growth factor (Scatter factor) through protease-activated receptors in human gingival fibroblasts in culture. J. Immunol., 2005, 175, 6076-6084

[67] Uehara, A.; Imamura, T.; Potempa, J.; Travis, J.; Takada, H. Gingipains from Porphyromonas gingivalis synergistically induce the production of proinflammatory cytokines through protease-activated receptors with Tolllike receptor and NOD1/2 ligands in human monocytic cells. Cell. Microbiol., 2008, 10, 1181-1189.

[68] McRedmond, J.P.; Harriott, P.; Walker, B.; Fitzgerald, D.J. Streptokinase-induced platelet activation involves antistreptokinase antibodies and cleavage of proteaseactivated receptor-1. Blood, 2000, 95, 1301-1308.

[69] van den Biggelaar, M.; Hernández-Fernaud, J.R.; van den Eshof, B.L.; Neilson, L.J.; Meijer, A.B.; Mertens, K.; Zanivan, S. Quantitative phosphoproteomics unveils temporal dynamics of thrombin signaling in human endothelial cells. Blood, 2014, 123, e22-e36.

[70] Swift, S.; Sheridan, P.J.; Covic, L.; Kuliopulos, A. PAR1 Thrombin Receptor-G Protein Interactions: Separation of binding and coupling determinants in the $\mathrm{G} \alpha$ subunit. $J$. Biol. Chem., 2000, 275, 2627-2635.

[71] McCoy, K.L.; Traynelis, S.F.; Hepler, J.R. PAR1 and PAR2 couple to overlapping and distinct sets of $G$ proteins and linked signaling pathways to differentially regulate cell physiology. Mol. Pharmacol., 2010, 77, 1005-1015.

[72] Hains, M.D.; Wing, M.R.; Maddileti, S.; Siderovski, D.P.; Harden, T.K. Ga12/13- and Rho-dependent activation of phospholipase $C-\epsilon$ by lysophosphatidic acid and thrombin receptors. Mol. Pharmacol., 2006, 69, 2068-2075.

[73] Deng, X.; Mercer, P.F.; Scotton, C.J.; Gilchrist, A.; Chambers, R.C. Thrombin induces fibroblast CCL2/JE production and release via coupling of PAR1 to Gaq and cooperation between ERK1/2 and Rho kinase signaling pathways. Mol. Biol. Cell, 2008, 19, 2520-2533.

[74] Voss, B.; McLaughlin, J.N.; Holinstat, M.; Zent, R.; Hamm, H.E. PAR1, but Not PAR4, activates human platelets through a Gi/o/phosphoinositide-3 kinase signaling axis. Mol. Pharmacol., 2007, 71, 1399-1406.

[75] Nakanishi, K.; Toyoda, H.; Tanaka, S.; Yamamoto, H.; Komada, Y.; Gabazza, E.C.; Hayashi, T.; Suzuki, K.; Ido, M. Phosphoinositide 3-kinase induced activation and cytoskeletal translocation of protein kinase CK2 in protease activated receptor 1 -stimulated platelets. Thromb. Res., 2010, 126, 511-516.

[76] Hatziapostolou, M.; Koukos, G.; Polytarchou, C.; Kottakis, F.; Serebrennikova, O.; Kuliopulos, A.; Tsichlis, P.N. Tumor progression locus 2 mediates signal-induced increases in cytoplasmic calcium and cell migration. Sci. Signal., 2011, 4, ra55.

[77] Nguyen, Q.D.; Faivre, S.; Bruyneel, E.; Rivat, C.; Seto, M.; Endo, T.; Mareel, M.; Emami, S.; Gespach, C. RhoAand RhoD-dependent regulatory switch of Galpha subunit signaling by PAR-1 receptors in cellular invasion. FASEB J, 2002, 16, 565-576

[78] Gavard, J.; Gutkind, J.S. Protein kinase Crelated kinase and ROCK are required for thrombin-induced endothelial cell permeability downstream from Galpha12/13 and Galpha1 1/q. J. Biol. Chem., 2008, 283, 29888-29896.

[79] De Vries, L.; Palmier, C.; Finana, F.; Le Grand, B.; Perez, M.; Cussac, D. Pharmacological characterization of protease activated receptor-1 by a serum responsive element-dependent reporter gene assay: major role of calmodulin. Biochem. Pharmacol., 2006, 71, 1449-1458.

[80] Klages, B.; Brandt, U.; Simon, M.l.; Schultz, G.; Offermanns, S. Activation of G12/G13 results in shape change and Rho/Rho-kinase-mediated myosin light chain phosphorylation in mouse platelets. J. Cell Biol., 1999, 144, 745-754.

[81] Huang, J.-S.; Dong, L.; Kozasa, T.; Breton, G.C. Signaling through Ga13 Switch Region I Is Essential for Proteaseactivated Receptor 1-mediated Human Platelet Shape Change, Aggregation, and Secretion. J. Biol. Chem., 2007, 282, 10210-10222.

[82] Vouret-Craviari, V.; Boquet, P.; Pouyssegur, J.; Van Obberghen-Schilling, E. Regulation of the actin cytoskeleton by thrombin in human endothelial cells: role 
of Rho proteins in endothelial barrier function. Mol. Biol. Cell, 1998, 9, 2639-2653.

[83] Offermanns, S.; Mancino, V.; Revel, J..P.; Simon, M.I. Vascular system defects and impaired cell chemokinesis as a result of Ga13 deficiency. Science 1997, 275, 533-536.

[84] Otani, H.; Yoshioka, K.; Nishikawa, H.; Inagaki, C.; Nakamura, $T$. Involvement of protein kinase $C$ and RhoA in protease-activated receptor 1-mediated F-actin reorganization and cell growth in rat cardiomyocytes. J. Pharmacol. Sci. , 2011, 115, 135-143.

[85] Nguyen, Q.D.; De Wever, O.; Bruyneel, E.; Hendrix, A.; Xie, W.Z.; Lombet, A.; Leibl, M.; Mareel, M.; Gieseler, F.; Bracke, M.; Gespach, C. Commutators of PAR-1 signaling in cancer cell invasion reveal an essential role of the RhoRho kinase axis and tumor microenvironment. Oncogene, $2005,24,8240-8251$

[86] Hatziapostolou, M.; Polytarchou, C.; Panutsopulos, D.; Covic, L.; Tsichlis, P.N. Proteinase-activated receptor-1triggered activation of tumor progression locus-2 promotes actin cytoskeleton reorganization and cell migration. Cancer Res., 2008, 68, 1851-1861.

[87] Watts, V.L.; Motley, E.D. Role of protease-activated receptor-1 in endothelial nitric oxide synthase-Thr495 phosphorylation. Exp. Biol. Med. , 2009, 234, 132-139.

[88] Turm, H.; Maoz, M.; Katz, V.; Yin, Y.J.; Offermanns, S.; Bar-Shavit, R. Protease-activated receptor-1 (PAR1) acts via a novel $\mathrm{G} \alpha 13-$ Dishevelled axis to stabilize $\beta$-catenin levels. J. Biol. Chem., 2010, 285, 15137-15148.

[89] Furuhashi, I.; Abe, K.; Sato, T.; Inoue, H. Thrombinstimulated proliferation of cultured human synovial fibroblasts through proteolytic activation of proteinaseactivated receptor-1. J. Pharmacol. Sci., 2008, 108, 104111.

[90] Palma-Nicolas, J.P.; López, E.; López-Colomé, A.M. PKC isoenzymes differentially modulate the effect of thrombin on MAPK-dependent RPE proliferation. Biosci. Rep., 2008, 28, 307-317.

[91] Chiu, Y.C.; Fong, Y.C.; Lai, C.H.; Hung, C.H.; Hsu, H.C.; Lee, T.S.; Yang, R.S.; Fu, W.M.; Tang, C.H. Thrombininduced IL-6 production in human synovial fibroblasts is mediated by PAR1, phospholipase $C$, protein kinase $C$ alpha, C-Src, NF-kappa B and p300 pathway. Mol. Immunol., 2008, 45, 1587-1599

[92] Huang, Y.L.; Shi, G.Y.; Lee, H.; Jiang, M.J.; Huang, B.M.; Wu, H.L.; Yang, H.Y. Thrombin induces nestin expression via the transactivation of EGFR signalings in rat vascular smooth muscle cells. Cell. Signal., 2009, 21, 954-968.

[93] Arora, P.; Cuevas, B.D.; Russo, A.; Johnson, G.L.; Trejo, J. Persistent transactivation of EGFR and ErbB2/HER2 by protease-activated receptor-1 promotes breast carcinoma cell invasion. Oncogene, 2008, 27, 4434-4445

[94] Chandrasekharan, U.M.; Waitkus, M.; Kinney, C.M.; Walters-Stewart, A.; DiCorleto, P.E. Synergistic induction of mitogen-activated protein kinase phosphatase-1 by thrombin and epidermal growth factor requires vascular endothelial growth factor receptor-2. Arterioscler., Thromb., Vasc. Biol., 2010, 30, 1983-1989.

[95] Hashimotodani, Y; Ohno-Shosaku, T.; Yamazaki, M.; Sakimura, K.; Kano, M. Neuronal protease-activated receptor 1 drives synaptic retrograde signaling mediated by the endocannabinoid 2-arachidonoylglycerol. J. Neurosci., $2011,31,3104-3109$.

[96] Faivre, S.; Régnauld, K.; Bruyneel, E.; Nguyen, Q.-D.; Mareel, M.; Emami, S.; Gespach, C. Suppression of cellular invasion by activated G-protein subunits Gao,

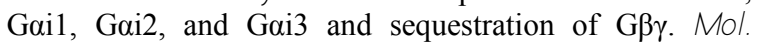
Pharmacol., 2001, 60, 363-372
[97] Wang, H.; Ubl, J.J.; Stricker, R.; Reiser, G. Thrombin (PAR-1)-induced proliferation in astrocytes via MAPK involves multiple signaling pathways. Am. J. Physiol. Cell Physiol., 2002, 283, C1351-C1364.

[98] Hollenberg, M.D.; Mihara, K.; Polley, D.; Suen, J.Y.; Han, A.; Fairlie, D.P.; Ramachandran, R. Biased signalling and proteinase-activated receptors (PARs): targeting inflammatory disease. Brit. J. Pharmacol., 2014, 171, 1180-1194.

[99] Russo, A.; Soh, U.J.K.; Paing, M.M.; Arora, P.; Trejo, J. Caveolae are required for protease-selective signaling by protease-activated receptor-1. Proc. Natl. Acad. Sci., 2009, $106,6393-6397$

[100] Dowal, L.; Sim, D.S.; Dilks, J.R.; Blair, P.; Beaudry, S.; Denker, B.M.; Koukos, G.; Kuliopulos, A.; Flaumenhaft, $\mathrm{R}$. Identification of an antithrombotic allosteric modulator that acts through helix 8 of PAR1. Proc. Natl. Acad. Sci. U. S. A., 2011, 108, 2951-2956.

[101] Dockendorff, C.; Aisiku, O.; VerPlank, L.; Dilks, J.R.; Smith, D.A.; Gunnink, S.F.; Dowal, L.; Negri, J.; Palmer, M.; MacPherson, L.; Schreiber, S.L.; Flaumenhaft, R. Discovery of 1,3-Diaminobenzenes as Selective Inhibitors of Platelet Activation at the PAR1 Receptor. ACS Med. Chem. Lett., 2012, 3, 232-237.

[102] Asteriti, S.; Daniele, S.; Porchia, F.; Dell' Anno, M.T.; Fazzini, A.; Pugliesi, I.; Trincavelli, M.L.; Taliani, S.; Martini, C.; Mazzoni, M.R.; Gilchrist, A. Modulation of PAR1 signalling by benzimidazole compounds. Brit. J. Pharmacol., 2012, 167, 80-94.

[103] Ayoub, M.A.; Trinquet, E.; Pfleger, K.D.G.; Pin, J.P. Differential association modes of the thrombin receptor PAR1 with Gai1, Ga12, and $\beta$-arrestin 1. FASEB J., 2010, 24, 3522-3535.

[104] Verrall, S.; Ishii, M.; Chen, M.; Wang, L.; Tram, T.; Coughlin, S.R. The thrombin receptor second cytoplasmic loop confers coupling to $\mathrm{Gq}$-like $\mathrm{G}$ proteins in chimeric receptors: Additional evidence for a common transmembrane signaling and $G$ ptotein coupling mechanism in G protein-coupled receptors. J. Biol. Chem., 1997, 272, 6898-6902.

[105] Covic, L.; Gresser, A.L.; Talavera, J.; Swift, S.; Kuliopulos, A. Activation and inhibition of $G$ proteincoupled receptors by cell-penetrating membrane-tethered peptides. Proc. Natl. Acad. Sci., 2002, 99, 643-648.

[106] Swift, S.; Leger, A.J.; Talavera, J.; Zhang, L.; Bohm, A.; Kuliopulos, A. Role of the PAR1 Receptor 8th Helix in Signaling: The 7-8-1 receptor activation mechanism. J. Biol. Chem., 2006, 281, 4109-4116.

[107] McCoy, K.L.; Gyoneva, S.; Vellano, C.P.; Smrcka, A.V.; Traynelis, S.F.; Hepler, J.R. Protease-activated receptor 1 (PAR 1 ) coupling to $G(q / 11)$ but not to $G(i / 0)$ or $G(12 / 13)$ is mediated by discrete amino acids within the receptor second intracellular loop. Cell. Signal., 2012, 24, 13511360 .

[108] Luttrell, L.M.; Lefkowitz, R.J. The role of $\beta$-arrestins in the termination and transduction of G-protein-coupled receptor signals. J. Cell Sci., 2002, 115, 455-465.

[109] DeFea, K. $\beta$-arrestins and heterotrimeric G-proteins: collaborators and competitors in signal transduction. Brit. J. Pharmacol., 2008, 153, S298-S309.

[110] Goel, R.; Phillips-Mason, P.J.; Raben, D.M.; Baldassare, J.J. $\alpha$-Thrombin induces rapid and sustained Akt phosphorylation by $\beta$-arrestin1-dependent and independent mechanisms, and only the sustained Akt phosphorylation Is essential for $\mathrm{G} 1$ phase progression. J. Biol. Chem., 2002, 277, 18640-18648. 
[111] Goel, R.; Baldassare, J.J. $\beta$-Arrestin 1 couples thrombin to the rapid activation of the Akt pathway. Ann. N. Y. Acad. Sci., 2002, 973, 138-141

[112] Kuo, F.-T.; Lu, T.七.; Fu, H.-W. Opposing effects of $\beta-$ arrestin1 and $\beta$-arrestin2 on activation and degradation of Src induced by protease-activated receptor 1. Cell. Signal., 2006, 18, 1914-1923.

[113] Soh, U.J.K.; Trejo, J. Activated protein C promotes protease-activated receptor-1 cytoprotective signaling through $\beta$-arrestin and dishevelled-2 scaffolds. Proc. Natl. Acad. Sci., 2011, 108, E1372-E1380

[114] Little, P.J.; Burch, M.L.; Al-Aryahi, S.; Zheng, W. The paradigm of $G$ protein receptor transactivation: a mechanistic definition and novel example. TheScientificWorldJ ournal, 2011, 11, 709-714.

[115] Narita, M.; Usui, A.; Narita, M.; Niikura, K.; Nozaki, H.; Khotib, J.; Nagumo, Y.; Yajima, Y.; Suzuki, T. Proteaseactivated receptor-1 and platelet-derived growth factor in spinal cord neurons are implicated in neuropathic pain after nerve injury. J. Neurosci., 2005, 25, 10000-10009.

[116] Du, J.; Sperling, L.S.; Marrero, M.B.; Phillips, L.; Delafontaine, P. G-protein and tyrosine kinase receptor cross-talk in rat aortic smooth muscle cells: thrombin-and angiotensin $\mid 1$-induced tyrosine phosphorylation of insulin receptor substrate-1 and insulin-like growth factor 1 receptor. Biochem. Biophys. Res. Commun., 1996, 218, 934-939.

[117] Delafontaine, P.; Anwar, A.; Lou, H.; Ku, L. G-protein coupled and tyrosine kinase receptors: evidence that activation of the insulin-like growth factor I receptor is required for thrombin-induced mitogenesis of rat aortic smooth muscle cells. J. Clin. Invest., 1996, 97, 139-145.

[118] Chan, B.; Sukhatme, V.P. Receptor tyrosine kinase EphA2 mediates thrombin-induced upregulation of ICAM-1 in endothelial cells in vitro. Thromb. Res., 2009, 123, 745752.

[119] Burch, M.L.; Ballinger, M.L.; Yang, S.N.Y.; Getachew, R.; Itman, C.; Loveland, K.; Osman, N.; Little, P.J. Thrombin stimulation of proteoglycan synthesis in vascular smooth muscle is mediated by protease-activated receptor1 transactivation of the transforming growth factor $\beta$ type I receptor. J. Biol. Chem., 2010, 285, 26798-26805.

[120] Jenkins, R.G.; Su, X.; Su, G.; Scotton, C.J .; Camerer, E.; Laurent, G.J.; Davis, G.E.; Chambers, R.C.; Matthay, M.A.; Sheppard, D. Ligation of protease-activated receptor 1 enhances $\alpha v \beta 6$ integrin-dependent TGF $\beta$ activation and promotes acute lung injury. J. Clin. Invest., 2006, 116, $1606-1614$

[121] Kaneider, N.C.; Leger, A.J.; Agarwal, A.; Nguyen, N.; Perides, G.; Derian, C.; Covic, L.; Kuliopulos, A. 'Role reversal' for the receptor PAR1 in sepsis-induced vascular damage. Nat. Immunol., 2007, 8, 1303-1312.

[122] O'Brien, P.J.; Prevost, N.; Molino, M.; Hollinger, M.K.; Woolkalis, M.J.; Woulfe, D.S.; Brass, L.F. Thrombin responses in human endothelial cells. Contributions from receptors other than PAR1 include the transactivation of PAR2 by thrombin-cleaved PAR1. J. Biol. Chem., 2000, 275, 13502-13509.

[123] Shi, X.; Gangadharan, B.; Brass, L.F.; Ruf, W.; Mueller, B.M. Protease-activated receptors (PAR1 and PAR2) contribute to tumor cell motility and metastasis. Mol. Cancer Res., 2004, 2, 395-402.

[124] McEachron, T.A.; Pawlinski, R.; Richards, K.L.; Church, F.C.; Mackman, N. Protease-activated receptors mediate crosstalk between coagulation and fibrinolysis. Blood, $2010,116,5037-5044$
[125] Lin, H.; Trejo, J. Transactivation of the PAR1-PAR2 heterodimer by thrombin elicits $\beta$-arrestin-mediated endosomal signaling. J. Biol. Chem., 2013, 288, 1120311215.

[126] Leger, A.J.; Jacques, S.L.; Badar, J.; Kaneider, N.C.; Derian, C.K.; Andrade-Gordon, P.; Covic, L.; Kuliopulos, A. Blocking the protease-activated receptor 1-4 heterodimer in platelet-mediated thrombosis. Circulation, 2006, 113, 1244-1254.

[127] Kaufmann, R.; Patt, S.; Zieger, M.; Kraft, R.; Tausch, S.; Henklein, P.; Nowak, G. The two-receptor system PAR1/PAR-4 mediates $\alpha$-thrombin-induced [Ca2+]i mobilization in human astrocytoma cells. J. Cancer Res. Clin. Oncol., 2000, 126, 91-94.

[128] Kaufmann, R.; Rahn, S.; Pollrich, K.; Hertel, J.; Dittmar,

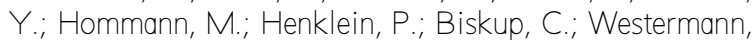
M.; Hollenberg, M.D.; Settmacher, U. Thrombin-mediated hepatocellular carcinoma cell migration: cooperative action via proteinase-activated receptors 1 and 4. J. Cell Physiol., 2007, 211, 699-707

[129] Feistritzer, C.; Riewald, M. Endothelial barrier protection by activated protein $C$ through PAR1-dependent sphingosine 1-phosphate receptor-1 crossactivation. Blood, 2005, 105, 3178-3184.

[130] Niessen, F.; Schaffner, F.; Furlan-Freguia, C.; Pawlinski, R.; Bhattacharjee, G.; Chun, J.; Derian, C.K.; AndradeGordon, P.; Rosen, H.; Ruf, W. Dendritic cell PAR1-S1P3 signalling couples coagulation and inflammation. Nature, 2008, 452, 654-658

[131] Guo, H.; Zhao, Z.; Yang, Q.; Wang, M.; Bell, R.D.; Wang, S.; Chow, N.; Davis, T.P.; Griffin, J.H.; Goldman, S.A.; Zlokovic, B.V. An activated protein C analog stimulates neuronal production by human neural progenitor cells via a PAR1-PAR3-S1PR1-Akt pathway. J. Neurosci., 2013, 33, 6181-6190.

[132] Nagai, T.; Ito, M.; Nakamichi, N.; Mizoguchi, H.; Kamei, H.; Fukakusa, A.; Nabeshima, T.; Takuma, K.; Yamada, K. The rewards of nicotine: regulation by tissue plasminogen activator-plasmin system through protease activated receptor-1. J. Neurosci., 2006, 26, 12374-12383.

[133] Hamill, C.E.; Mannaioni, G.; Lyuboslavsky, P.; Sastre, A.A.; Traynelis, S.F. Protease-activated receptor 1dependent neuronal damage involves NMDA receptor function. Exp. Neurol., 2009, 217, 136-146.

[134] Gingrich, M.B.; Junge, C.E.; Lyuboslavsky, P.; Traynelis, S.F. Potentiation of NMDA receptor function by the serine protease thrombin. J. Neurosci., 2000, 20, 4582-4595.

[135] Lee, C.J.; Mannaioni, G.; Yuan, H.; Woo, D.H.; Gingrich, M.B.; Traynelis, S.F. Astrocytic control of synaptic NMDA receptors. J. Physiol. , 2006, 581, 1057-1081.

[136] Vellani, V.; Kinsey, A.M.; Prandini, M.; Hechtfischer, S.C.; Reeh, P.; Magherini, P.C.; Giacomoni, C.; McNaughton, P.A. Protease activated receptors 1 and 4 sensitize TRPV1 in nociceptive neurones. Mol. Pain, 2010, 6,61

[137] Schuepbach, R.A.; Feistritzer, C.; Brass, L.F.; Riewald, M. Activated protein C-cleaved protease activated receptor-1 is retained on the endothelial cell surface even in the presence of thrombin. Blood, 2008, 111, 2667-2673.

[138] Ishii, K.; Chen, J.; Ishii, M.; Koch, W.J .; Freedman, N.J.; Lefkowitz, R.J.; Coughlin, S.R. Inhibition of thrombin receptor signaling by a G-protein coupled receptor kinase. Functional specificity among G-protein coupled receptor kinases. J. Biol. Chem., 1994, 269, 1125-1130.

[139] Tiruppathi, C.; Yan, W.; Sandoval, R.; Naqvi, T.; Pronin, A.N.; Benovic, J.L.; Malik, A.B. G protein-coupled receptor kinase -5 regulates thrombin-activated signaling in 
endothelial cells. Proc. Natl. Acad. Sci. U. S. A., 2000, 97, 7440-7445

[140] Paing, M.M.; Stutts, A.B.; Kohout, T.A.; Lefkowitz, R.J.; Trejo, J. $\beta$-Arrestins regulate protease-activated receptor-1 desensitization but not internalization or down-regulation. J. Biol. Chem., 2002, 277, 1292-1300.

[141] Chen, C.H.; Paing, M.M.; Trejo, J. Termination of protease-activated receptor-1 signaling by $\beta$-arrestins is independent of receptor phosphorylation. J. Biol. Chem., 2004, 279, 10020-10031.

[142] Ghil, S.; McCoy, K.L.; Hepler, J.R. Regulator of G protein signaling 2 (RGS2) and RGS4 form distinct G proteindependent complexes with protease activated-receptor 1 (PAR1) in live cells. PLoS One, 2014, 9, e95355.

[143] Chen, B.; Siderovski, D.P.; Neubig, R.R.; Lawson, M.A.; Trejo, J. Regulation of protease-activated receptor 1 signaling by the adaptor protein complex 2 and R4 subfamily of regulator of $G$ protein signaling proteins. $J$. Biol. Chem., 2014, 289, 1580-1591.

[144] Wolfe, B.L.; Marchese, A.; Trejo, J. Ubiquitination differentially regulates clathrin-dependent internalization of protease-activated receptor-1. J. Cell Biol., 2007, 177, 905-916.

[145] Chen, B.; Dores, M.R.; Grimsey, N.; Canto, I.; Barker, B.L.; Trejo, J. Adaptor protein complex-2 (AP-2) and epsin-1 mediate protease-activated receptor-1 internalization via phosphorylation- and ubiquitinationdependent sorting signals. J. Biol. Chem., 2011, 286, 40760-40770

[146] Swift, S.; Xu, J.; Trivedi, V.; Austin, K.M.; Tressel, S.L.; Zhang, L.; Covic, L.; Kuliopulos, A. A novel proteaseactivated receptor-1 interactor, bicaudal D1, regulates G protein signaling and internalization. J. Biol. Chem., 2010, 285, 11402-11410.

[147] Wang, Y.; Zhou, Y.; Szabo, K.; Haft, C.R.; Trejo, J. Down-regulation of protease-activated receptor-1 is regulated by sorting nexin 1. Mol. Biol. Cell, 2002, 13, 1965-1976.

[148] Gullapalli, A.; Wolfe, B.L.; Griffin, C.T.; Magnuson, T.; Trejo, J. An essential role for SNX1 in lysosomal sorting of protease-activated receptor-1: evidence for Retromer-, Hrs-, and Tsg101-independent functions of sorting nexins. Mol. Biol. Cell, 2006, 17, 1228-1238

[149] Wang, Y.J.; Guo, X.t.; Li, S.A.; Zhao, Y.-Q.; Liu, Z.C.; Lee, W.H.; Xiang, $Y$.; Zhang, $Y$. Prohibitin is involved in the activated internalization and degradation of protease-activated receptor 1. Biochim. Biophys. Acta 2014, 1843, 1393-1401

[150] Kuliopulos, A.; Covic, L.; Seeley, S.K.; Sheridan, P.J.; Helin, J.; Costello, C.E. Plasmin desensitization of the PAR1 thrombin receptor: Kinetics, sites of truncation, and implications for thrombolytic therapy. Biochemistry, 1999, 38, 4572-4585

[151] Renesto, P.; Si-Tahar, M.; Moniatte, M.; Balloy, V.; Van Dorsselaer, A.; Pidard, D.; Chignard, M. Specific inhibition of thrombin-induced cell activation by the neutrophil proteinases elastase, cathepsin $\mathrm{G}$, and proteinase 3: evidence for distinct cleavage sites within the amino terminal domain of the thrombin receptor. Blood, 1997, 89, 1944-1953.

[152] Xiao, Y.P.; Morice, A.H.; Compton, S.J .; Sadofsky, L. NLinked glycosylation regulates human proteinase-activated receptor-l cell surface expression and disarming via neutrophil proteinases and thermolysin. J. Biol. Chem., 2011, 286, 22991-23002.

[153] Nakayama, T.; Hirano, K.; Shintani, Y.; Nishimura, J.; Nakatsuka, A.; Kuga, H.; Takahashi, S.; Kanaide, H.
Unproductive cleavage and the inactivation of proteaseactivated receptor-1 by trypsin in vascular endothelial cells. Br. J. Pharmacol., 2003, 138, 121-130.

[154] Schechter, N.M.; Brass, L.F.; Lavker, R.M.; lensen, P.J. Reaction of mast cell proteases tryptase and chymase with protease activated receptors (PARs) on keratinocytes and fibroblasts. J. Cell. Physiol., 1998, 176, 365-373.

[155] Molino, M.; Blanchard, N.; Belmonte, E.; Tarver, A.P.; Abrams, C.; Hoxie, J.A.; Cerletti, C.; Brass, L.F. Proteolysis of the human platelet and endothelial cell thrombin receptor by neutrophil-derived cathepsin G. J. Biol. Chem., 1995, 270, 11168-11175

[156] Paing, M.M.; Johnston, C.A.; Siderovski, D.P.; Trejo, J. Clathrin adaptor AP2 regulates thrombin receptor constitutive internalization and endothelial cell resensitization. Mol. Cell. Biol., 2006, 26, 3231-3242.

[157] Alberelli, M.A.; De Candia, E. Functional role of protease activated receptors in vascular biology. Vascul. Pharmacol., 2014.

[158] Lee, H.; Hamilton, J.R. Physiology, pharmacology, and therapeutic potential of protease-activated receptors in vascular disease. Pharmacol. Ther., 2012, 134, 246-259.

[159] Shpacovitch, V.; Feld, M.; Bunnett, N.W.; Steinhoff, M. Protease-activated receptors: novel PARtners in innate immunity. Trends Immunol., 2007, 28, 541-550.

[160] Zlokovic, B.V.; Griffin, J.H. Cytoprotective protein C pathways and implications for stroke and neurological disorders. Trends Neurosci., 2011, 34, 198-209.

[161] Maggio, N.; Cavaliere, C.; Papa, M.; Blatt, I.; Chapman, J.; Segal, M. Thrombin regulation of synaptic transmission: Implications for seizure onset. Neurobiol. Dis., 2013, 50, $171-178$

[162] Landis, R.C. Protease activated receptors: clinical relevance to hemostasis and inflammation. Hematol. Oncol. Clin. North Am., 2007, 21, 103-113.

[163] Sokolova, E.; Reiser, G. A novel therapeutic target in various lung diseases: Airway proteases and proteaseactivated receptors. Pharmacol. Ther., 2007, 115, 70-83.

[164] Chambers, R.C. Procoagulant signalling mechanisms in lung inflammation and fibrosis: novel opportunities for pharmacological intervention? Br. J. Pharmacol., 2008, 153, S367-S378

[165] Kobrinsky, B.; Karpatkin, S. The role of thrombin in tumor biology. In Thrombin: Physiology and Disease. Maragoudakis, M.E.; Tsopanoglou, N.E., Eds.; Springer: New York, 2009, pp 161-172.

[166] Salah, Z.; Grisaru-Granovsky, S.; Maoz, M.; Uziely, B.; Cohen, I.; Turn, H.; Perezt, T.; Bar-Shavit, R. The role of thrombin and its receptors in epithelial malignancies: Lessons from a transgenic mouse model and transcriptional regulation. In Thrombin: Physiology and Disease. Maragoudakis, M.E.; Tsopanoglou, N.E., Eds.; Springer: New York, 2009, pp 173-188.

[167] Gudmundsdóttir, I.J .; Lang, N.N.; Boon, N.A.; Ludlam, C.A.; Webb, D.J.; Fox, K.A.; Newby, D.E. Role of the endothelium in the vascular effects of the thrombin receptor (protease-activated receptor type 1) in humans. J. Am. Coll. Cardiol., 2008, 51, 1749-1756.

[168] Kahn, M.L.; Zheng, Y.W.; Huang, W.; Bigornia, V.; Zeng, D.; Moff, S.; Farese, R.V., Jr.; Tam, C.; Coughlin, S.R. A dual thrombin receptor system for platelet activation. Nature, 1998, 394, 690-694.

[169] Covic, L.; Gresser, A.L.; Kuliopulos, A. Biphasic Kinetics of activation and signaling for PAR 1 and PAR4 thrombin receptors in platelets. Biochemistry, 2000, 39, 5458-5467. 
[170] White, H.D. Oral antiplatelet therapy for atherothrombotic disease: Current evidence and new directions. Am. Heart J., $2011,161,450-461$

[171] Van de Werf, F. Thrombin receptor antagonists may become an important antiplatelet therapy for coronary artery disease. Eur. Heart J., 2010, 31, 2575-2576.

[172] Bassand, J.P. Current antithrombotic agents for acute coronary syndromes: focus on bleeding risk. Int. J. Cardiol., 2013, 163, 5-18.

[173] Costopoulos, C.; Niespialowska-Steuden, M.; Kukreja, N.; Gorog, D.A. Novel oral anticoagulants in acute coronary syndrome. Int. J. Cardiol., 2013, 167, 2449-2455.

[174] Mizuno, O.; Hirano, K.; Nishimura, J.; Kubo, C.; Kanaide, $H$. Mechanism of endothelium-dependent relaxation induced by thrombin in the pig coronary artery. Eur. J. Pharmacol., 1998, 351, 67-77.

[175] Hamilton, J.R.; Nguyen, P.B.; Cocks, T.M. Atypical protease-activated receptor mediates endotheliumdependent relaxation of human coronary arteries. Circ. Res., 1998, 82, 1306-1311.

[176] Derkach, D.N.; Ihara, E.; Hirano, K.; Nishimura, J.; Takahashi, S.; Kanaide, H. Thrombin causes endotheliumdependent biphasic regulation of vascular tone in the porcine renal interlobar artery. Br. J. Pharmacol., 2000, 131, 1635-1642

[177] Malik, A.B.; Fenton, J.W., 2nd Thrombin-mediated increase in vascular endothelial permeability. Semin. Thromb. Hemost., 1992, 18, 193-199.

[178] Nobe, K.; Sone, T.; Paul, R.J.; Honda, K. Thrombininduced force development in vascular endothelial cells: Contribution to alteration of permeability mediated by calcium-dependent and -independent pathways. J. Pharmacol. Sci. , 2005, 99, 252-263.

[179] Garcia, J.G.N.; Patterson, C.; Bahler, C.; Aschner, J.; Hart, C.M.; English, D. Thrombin receptor activating peptides induce calcium mobilization, barrier dysfunction, prostaglandin synthesis, and platelet-derived growth factor mRNA expression in cultured endothelium. J. Cell. Physiol., 1993, 156, 541-549.

[180] Coughlin, S.R. Protease-activated receptors in hemostasis, thrombosis and vascular biology. J. Thromb. Haemost., 2005, 3, 1800-1814.

[181] Cleator, J.H.; Zhu, W.Q.; Vaughan, D.E.; Hamm, H.E. Differential regulation of endothelial exocytosis of $\mathrm{P}$ selectin and von Willebrand factor by protease-activated receptors and CAMP. Blood, 2006, 107, 2736-2744.

[182] Hirano, K. The roles of proteinase-activated receptors in the vascular physiology and pathophysiology. Arterioscler. Thromb. Vasc. Biol., 2007, 27, 27-36.

[183] De Garavilla, L.; Vergnolle, N.; Young, S.H.; Ennes, H.; Steinhoff, M.; Ossovskaya, V.S.; D'Andrea, M.R.; Mayer, E.A.; Wallace, J.L.; Hollenberg, M.D.; Andrade-Gordon, P.; Bunnett, N.W. Agonists of proteinase-activated receptor 1 induce plasma extravasation by a neurogenic mechanism. Br. J. Pharmacol., 2001, 133, 975-987.

[184] Sugama, Y.; Malik, A.B. Thrombin receptor 14-amino acid peptide mediates endothelial hyperadhesivity and neutrophil adhesion by P-selectin-dependent mechanism. Circ. Res., 1992, 71, 1015-1019.

[185] Minami, T.; Miura, M.; Aird, W.C.; Kodama, T. Thrombin-induced autoinhibitory factor, Down Syndrome critical region-1, attenuates NFAT-dependent vascular cell adhesion molecule-1 expression and inflammation in the endothelium. J. Biol. Chem., 2006, 281, 20503-20520.

[186] Connolly, A.J.; Ishihara, H.; Kahn, M.L.; Farese, R.V., Jr.; Coughlin, S.R. Role of the thrombin receptor in development and evidence for a second receptor. Nature, 1996, 381, 516-519.

[187] Griffin, C.T.; Srinivasan, Y.; Zheng, Y.-W.; Huang, W.; Coughlin, S.R. A role for thrombin receptor signaling in endothelial cells during embryonic development. Science, 2001, 293, 1666-1670.

[188] Moser, M.; Patterson, C. The role of thrombin in vascular development. In Thrombin: Physiology and Disease. Maragoudakis, M.E.; Tsopanoglou, N.E., Eds.; Springer: New York, 2009, pp 81-92.

[189] Smadja, D.M.; Laurendeau, I.; Avignon, C.; Vidaud, M.; Aiach, M.; Gaussem, P. The angiopoietin pathway is modulated by PAR-1 activation on human endothelial progenitor cells. J. Thromb. Haemost., 2006, 4, 2051-2058.

[190] Tsopanoglou, N.E.; Pipili-Synetos, E.; Maragoudakis, M.E. Thrombin promotes angiogenesis by a mechanism independent of fibrin formation. Am. J. Physiol., 1993, 264, C1302-C1307

[191] Tsopanoglou, N.E.; Maragoudakis, M.E. The role of thrombin in angiogenesis. In Thrombin: Physiology and Disease. Maragoudakis, M.E.; Tsopanoglou, N.E., Eds.; Springer: New York, 2009, pp 93-113.

[192] Nelken, N.A.; Soifer, S.J.; O'Keefe, J.; Vu, T.K.; Charo, I.F.; Coughlin, S.R. Thrombin receptor expression in normal and atherosclerotic human arteries. J. Clin. Invest., 1992, 90, 1614-1621

[193] Damiano, B.P.; D'Andra, M.R.; De Garavilla, L.; Cheung, W.-M.; Andrade-Gordon, P. Increased expression of protease activated receptor-2 (PAR-2) in balloon-injured rat carotid artery. Thromb. Haemostasis, 1999, 81, 808814.

[194] Ku, D.D.; Dai, J. Expression of thrombin receptors in human atherosclerotic coronary arteries leads to an exaggerated vasoconstrictory response in vitro. $\mathrm{J}$. Cardiovasc. Pharmacol., 1997, 30, 649-657.

[195] Capers, Q.I.V.; Laursen, J.B.; Fukui, T.; Rajagopalan, S.; Mori, I.; Lou, P.; Freeman, B.A.; Berrington, W.R.; Griendling, K.K.; et, a. Vascular thrombin receptor regulation in hypertensive rats. Circ. Res., 1997, 80, 838844.

[196] Wilcox, J.N.; Rodriguez, J.; Subramanian, R.; Ollerenshaw, J.; Zhong, C.; Hayzer, D.J.; Horaist, C.; Hanson, S.R.; Lumsden, A.; et, a. Characterization of thrombin receptor expression during vascular lesion formation. Circ. Res., 1994, 75, 1029-1038.

[197] Cheung, W.-m.; D'Andrea, M.R.; Andrade-Gordon, P. Damiano, B.P. Altered vascular injury responses in mice deficient in protease-activated receptor-1. Arterioscler. Thromb. Vasc. Biol., 1999, 19, 3014-3024.

[198] Sabri, A.; Muske, G.; Zhang, H.; Pak, E.; Darrow, A.; Andrade-Gordon, P.; Steinberg, S.F. Signaling properties and functions of two distinct cardiomyocyte proteaseactivated receptors. Circ. Res., 2000, 86, 1054-1061.

[199] Snead, A.N.; Insel, P.A. Defining the cellular repertoire of GPCRs identifies a profibrotic role for the most highly expressed receptor, protease-activated receptor 1, in cardiac fibroblasts. FASEB J., 2012, 26, 4540-4547, 4510.1096/fj. 4512-213496

[200] Moshal, K.S.; Tyagi, N.; Moss, V.; Henderson, B.; Steed, M.; Ovechkin, A.; Aru, G.M.; Tyagi, S.C. Early induction of matrix metalloproteinase-9 transduces signaling in human heart end stage failure. J. Cell. Mol. Med., 2005, 9, 704-713

[201] Moshal, K.S.; Tyagi, N.; Henderson, B.; Ovechkin, A.V.; Tyagi, S.C. Protease-activated receptor and endothelialmyocyte uncoupling in chronic heart failure. Am. J. Physiol. , 2005, 288, H2770-2777. 
[202] Glembotski, C.C.; Irons, C.E.; Krown, K.A.; Murray, S.F.; Sprenkle, A.B.; Sei, C.A. Myocardial $\alpha$ thrombin receptor activation induces hypertrophy and increases atrial natriuretic factor gene expression. J. Biol. Chem., 1993, 268, 20646-20652.

[203] Yasutake, M.; Haworth, R.S.; King, A.; Avkiran, M. Thrombin activates the sarcolemmal $\mathrm{Na}+-\mathrm{H}+$ exchanger. Evidence for a receptor-mediated mechanism involving protein kinase C. Circ. Res., 1996, 79, 705-715.

[204] Pinet, C.; Algalarrondo, V.; Sablayrolles, S.; Le Grand, B.; Pignier, C.; Cussac, D.; Perez, M.; Hatem, S.N.; Coulombe, A. Protease-activated receptor-1 mediates thrombin-induced persistent sodium current in human cardiomyocytes. Mol. Pharmacol., 2008, 73, 1622-1631.

[205] Sonin, D.L.; Wakatsuki, T.; Routhu, K.V.; Harmann, L.M.; Petersen, M.; Meyer, J.; Strande, J.L. Protease-activated receptor I inhibition by SCH79797 attenuates left ventricular remodeling and profibrotic activities of cardiac fibroblasts. J. Cardiovasc. Pharmacol. Ther., 2013, 18, 460-475.

[206] Shpacovitch, V.; Feld, M.; Hollenberg, M.D.; Luger, T.A.; Steinhoff, M. Role of protease-activated receptors in inflammatory responses, innate and adaptive immunity. J. Leukocyte Biol., 2008, 83, 1309-1322.

[207] Vergnolle, N.; Cellars, L.; Mencarelli, A.; Rizzo, G.; Swaminathan, S.; Beck, P.; Steinhoff, M.; AndradeGordon, P.; Bunnett, N.W.; Hollenberg, M.D.; Wallace, J.L.; Cirino, G.; Fiorucci, S. A role for proteinase-activated receptor-1 in inflammatory bowel diseases. J. Clin. Invest., 2004, 114, 1444-1456.

[208] Cenac, N.; Cellars, L.; Steinhoff, M.; Andrade-Gordon, P.; Hollenberg, M.D.; Wallace, J.L.; Fiorucci, S.; Vergnolle, N. Proteinase-activated receptor-1 is an anti-inflammatory signal for colitis mediated by a type 2 immune response. Inflamm. Bowel Dis., 2005, 11, 792-798.

[209] Moore, L.J.; Moore, F.A.; Todd, S.R.; Jones, S.L.; Turner, K.L.; Bass, B.L. Sepsis in general surgery: the 2005-2007 national surgical quality improvement program perspective. Arch. Surg., 2010, 145, 695-700.

[210] Rittirsch, D.; Flierl, M.A.; Ward, P.A. Harmful molecular mechanisms in sepsis. Nat. Rev. Immunol., 2008, 8, 776787.

[211] Kerschen, E.J ;; Fernández, J.A.; Cooley, B.C.; Yang, X.V.; Sood, R.; Mosnier, L.O.; Castellino, F.J.; Mackman, N.; Griffin, J.H.; Weiler, H. Endotoxemia and sepsis mortality reduction by non-anticoagulant-activated protein C. J. Exp. Med., 2007, 204, 2439-2448.

[212] Tressel, S.L.; Kaneider, N.C.; Kasuda, S.; Foley, C.; Koukos, G.; Austin, K.; Agarwal, A.; Covic, L.; Opal, S.M.; Kuliopulos, A. A matrix metalloprotease-PAR1 system regulates vascular integrity, systemic inflammation and death in sepsis. EMBO Mol. Med., 2011, 3, 370-384.

[213] Vergnolle, $N$. Clinical relevance of proteinase activated receptors (PARS) in the gut. Gut, 2005, 54, 867-874.

[214] Buresi, M.C.; Vergnolle, N.; Sharkey, K.A.; Keenan, C.M.; Andrade-Gordon, P.; Cirino, G.; Cirillo, D.; Hollenberg, M.D.; MacNaughton, W.K. Activation of proteinaseactivated receptor-1 inhibits neurally evoked chloride secretion in the mouse colon in vitro. Am. J. Physiol. Gastrointest. Liver Physiol., 2005, 288, G337-G345.

[215] Chin, A.C.; Vergnolle, N.; MacNaughton, W.K.; Wallace, J.L.; Hollenberg, M.D.; Buret, A.G. Proteinase-activated receptor 1 activation induces epithelial apoptosis and increases intestinal permeability. Proc. Natl. Acad. Sci. U. S. A., 2003, 100, 11104-11109.

[216] Kawabata, A.; Kuroda, R.; Nagata, N.; Kawao, N.; Masuko, T.; Nishikawa, H.; Kawai, K. In vivo evidence that protease-activated receptors 1 and 2 modulate gastrointestinal transit in the mouse. Br. J. Pharmacol., 2001, 133, 1213-1218.

[217] Saifeddine, M.; Al-Ani, B.; Cheng, C.H.; Wang, L.; Hollenberg, M.D. Rat proteinase-activated receptor-2 (PAR-2): cDNA sequence and activity of receptor-derived peptides in gastric and vascular tissue. Br. J. Pharmacol., $1996,118,521-530$

[218] Mule, F.; Baffi, M.C.; Cerra, M.C. Dual effect mediated by protease-activated receptors on the mechanical activity of rat colon. Br. J. Pharmacol., 2002, 136, 367-374.

[219] Mule, F.; Baffi, M.C.; Falzone, M.; Cerra, M.C. Signal transduction pathways involved in the mechanical responses to protease-activated receptors in rat colon. J. Pharmacol. Exp. Ther., 2002, 303, 1265-1272.

[220] Wee, J.L.K.; Chionh, Y.-T.; Ng, G.Z.; Harbour, S.N.; Allison, C.; Pagel, C.N.; Mackie, E.J.; Mitchell, H.M.; Ferrero, R.L.; Sutton, P. Protease-activated receptor-1 down-regulates the murine inflammatory and humoral response to Helicobacter pylori. Gastroenterology, 2010, 138, 573-582.

[221] Vergnolle, N. Modulation of visceral pain and inflammation by protease-activated receptors. Br. J. Pharmacol., 2004, 141, 1264-1274.

[222] Martin, L.; Auge, C.; Boue, J.; Buresi, M.C.; Chapman, K.; Asfaha, S.; Andrade-Gordon, P.; Steinhoff, M.; Cenac, N.; Dietrich, G.; Vergnolle, N. Thrombin receptor: An endogenous inhibitor of inflammatory pain, activating opioid pathways. Pain, 2009, 146, 121-129.

[223] Vera, P.L.; Wolfe, T.E.; Braley, A.E.; Meyer-Siegler, K.L. Thrombin induces macrophage migration inhibitory factor release and upregulation in urothelium: a possible contribution to bladder inflammation. PLOS One, 2010, 5, e15904.

[224] Sakai, T.; Nambu, T.; Katoh, M.; Uehara, S.; Fukuroda, T.; Nishikibe, M. Up-regulation of protease-activated receptor-1 in diabetic glomerulosclerosis. Biochem. Biophys. Res. Commun., 2009, 384, 173-179.

[225] Idell, S. Coagulation, fibrinolysis, and fibrin deposition in acute lung injury. Crit. Care Med., 2003, 31, S213-\$220.

[226] Chambers, R.C.; Dabbagh, K.; McAnulty, R.J ; Gray, A.J.; Blanc-Brude, O.P.; Laurent, G.J. Thrombin stimulates fibroblast procollagen production via proteolytic activation of protease-activated receptor 1. Biochem. J., 1998, 333, $121-127$.

[227] Chambers, R.C.; Leoni, P.; Blanc-Brude, O.P.; Wembridge, D.E.; Laurent, G.J.' Thrombin is a potent inducer of connective tissue growth factor production via proteolytic activation of protease-activated receptor-1. J. Biol. Chem., 2000, 275, 35584-35591

[228] Blanc-Brude, O.P.; Chambers, R.C.; Leoni, P.; Dik, W.A.; Laurent, G.J. Factor $X a$ is a fibroblast mitogen via binding to effector-cell protease receptor-1 and autocrine release of PDGF. Am. J. Physiol. Cell Physiol., 2001, 281, C681C689.

[229] Trejo, J.; Connolly, A.J.; Coughlin, S.R. The cloned thrombin receptor is necessary and sufficient for activation of mitogen-activated protein kinase and mitogenesis in mouse lung fibroblasts. Loss of responses in fibroblasts from receptor knockout mice. J. Biol. Chem., 1996, 271, 21536-21541

[230] Bogatkevich, G.S.; Tourkina, E.; Silver, R.M.; LudwickaBradley, A. Thrombin differentiates normal lung fibroblasts to a myofibroblast phenotype via the proteolytically activated receptor-1 and a protein kinase Cdependent pathway. J. Biol. Chem., 2001, 276, 4518445192. 
[231] Hauck, R.W.; Schulz, C.; Schomig, A.; Hoffman, R.K.; Panettieri, R.A., Jr. $\alpha$-Thrombin stimulates contraction of human bronchial rings by activation of protease-activated receptors. Am. J. Physiol., 1999, 277, L22 Ł29.

[232] Lan, R.S.; Stewart, G.A.; Henry, P.J. Modulation of airway smooth muscle tone by protease activated receptor $-1,-2,-3$ and -4 in trachea isolated from influenza $A$ virus-infected mice. Br. J. Pharmacol., 2000, 129, 63-70.

[233] Lan, R. S.; Knight, D.A.; Stewart, G.A.; Henry, P.J. Role of PGE2 in protease-activated receptor-1, -2 and -4 mediated relaxation in the mouse isolated trachea. Br. J. Pharmacol., 2001, 132, 93-100

[234] Wang, $Y_{\text {.; }}$ Gu, Y.; Lucas, M.J. Expression of thrombin receptors in endothelial cells and neutrophils from normal and preeclamptic pregnancies. J. Clin. Endocrinol. Metab., 2002, 87, 3728-3734.

[235] Bolton, S.J.; McNulty, C.A.; Thomas, R.J.; Hewitt, C.R.A.; Wardlaw, A.J. Expression of and functional responses to protease-activated receptors on human eosinophils. J. Leukocyte Biol., 2003, 74, 60-68.

[236] Feistritzer, C.; Mosheimer, B.A.; Kaneider, N.C.; Riewald, M.; Patsch, J.R.; Wiedermann, C.J. Thrombin Affects Eosinophil Migration via Protease-Activated Receptor-1. Int. Arch. Allergy Immunol., 2004, 135, 12-16.

[237] Colognato, R.; Slupsky, J.R.; Jendrach, M.; Burysek, L.; Syrovets, $T$; Simmet, $T$. Differential expression and regulation of protease-activated receptors in human peripheral monocytes and monocyte-derived antigenpresenting cells. Blood, 2003, 102, 2645-2652

[238] Mitchell, J.W.; Baik, N.; Castellino, F.J.; Miles, L.A. Plasminogen inhibits TNF $\alpha$-induced apoptosis in monocytes. Blood, 2006, 107, 4383-4390.

[239] Lippuner, N.; Morell, B.; Schaffner, A.; Schaer, D.J. Proteinase-activated receptors induce nonoxidative, antimicrobial peptides and increased antimicrobial activity in human mononuclear phagocytes. J. Leukocyte Biol., $2006,81,465-473$

[240] Roche, N.; Stirling, R.G.; Lim, S.; Oliver, B.G.; Oates, T.; Jazrawi, E.; Caramori, G.; Chung, K.F. Effect of acute and chronic inflammatory stimuli on expression of proteaseactivated receptors 1 and 2 alveolar macrophages. J. Allergy Clin. Immunol., 2003, 111, 367-373.

[241] Raza, S.L.; Nehring, L.C.; Shapiro, S.D.; Cornelius, L.A. Proteinase-activated receptor-1 regulation of macrophage elastase (MMP-12) secretion by serine proteinases. J. Biol. Chem., 2000, 275, 41243-41250

[242] Kallis, Y.N.; Scotton, C.J.; MacKinnon, A.C.; Goldin, R.D.; Wright, N.A.; Iredale, J.P.; Chambers, R.C.; Forbes, S.J. Proteinase activated receptor 1 mediated fibrosis in a mouse model of liver injury: a role for bone marrow derived macrophages. PLoS One, 2014, 9, e86241/86241e86241/86247, $86247 \mathrm{pp}$.

[243] Tordai, A.; Fenton, J.W., II; Andersen, T.; Gelfand, E.W. Functional thrombin receptors on human $T$ Iymphoblastoid cells. J. Immunol., 1993, 150, 4876-4886.

[244] Mari, B.; Imbert, V.; Belhacene, N.; Far, D.F.; Peyron, J.F.; Pouyssegur, J.; Van Obberghen-Schilling, E.; Rossi, B.; Auberger, $P$. Thrombin and thrombin receptor agonist peptide induce early events of $T$ cell activation and synergize with TCR crosslinking for CD69 expression and interleukin 2 production. J. Biol. Chem., 1994, 269, 85178523.

[245] Bar-Shavit, R.; Maoz, M.; Yin, Y.; Groysman, M.; Dekel, I.; Katzav, S. Signalling pathways induced by proteaseactivated receptors and integrins in T cells. Immunology, $2002,105,35-46$.
[246] Li, T:; He, S. Induction of IL-6 release from human T cells by PAR-1 and PAR-2 agonists. Immunol. Cell Biol., 2006, $84,461-466$

[247] Yanagita, M.; Kobayashi, R.; Kashiwagi, Y.; Shimabukuro, $Y_{\text {; }}$ Murakami, S. Thrombin regulates the function of human blood dendritic cells. Biochem. Biophys. Res. Commun., 2007, 364, 318-324.

[248] Moormann, C.; Artuc, M.; Pohl, E.; Varga, G.; Buddenkotte, J.; Vergnolle, N.; Brehler, R.; Henz, B.M.; Schneider, S.W.; Luger, T.A.; Steinhoff, M. Functional characterization and expression analysis of the proteinaseactivated receptor-2 in human cutaneous mast cells. J. Invest. Dermatol., 2006, 126, 746-755.

[249] Gordon, J.R.; Zhang, X.; Stevenson, K.; Cosford, K. Thrombin Induces I $L-6$ but Not TNF $\alpha$ Secretion by Mouse Mast Cells: Threshold Level Thrombin Receptor and Very Low Level FceRI Signaling Synergistically Enhance IL-6 Secretion. Cell. Immunol., 2000, 205, 128-135.

[250] Vliagoftis, $H$. Thrombin induces mast cell adhesion to fibronectin: evidence for involvement of protease-activated receptor-1. J. Immunol., 2002, 169, 4551-4558.

[251] Zhang, $H_{\text {.; }}$ Yang, $H_{\text {.; }}$ Ma, W.; He, S. Induction of IL-13 production and upregulated expression of protease activated receptor-1 by RANTES in a mast cell line. Cytokine, 2011, 53, 231-238

[252] Rohani, M.G.; DiJulio, D.H.; An, J.Y.; Hacker, B.M.; Dale, B.A.; Chung, W.O. PAR1-and PAR2-induced innate immune markers are negatively regulated by PI3K/AKt signaling pathway in oral keratinocytes. BMC Immunol., 2010, 11, 53

[253] Rana, T.; Misra, S.; Mittal, M.K.; Farrow, A.L.; Wilson, K.T.; Linton, M.F.; Fazio, S.; Willis, I.M.; Chaudhuri, G. Mechanism of down-regulation of RNA polymerase $\|$ transcribed non-coding RNA genes in macrophages by Leishmania. J. Biol. Chem., 2011, 286, 6614-6626.

[254] Lan, R.S.; Stewart, G.A.; Goldie, R.G.; Henry, P.J. Altered expression and in vivo lung function of protease-activated receptors during influenza $A$ virus infection in mice. Am. J. Physiol. Lung Cell Mol. Physiol., 2004, 286, L388_398.

[255] Khoufache, K.; Berri, F.; Nacken, W.; Vogel, A.B.; Delenne, M.; Camerer, E.; Coughlin, S.R.; Carmeliet, P.; Lina, B.; Rimmelzwaan, G.F.; Planz, O.; Ludwig, S.; Riteau, B. PAR1 contributes to influenza $A$ virus pathogenicity in mice. J. Clin. Invest., 2013, 123, 206-214.

[256] Niclou, S.P.; Suidan, H.S.; Pavlik, A.; Vejsada, R.; Monard, D. Changes in the expression of proteaseactivated receptor 1 and protease nexin-1 mRNA during rat nervous system development and after nerve lesion. Eur. J. Neurosci., 1998, 10, 1590-1607.

[257] Striggow, F.; Riek-Burchardt, M.; Kiesel, A.; Schmidt, W.; Henrich-Noack, P.; Breder, J.; Krug, M.; Reymann, K.G.; Reiser, G. Four different types of protease-activated receptors are widely expressed in the brain and are upregulated in hippocampus by severe ischemia. Eur. J. Neurosci., 2001, 14, 595-608.

[258] Ubl, J.J.; Vohringer, C.; Reiser, G. Co-existence of two types of $[\mathrm{Ca} 2+]$-inducing protease-activated receptors (PAR-1 and PAR-2) in rat astrocytes and C6 glioma cells. Neuroscience 1998, 86, 597-609.

[259] Suo, Z.; Wu, M.; Ameenuddin, S.; Anderson, H.E.; Zoloty, J.E.; Citron, B.A.; Andrade-Gordon, P.; Festoff, B.W. Participation of protease-activated receptor-1 in thrombininduced microglial activation. J. Neurochem., 2002, 80, 655-666

[260] Wang, H.; Ubl, J.J.; Reiser, G. Four subtypes of proteaseactivated receptors, co-expressed in rat astrocytes, evoke different physiological signaling. Glia, 2002, 37, 53-63. 
[261] Wang, Y.; Richter-Landsberg, C.; Reiser, G. Expression of protease-activated receptors (PARs) in OLN-93 oligodendroglial cells and mechanism of PAR-1-induced calcium signaling. Neuroscience 2004, 126, 69-82.

[262] Henrich-Noack, P.; Riek-Burchardt, M.; Baldauf, K.; Reiser, G.; Reymann, K.G. Focal ischemia induces expression of protease-activated receptor 1 (PAR1) and PAR3 on microglia and enhances PAR4 labeling in the penumbra. Brain Res., 2006, 1070, 232-241.

[263] Jalink, K.; van Corven, E.J.; Hengeveld, T.; Morii, N.; Narumiya, S.; Moolenaar, W.H. Inhibition of lysophosphatidate-and thrombin-induced neurite retraction and neuronal cell rounding by ADP ribosylation of the small GTP-binding protein Rho. J. Cell Biol., 1994, 126, 801-810.

[264] Mahajan, V.B.; Pai, K.S.; Lau, A.; Cunningham, D.D. Creatine kinase, an ATP-generating enzyme, is required for thrombin receptor signaling to the cytoskeleton. Proc. Natl. Acad. Sci. U. S. A., 2000, 97, 12062-12067.

[265] Pai, K.S.; Mahajan, V.B.; Lau, A.; Cunningham, D.D. Thrombin receptor signaling to cytoskeleton requires Hsp90. J. Biol. Chem., 2001, 276, 32642-32647.

[266] Liu, Y.; Fields, R.D.; Festoff, B.W.; Nelson, P.G. Proteolytic action of thrombin is required for electrical activity-dependent synapse reduction. Proc. Natl. Acad. Sci. U. S. A., 1994, 91, 10300-10304.

[267] Lanuza, M.A.; Garcia, N.; Gonzalez, C.M.; Santafe, M.M.; Nelson, P.G.; Tomas, J. Role and expression of thrombin receptor PAR-1 in muscle cells and neuromuscular junctions during the synapse elimination period in the neonatal rat. J. Neurosci. Res., 2003, 73, 10-21.

[268] Almonte, A.G.; Qadri, L.H.; Sultan, F.A.; Watson, J.A.; Mount, D.J.; Rumbaugh, G.; Sweatt, J.D. Proteaseactivated receptor-1 modulates hippocampal memory formation and synaptic plasticity. J. Neurochem., 2013, 124, 109-122.

[269] Han, K.-S.; Woo, J.; Park, H.; Yoon, B.-.; Choi, S.; Lee, C.J. Channel-mediated astrocytic glutamate release via Bestrophin-1 targets synaptic NMDARs. Mol. Brain, 2013, 6,4 .

[270] Almonte, A.G.; Hamill, C.E.; Chhatwal, J.P.; Wingo, T.S.; Barber, J.A.; Lyuboslavsky, P.N.; Sweatt, J.D.; Ressler, K.J.; White, D.A.; Traynelis, S.F. Learning and memory deficits in mice lacking protease activated receptor-1. Neurobiol. Learn. Mem., 2007, 88, 295-304.

[271] Maggio, N.; Itsekson, Z.; Ikenberg, B.; Strehl, A.; Vlachos, A.; Blatt, I.; Tanne, D.; Chapman, J. The anticoagulant activated protein $\mathrm{C}$ (aPC) promotes metaplasticity in the hippocampus through an EPCR-PAR1-S1P1 receptors dependent mechanism. Hippocampus, 2014, 24, 10301038.

[272] Han, K.-S.; Mannaioni, G.; Hamill, C.E.; Lee, J.; Junge, C.E.; Lee, C.J.; Traynelis, S.F. Activation of proteaseactivated receptor 1 increases the excitability of the dentate granule neurons of hippocampus. Mol. Brain, 2011, 4, 32.

[273] Wang, Y.; Luo, W.; Stricker, R.; Reiser, G. Proteaseactivated receptor-1 protects rat astrocytes from apoptotic cell death via JNK-mediated release of the chemokine GRO/CINC-1. J. Neurochem., 2006, 98, 1046-1060.

[274] Wang, Y:; Luo, W.; Reiser, G. Proteinase-activated receptor-1 and -2 induce the release of chemokine $\mathrm{GRO} / \mathrm{CINC}-1$ from rat astrocytes via differential activation of JNK isoforms, evoking multiple protective pathways in brain. Biochem. J., 2007, 401, 65-78.

[275] Wang, Y.; Luo, W.; Reiser, G. Activation of proteaseactivated receptors in astrocytes evokes a novel neuroprotective pathway through release of chemokines of the growth-regulated oncogene/cytokine-induced neutrophil chemoattractant family. Eur. J. Neurosci., 2007, 26, 3159-3168.

[276] Junge, C.E.; Sugawara, T.; Mannaioni, G.; Alagarsamy, S.; Conn, P.J.; Brat, D.J.; Chan, P.H.; Traynelis, S.F. The contribution of protease-activated receptor 1 to neuronal damage caused by transient focal cerebral ischemia. Proc. Natl. Acad. Sci. U. S. A., 2003, 100, 13019-13024.

[277] Donovan, F.M.; Pike, C.J.; Cotman, C.W.; Cunningham, D.D. Thrombin induces apoptosis in cultured neurons and astrocytes via a pathway requiring tyrosine kinase and RhoA activities. J. Neurosci., 1997, 17, 5316-5326.

[278] Donovan, F.M.; Cunningham, D.D. Signaling pathways involved in thrombin-induced cell protection. J. Biol. Chem., 1998, 273, 12746-12752

[279] Xue, M.; Hollenberg, M.D.; Yong, V.W. Combination of thrombin and matrix metalloproteinase-9 exacerbates neurotoxicity in cell culture and intracerebral hemorrhage in mice. J. Neurosci., 2006, 26, 10281-10291.

[280] Svedin, P.; Hagberg, H.; Saevman, K.; Zhu, C.; Mallard, C. Matrix metalloproteinase-9 gene knock-out protects the immature brain after cerebral hypoxia-ischemia. J. Neurosci., 2007, 27, 1511-1518.

[281] Heneka, M.T.; O'Banion, M.K. Inflammatory processes in Alzheimer's disease. J. Neuroimmunol., 2007, 184, 69-91.

[282] Arai, T.; Miklossy, J.; Klegeris, A.; Guo, J.P.; McGeer, P.L. Thrombin and prothrombin are expressed by neurons and glial cells and accumulate in neurofibrillary tangles in alzheimer disease brain. J. Neuropathol. Exp. Neurol., 2006, 65, 19-25

[283] Grammas, P.; Samany, P.G.; Thirumangalakudi, L. Thrombin and inflammatory proteins are elevated in Alzheimer's disease microvessels: implications for disease pathogenesis. J. Alzheimers Dis., 2006, 9, 51-58.

[284] Suo, Z.; Wu, M.; Citron, B.A.; Palazzo, R.E.; Festoff, B.W. Rapid Tau Aggregation and Delayed Hippocampal Neuronal Death Induced by Persistent Thrombin Signaling. J. Biol. Chem., 2003, 278, 37681-37689.

[285] Pike, C.J.; Vaughan, P.J.; Cunningham, D.D.; Cotman, C.W. Thrombin attenuates neuronal cell death and modulates astrocyte reactivity induced by $\beta$-amyloid in vitro. J. Neurochem., 1996, 66, 1374-1382.

[286] Thirumangalakudi, L.; Samany, P.G.; Owoso, A.; Wiskar, B.; Grammas, P. Angiogenic proteins are expressed by brain blood vessels in Alzheimer's disease. J. Alzheimers Dis., 2006, 10, 111-118.

[287] Ishida, Y.; Nagai, A.; Kobayashi, S.; Kim, S.U. Upregulation of protease-activated receptor-1 astrocytes in Parkinson disease: astrocyte-mediated neuroprotection through increased levels of glutathione peroxidase. J. Neuropathol. Exp. Neurol., 2006, 65, 66-77.

[288] Hamill, C.E.; Caudle, W.M.; Richardson, J.R.; Yuan, H.; Pennell, K.D.; Greene, J.G.; Miller, G.W.; Traynelis, S.F. Exacerbation of dopaminergic terminal damage in a mouse model of Parkinson's disease by the G-protein-coupled receptor protease-activated receptor 1. Mol. Pharmacol., 2007, 72, 653-664.

[289] Lee, E.-.; Woo, M.-S.; Moon, P.-G.; Baek, M.C.; Choi, I.-Y.; Kim, W.-K.; Junn, E.; Kim, H.-S. $\alpha$-Synuclein activates microglia by inducing the expressions of matrix metalloproteinases and the subsequent activation of protease-activated receptor-1. J. Immunol., 2010, 185, 615623.

[290] Cannon, J.R.; Keep, R.F.; Schallert, T:; Hua, Y.; Richardson, R.J.; Xi, G. Protease-activated receptor-1 mediates protection elicited by thrombin preconditioning in 
a rat 6-hydroxydopamine model of Parkinson's disease. Brain Res., 2006, 1116, 177-186.

[291] Paterson, P.Y.; Koh, C.S.; Kwaan, H.C. Role of the clotting system in the pathogenesis of neuroimmunologic disease. Fed. Proc., 1987, 46, 91-96.

[292] Lyman, G.H.; Khorana, A.A.; Kuderer, N.M.; Lee, A.Y. Cancer and thrombosis: back to the future renewed interest in an old problem. Cancer Invest., 2009, 27, 472-473.

[293] Trousseau, A. Phlegmasia alba dolens. In Lectures on Clinical Medicine, Delivered at the Hotel-Dieu, Paris; New Sydenham Society: London, 1865; Vol. 5, pp 281332

[294] Shen, V.S.; Pollak, E.W. Fatal pulmonary embolism in cancer patients: is heparin prophylaxis justified? South Med. J., 1980, 73, 841-843

[295] Svendsen, E.; Karwinski, B. Prevalence of pulmonary embolism at necropsy in patients with cancer. J. Clin. Pathol., 1989, 42, 805-809.

[296] Rickles, F.R.; Edwards, R.L. Activation of blood coagulation in cancer: Trousseau's syndrome revisited. Blood, 1983, 62, 14-31.

[297] Petralia, G.A.; Kakkar, A.K. Anti-thrombotic therapy in cancer patients. In Thrombin: Physiology and Disease. Maragoudakis, M.E.; Tsopanoglou, N.E., Eds.; Springer: New York, 2009, pp 189-203.

[298] Prandoni, P.; Lensing, A.W.; Buller, H.R.; Cogo, A.; Prins, M.H.; Cattelan, A.M.; Cuppini, S.; Noventa, F.; ten Cate, J.W. Deep-vein thrombosis and the incidence of subsequent symptomatic cancer. N. Engl. J. Med., 1992, $327,1128-1133$

[299] Sørensen, H.T.; Mellemkjaer, L.; Olsen, J.H.; Baron, J.A. Prognosis of cancers associated with venous thromboembolism. N. Engl. J. Med., 2000, 343, 18461850

[300] Kakkar, A.K. An expanding role for antithrombotic therapy in cancer patients. Cancer Treat. Rev., 2003, 29 Supp/ 2, 23-26

[301] Gronostaj, K.; Richter, P.; Nowak, W.; Undas, A. Altered plasma fibrin clot properties in patients with digestive tract cancers: Links with the increased thrombin generation. Thromb. Res., 2013, 131, 262-267.

[302] Nierodzik, M.L.; Karpatkin, S. Thrombin induces tumor growth, metastasis, and angiogenesis: Evidence for a thrombin-regulated dormant tumor phenotype. Cancer Cell, 2006, 10, 355-362

[303] Zacharski, L.R.; Henderson, W.G.; Rickles, F.R.; Forman, W.B.; Cornell, C.J., Jr.; Forcier, R.J.; Edwards, R.L.; Headley, E.; Kim, S.H.; O'Donnell, J.F.; et al. Effect of warfarin anticoagulation on survival in carcinoma of the lung, colon, head and neck, and prostate. Final report of VA Cooperative Study \#75. Cancer, 1984, 53, 2046-2052.

[304] Lebeau, B.; Chastang, C.; Brechot, J.M.; Capron, F.; Dautzenberg, B.; Delaisements, C.; Mornet, M.; Brun, J.; Hurdebourcq, J.P.; Lemarie, E. Subcutaneous heparin treatment increases survival in small cell lung cancer. "Petites Cellules" Group. Cancer, 1994, 74, 38-45.

[305] Altinbas, M.; Coskun, H.S.; Er, O.; Ozkan, M.; Eser, B.; Unal, A.; Cetin, M.; Soyuer, S. A randomized clinical trial of combination chemotherapy with and without lowmolecular-weight heparin in small cell lung cancer. J. Thromb. Haemost., 2004, 2, 1266-1271.

[306] Kakkar, A.K.; Levine, M.N.; Kadziola, Z.; Lemoine, N.R.; Low, V.; Patel, H.K.; Rustin, G.; Thomas, M.; Quigley, M.; Williamson, R.C. Low molecular weight heparin, therapy with dalteparin, and survival in advanced cancer: the fragmin advanced malignancy outcome study (FAMOUS). J. Clin. Oncol., 2004, 22, 1944-1948.
[307] Klerk, C.P.; Smorenburg, S.M.; Otten, H.M.; Lensing, A.W.; Prins, M.H.; Piovella, F.; Prandoni, P.; Bos, M.M.; Richel, D.J.; van Tienhoven, G.; Buller, H.R. The effect of low molecular weight heparin on survival in patients with advanced malignancy. J. Clin. Oncol., 2005, 23, 21302135

[308] Lee, A.Y.; Rickles, F.R.; Julian, J.A.; Gent, M.; Baker, R.I.; Bowden, C.; Kakkar, A.K.; Prins, M.; Levine, M.N. Randomized comparison of low molecular weight heparin and coumarin derivatives on the survival of patients with cancer and venous thromboembolism. J. Clin. Oncol., 2005, 23, 2123-2129

[309] Leshchenko lu, M.; Miasoiedov, D.V.; Oliinichenko, H.P.; Koshel, K.V.; latsenko, S.M. The effect of low-molecularweight heparin on the late follow-up results of the combined and complex treatment of patients with rectal cancer. Klin. Khir., 2007, 21-24.

[310] Bobek, V.; Boubelik, M.; Fiserova, A.; L'Uptovcova, M.; Vannucci, L.; Kacprzak, G.; Kolodzej, J.; Majewski, A.M.; Hoffman, R.M. Anticoagulant drugs increase natural killer cell activity in lung cancer. Lung Cancer, 2005, 47, 215223.

[311] Battinelli, E.M.; Markens, B.A.; Kulenthirarajan, R.A.; Machlus, K.R.; Flaumenhaft, R.; Italiano, J.E., Jr. Anticoagulation inhibits tumor cell-mediated release of platelet angiogenic proteins and diminishes platelet angiogenic response. Blood, 2014, 123, 101-112.

[312] Garnier, D.; Magnus, N.; D'Asti, E.; Hashemi, M.; Meehan, B.; Milsom, C.; Rak, J. Genetic pathways linking hemostasis and cancer. Thromb. Res., 2012, 129, S22-S29.

[313] Kakkar, A.K.; DeRuvo, N.; Chinswangwatanakul, V.; Tebbutt, S.; Williamson, R.C. Extrinsic-pathway activation in cancer with high factor VIla and tissue factor. Lancet, 1995, 346, 1004-1005.

[314] Zhang, Y.; Deng, Y.; Luther, T.; Mueller, M.; Ziegler, R.; Waldherr, R.; Stern, D.M.; Nawroth, P.P. Tissue factor controls the balance of angiogenic and antiangiogenic properties of tumor cells in mice. J. Clin. Invest., 1994, 94, 1320-1327.

[315] Borensztajn, K.S.; Spek, C.A. Protease-activated receptors, apoptosis and tumor growth. Pathophysiol. Haemost. Thromb., 2008, 36, 137-147.

[316] Tellez, C.; Bar-Eli, M. Role and regulation of the thrombin receptor (PAR-1) in human melanoma. Oncogene, 2003, 22, 3130-3137.

[317] Granovsky-Grisaru, S.; Zaidoun, S.; Grisaru, D.; Yekel, Y.; Prus, D.; Beller, U.; Bar-Shavit, R. The pattern of Protease Activated Receptor 1 (PAR1) expression in endometrial carcinoma. Gynecol. Oncol., 2006, 103, 802806.

[318] Even-Ram, S.; Uziely, B.; Cohen, P.; Grisaru-Granovsky, S.; Maoz, M.; Ginzburg, Y.; Reich, R.; Vlodavsky, I.; BarShavit, R. Thrombin receptor overexpression in malignant and physiological invasion processes. Nat. Med., 1998, 4, 909-914.

[319] Salah, Z.; Uziely, B.; Jaber, M.; Maoz, M.; Cohen, I.; Hamburger, T.; Maly, B.; Peretz, T.; Bar-Shavit, R. Regulation of human protease-activated receptor 1 (hParl) gene expression in breast cancer by estrogen. FASEB J., 2012, 26, 2031-2042

[320] Yuan, T.C.; Lin, M.F. Protease-activated receptor 1: a role in prostate cancer metastasis. Clin. Prostate Cancer, 2004, 3, 189-191.

[321] Black, P.C.; Mize, G.J.; Karlin, P.; Greenberg, D.L.; Hawley, S.J.; True, L.D.; Vessella, R.L.; Takayama, T.K Overexpression of protease-activated receptors $-1,-2$, and -4 
(PAR-1, -2, and -4) in prostate cancer. Prostate, 2007, 67, $743-756$

[322] Zhang, X.; Wang, W.; True, L.D.; Vessella, R.L.; Takayama, T.K. Protease-activated receptor-1 is upregulated in reactive stroma of primary prostate cancer and bone metastasis. Prostate, 2009, 69, 727-736.

[323] Rudroff, C.; Seibold, S.; Kaufmann, R.; Zetina, C.C.; Reise, K.; Schafer, U.; Schneider, A.; Brockmann, M.; Scheele, J.; Neugebauer, E.A. Expression of the thrombin receptor PAR-1 correlates with tumour cell differentiation of pancreatic adenocarcinoma in vitro. Clin. Exp. Metastasis, 2002, 19, 181-189.

[324] Grisaru-Granovsky, S.; Salah, Z.; Maoz, M.; Pruss, D.; Beller, U.; Bar-Shavit, R. Differential expression of protease activated receptor 1 (Par1) and pY397FAK in benign and malignant human ovarian tissue samples. Int. J. Cancer, 2005, 113, 372-378.

[325] Darmoul, D.; Gratio, V.; Devaud, H.; Lehy, T.; Laburthe, M. Aberrant expression and activation of the thrombin receptor protease-activated receptor-1 induces cell proliferation and motility in human colon cancer cells. Am. J. Pathol., 2003, 162, 1503-1513.

[326] Zhang, X.; Hunt, J.L.; Landsittel, D.P.; Muller, S.; AdlerStorthz, K.; Ferris, R.L.; Shin, D.M.; Chen, Z.G. Correlation of protease-activated receptor-l with differentiation markers in squamous cell carcinoma of the head and neck and its implication in lymph node metastasis. Clin. Cancer Res., 2004, 10, 8451-8459.

[327] Veiga, C.d.S.B.; CarneiroŁobo, T.C.; Coelho, C.J.B.P.; Carvalho, S.M.F.; Maia, R.C.; Vasconcelos, F.C.; Abdelhay, E.; Mencalha, A.L.; Ferreira, A.F.; Castro, F.A.; Monteiro, R.Q. Increased expression of protease-activated receptor 1 (PAR-1) in human leukemias. Blood Cells, Mol., Dis., 2011, 46, 230-234

[328] Diaz, J.; Aranda, E.; Henriquez, S.; Quezada, M.; Espinoza, E.; Bravo, M.L.; Oliva, B.; Lange, S.; Villalon, M.; Jones, M.; Brosens, J.J.; Kato, S.; Cuello, M.A.; Knutson, T.P.; Lange, C.A.; Leyton, L.; Owen, G.I. Progesterone promotes focal adhesion formation and migration in breast cancer cells through induction of protease-activated receptor-1. J. Endocrinol., 2012, 214, 165-175.

[329] Chu, H.-W.; Cheng, C.-W.; Chou, W.-C.; Hu, L.-Y.; Wang, H.-W.; Hsiung, C.-N.; Hsu, H. -M.; Wu, P.E.; Hou, M.F.; Shen, C.-Y; Yu, J.-C. A novel estrogen receptormicroRNA 190a-PAR-1-pathway regulates breast cancer progression, a finding initially suggested by genome-wide analysis of loci associated with lymph-node metastasis. Hum. Mol. Genet., 2014, 23, 355-367.

[330] Jin, E.; Fujiwara, M.; Pan, X.; Ghazizadeh, M.; Arai, S.; Ohaki, $Y_{\text {; }}$ Kajiwara, K.; Takemura, T.; Kawanami, $O$. Protease-activated receptor (PAR)-1 and PAR-2 participate in the cell growth of alveolar capillary endothelium in primary lung adenocarcinomas. Cancer, 2003, 97, 703713

[331] Ghio, P.; Cappia, S.; Selvaggi, G.; Novello, S.; Lausi, P.; Zecchina, G.; Papotti, M.; Borasio, P.; Scagliotti, G.V. Prognostic role of protease-activated receptors 1 and 4 in resected stage IB non-small-cell lung cancer. Clin. Lung Cancer, 2006, 7, 395-400

[332] D'Andrea, M.R.; Derian, C.K.; Santulli, R.J.; AndradeGordon, P. Differential expression of protease-activated receptors -1 and -2 in stromal fibroblasts of normal, benign, and malignant human tissues. Am. J. Pathol., 2001, 158, 2031-2041

[333] Eroglu, A.; Karabiyik, A.; Akar, N. The association of protease activated receptor 1 gene -506 I/D polymorphism with disease-free survival in breast cancer patients. Ann. Surg. Oncol., 2012, 19, 1365-1369.

[334] Lurje, G.; Leers, J.M.; Pohl, A.; Oezcelik, A.; Zhang, W.; Ayazi, S.; Winder, T.; Ning, Y.; Yang, D.; Klipfel, N.E.; Chandrasoma, P.; Hagen, J.A.; DeMeester, S.R.; DeMeester, T.R.; Lenz, H.J. Genetic variations in angiogenesis pathway genes predict tumor recurrence in localized adenocarcinoma of the esophagus. Ann. Surg. Oncol., 2010, 251, 857-864.

[335] Lurje, G.; Husain, H.; Power, D.G.; Yang, D.; Groshen, S.; Pohl, A.; Zhang, W.; Ning, Y.; Manegold, P.C.; ElKhoueiry, A.; labal, S.; Tang, L.H.; Shah, M.A.; Lenz, H.J . Genetic variations in angiogenesis pathway genes associated with clinical outcome in localized gastric adenocarcinoma. Ann. Oncol., 2010, 21, 78-86.

[336] Martin, C.B.; Mahon, G.M.; Klinger, M.B.; Kay, R.J.; Symons, M.; Der, C.J.; Whitehead, I.P. The thrombin receptor, PAR-1, causes transformation by activation of Rho-mediated signaling pathways. Oncogene, 2001, 20, 1953-1963.

[337] Wu, Z.; Zeng, Y.; Zhong, M.; Wang, B. Targeting A549 lung adenocarcinoma cell growth and invasion with protease-activated receptor-1 siRNA. Mol. Med. Rep., 2014, 9, 1787-1793

[338] Salah, Z.; Maoz, M.; Pokroy, E.; Lotem, M.; Bar-Shavit, R.; Uziely, B. Protease-activated receptor-1 (hPar1), a survival factor eliciting tumor progression. Mol. Cancer Res., 2007, 5, 229-240.

[339] Villares, G.J.; Zigler, M.; Wang, H.; Melnikova, V.O.; Wu, H.; Friedman, R.; Leslie, M.C.; Vivas-Mejia, P.E.; LópezBerestein, G.; Sood, A.K.; Bar-Eli, M. Targeting melanoma growth and metastasis with systemic delivery of liposome-incorporated protease-activated receptor-l small interfering RNA. Cancer Res., 2008, 68, 9078-9086.

[340] Kepner, N.; Lipton, A. A mitogenic factor for transformed fibroblasts from human platelets. Cancer Res., 1981, 41, 430-432

[341] Möhle, R.; Green, D.; Moore, M.A.; Nachman, R.L.; Rafii, S. Constitutive production and thrombin-induced release of vascular endothelial growth factor by human megakaryocytes and platelets. Proc. Natl. Acad. Sci. US A, 1997, 94, 663-668.

[342] Li, J.J.; Huang, Y.Q.; Basch, R.; Karpatkin, S. Thrombin induces the release of angiopoietin-1 from platelets. Thromb. Haemost., 2001, 85, 204-206.

[343] Boucharaba, A.; Serre, C.M.; Gres, S.; Saulnier-Blache, J.S.; Bordet, J.-C.; Guglielmi, J.; Clezardin, P.; Peyruchaud, O. Platelet-derived lysophosphatidic acid supports the progression of osteolytic bone metastases in breast cancer. J. Clin. Invest., 2004, 114, 1714-1725.

[344] Nieswandt, B.; Hafner, M.; Echtenacher, B.; Mannel, D.N. Lysis of tumor cells by natural killer cells in mice is impeded by platelets. Cancer Res., 1999, 59, 1295-1300.

[345] Melnikova, V.O.; Villares, G.J.; Bar-Eli, M. Emerging roles of PAR-1 and PAFR in melanoma metastasis. Cancer Microenviron., 2008, 1, 103-111.

[346] Beaulieu, L.M.; Church, F.C. Activated protein C promotes breast cancer cell migration through interactions with EPCR and PAR-1. Exp. Cell. Res., 2007, 313, 677687.

[347] Keshava, S.; Kothari, H.; Rao, L.V.M.; Pendurthi, U.R. Influence of endothelial cell protein $C$ receptor on breast cancer development. J. Thromb. Haemostasis, 2013, 11, 2062-2065.

[348] Suzuki, K.; Hayashi, T. Protein C and its inhibitor in malignancy. Semin. Thromb. Hemostasis, 2007, 33, 667672. 
[349] Agarwal, A.; Covic, L.; Sevigny, L.M.; Kaneider, N.C.; Lazarides, K.; Azabdaftari, G.; Sharifi, S.; Kuliopulos, A. Targeting a metalloprotease-PAR1 signaling system with cell-penetrating pepducins inhibits angiogenesis, ascites, and progression of ovarian cancer. Mol. Cancer Ther., 2008, 7, 2746-2757

[350] Page-McCaw, A.; Ewald, A.J.; Werb, Z. Matrix metalloproteinases and the regulation of tissue remodelling. Nat. Rev. Mol. Cell Biol., 2007, 8, 221-233.

[351] Ala-aho, R.; Kahari, V.M. Collagenases in cancer. Biochimie, 2005, 87, 273-286

[352] Sang, Q.X. Complex role of matrix metalloproteinases in angiogenesis. Cell Res., 1998, 8, 171-177.

[353] Blackburn, J.S.; Rhodes, C.H.; Coon, C.I.; Brinckerhoff, C.E. RNA interference inhibition of matrix metalloproteinase-l prevents melanoma metastasis by reducing tumor collagenase activity and angiogenesis. Cancer Res., 2007, 67, 10849-10858.

[354] Nguyen, N.; Kuliopulos, A.; Graham, R.A.; Covic, L. Tumor-derived Cyr61(CCN1) promotes stromal matrix metalloproteinase-1 production and protease-activated receptor 1-dependent migration of breast cancer cells. Cancer Res., 2006, 66, 2658-2665.

[355] Radjabi, A.R.; Sawada, K.; Jagadeeswaran, S.; Eichbichler, A.; Kenny, H.A.; Montag, A.; Bruno, K.; Lengyel, E. Thrombin Induces Tumor Invasion through the Induction and Association of Matrix Metalloproteinase- -9 and $\beta 1-$ Integrin on the Cell Surface. J. Biol. Chem., 2008, 283, 2822-2834

[356] Darmoul, D.; Gratio, V.; Devaud, H.; Peiretti, F.; Laburthe, M. Activation of proteinase-activated receptor 1 promotes human colon cancer cell proliferation through epidermal growth factor receptor transactivation. Mol. Cancer Res., 2004, 2, 514-522.

[357] Ohshiro, K.; Bui-Nguyen, T.M.; Natha, R.S.D.; Schwartz, A.M.; Levine, P.; Kumar, R. Thrombin stimulation of inflammatory breast cancer cells leads to aggressiveness via the EGFR-PAR1-Pak1 pathway. Int. J. Biol. Markers, 2012,27, e305-e313

[358] Cohen, I.; Maoz, M.; Turm, H.; Grisaru-Granovsky, S.; Maly, B.; Uziely, B.; Weiss, E.; Abramovitch, R.; Gross, E.; Barzilay, O.; Qiu, Y.; Bar-Shavit, R. Etk/Bmx regulates proteinase-activated-receptorl (PAR1) in breast cancer invasion: signaling partners, hierarchy and physiological significance. PLoS One, 2010, 5, el1135.

[359] Liu, J.; Schuff-Werner, P.; Steiner, M. Thrombin/thrombin receptor (PAR-1)-mediated induction of $\mathrm{IL}-8$ and VEGF expression in prostate cancer cells. Biochem. Biophys. Res. Commun., 2006, 343, 183-189.

[360] Furukawa, Y.; Kawano, Y.; Fukuda, J.; Matsumoto, $H_{\text {.; }}$ Narahara, $H$. The production of vascular endothelial growth factor and metalloproteinase via protease-activated receptor in human endometrial stromal cells. Fertil. Steril., 2009, 91, 535-541

[361] Yin, Y.J.; Katz, V.; Salah, Z.; Maoz, M.; Cohen, I.; Uziely, B.; Turm, H.; Grisaru-Granovsky, S.; Suzuki, H.; BarShavit, R. Mammary gland tissue targeted overexpression of human protease-activated receptor 1 reveals a novel link to beta-catenin stabilization. Cancer Res., 2006, 66, 5224 5233.

[362] Grisaru-Granovsky, S.; Maoz, M.; Barzilay, O.; Yin, Y.J.; Prus, D.; Bar-Shavit, R. Protease activated receptor-1, PAR1, promotes placenta trophoblast invasion and betacatenin stabilization. J. Cell Physiol., 2009, 218, 512-521.

[363] Salah, Z.; Maoz, M.; Cohen, I.; Pizov, G.; Pode, D.; Runge, M.S.; Bar-Shavit, R. Identification of a novel functional androgen response element within hParl promoter: implications to prostate cancer progression. FASEB J., 2005, 19, 62-72

[364] Salah, Z.; Maoz, M.; Pizov, G.; Bar-Shavit, R. Transcriptional regulation of human protease-activated receptor 1: a role for the early growth response-1 protein in prostate cancer. Cancer Res., 2007, 67, 9835-9843.

[365] Salah, Z.; Haupt, S.; Maoz, M.; Baraz, L.; Rotter, V. Peretz, T.; Haupt, Y.; Bar-Shavit, R. p53 controls hPar function and expression. Oncogene, 2008, 27, 6866-6874.

[366] Caunt, M.; Huang, Y.Q.; Brooks, P.C.; Karpatkin, S Thrombin induces neoangiogenesis in the chick chorioallantoic membrane. J. Thromb. Haemost., 2003, 1, 2097-2102.

[367] Tsopanoglou, N.E.; Maragoudakis, M.E. On the mechanism of thrombin-induced angiogenesis. Potentiation of vascular endothelial growth factor activity on endothelial cells by up-regulation of its receptors. J. Biol. Chem., 1999, 274, 23969-23976.

[368] Huang, Y.Q.; Li, J.J.; Hu, L.; Lee, M.; Karpatkin, S. Thrombin induces increased expression and secretion of angiopoietin-2 from human umbilical vein endothelial cells. Blood, 2002, 99, 1646-1650.

[369] Caunt, M.; Hu, L.; Tang, T.; Brooks, P.C.; Ibrahim, S.; Karpatkin, S. Growth-regulated oncogene is pivotal in thrombin-induced angiogenesis. Cancer Res., 2006, 66, 4125-4132.

[370] Zania, P.; Kritikou, S.; Flordellis, C.S.; Maragoudakis, M.E.; Tsopanoglou, N.E. Blockade of angiogenesis by small molecule antagonists to protease-activated receptor1: association with endothelial cell growth suppression and induction of apoptosis. J. Pharmacol. Exp. Ther., 2006, $318,246-254$

[371] Zania, P.; Gourni, D.; Aplin, A.C.; Nicosia, R.F.; Flordellis, C.S.; Maragoudakis, M.E.; Tsopanoglou, N.E. Parstatin, the cleaved peptide on proteinase-activated receptor 1 activation, is a potent inhibitor of angiogenesis. J. Pharmacol. Exp. Ther., 2009, 328, 378-389.

[372] Huang, $H_{. ;}$; Vasilakis, P.; Zhong, $X_{\text {.; }}$ Shen, J.-K.; Geronatsiou, K.; Papadaki, H.; Maragoudakis, M.E.; Gartaganis, S.P.; Vinores, S.A.; Tsopanoglou, N.E. Parstatin suppresses ocular neovascularization and inflammation. Invest. Ophthalmol. Vis. Sci., 2010, 51, 5825-5832.

[373] Givvimani, S.; Narayanan, N.; Pushpakumar, S.B.; Tyagi, S.C. Anti-parstatin promotes angiogenesis and ameliorates left ventricular dysfunction during pressure overload. Int. J. Biomed. Sci. , 2014, 10, 1-7

[374] Vu, T.K.; Wheaton, V.I.; Hung, D.T.; Charo, I.; Coughlin, S.R. Domains specifying thrombin-receptor interaction. Nature, 1991, 353, 674-677.

[375] Nieman, M.T.; Schmaier, A.H. Interaction of thrombin with PAR1 and PAR4 at the thrombin cleavage site. Biochemistry, 2007, 46, 8603-8610.

[376] Ayala, Y.M.; Cantwell, A.M.; Rose, T.; Bush, L.A.; Arosio, D.; Di Cera, E. Molecular mapping of thrombinreceptor interactions. Proteins, 2001, 45, 107-116.

[377] Gandhi, P.S.; Chen, Z.; Di Cera, E. Crystal structure of thrombin bound to the uncleaved extracellular fragment of PAR1. J. Biol. Chem., 2010, 285, 15393-15398.

[378] Jacques, S.L.; LeMasurier, M.; Sheridan, P.J.; Seeley, S.K.; Kuliopulos, A. Substrate-assisted catalysis of the PAR1 thrombin receptor. Enhancement of macromolecular association and cleavage. J. Biol. Chem., 2000, 275, 40671-44068

[379] Mathews, II; Padmanabhan, K.P.; Ganesh, V.; Tulinsky, A.; Ishii, M.; Chen, J.; Turck, C.W.; Coughlin, S.R.; Fenton, J.W., 2nd Crystallographic structures of thrombin 
complexed with thrombin receptor peptides: existence of expected and novel binding modes. Biochemistry, 1994, 33, 3266-3279.

[380] Myles, T.; Le Bonniec, B.F.; Stone, S.R. The dual role of thrombin's anion-binding exosite- 1 in the recognition and cleavage of the protease-activated receptor 1. Eur. J. Biochem., 2001, 268, 70-77

[381] Gandhi, P.S.; Chen, Z.; Mathews, F.S.; Di Cera, E. Structural identification of the pathway of long-range communication in an allosteric enzyme. Proc. Natl. Acad. Sci. US A, 2008, 105, 1832-1837.

[382] Bahou, W.F.; Kutok, J.L.; Wong, A.; Potter, C.L.; Coller, B.S. Identification of a novel thrombin receptor sequence required for activation-dependent responses. Blood, 1994, 84, 4195-4202.

[383] Nanevicz, T.; Ishii, M.; Wang, L.; Chen, M.; Chen, J.; Turck, C.W.; Cohen, F.E.; Coughlin, S.R. Mechanisms of thrombin receptor agonist specificity. Chimeric receptors and complementary mutations identify an agonist recognition site. J. Biol. Chem., 1995, 270, 21619-21625

[384] Feng, D.M.; Veber, D.F.; Connolly, T.M.; Condra, C.; Tang, M.J.; Nutt, R.F. Development of a potent thrombin receptor ligand. J. Med. Chem., 1995, 38, 4125-4130.

[385] Ceruso, M.A.; McComsey, D.F.; Leo, G.C.; AndradeGordon, P.; Addo, M.F.; Scarborough, R.M.; Oksenberg, D.; Maryanoff, B.E. Thrombin receptor-activating peptides (TRAPs): investigation of bioactive conformations via structure-activity, spectroscopic, and computational studies. Bioorg. Med. Chem., 1999, 7, 2353-2371.

[386] Scarborough, R.M.; Naughton, M.A.; Teng, W.; Hung, D.T.; Rose, J.; $V u$, T.K.; Wheaton, V.I.; Turck, C.W.; Coughlin, S.R. Tethered ligand agonist peptides. Structural requirements for thrombin receptor activation reveal mechanism of proteolytic unmasking of agonist function. J. Biol. Chem., 1992, 267, 13146-13149.

[387] Chao, B.H.; Kalkunte, S.; Maraganore, J.M.; Stone, S.R. Essential groups in synthetic agonist peptides for activation of the platelet thrombin receptor. Biochemistry, 1992, 31, 6175-6178

[388] Vassallo, R.R., Jr.; Kieber-Emmons, T.; Cichowski, K.; Brass, L.F. Structure-function relationships in the activation of platelet thrombin receptors by receptorderived peptides. J. Biol. Chem., 1992, 267, 6081-6085

[389] Sabo, T.; Gurwitz, D.; Motola, L.; Brodt, P.; Barak, R.; Elhanaty, E. Structure-activity studies of the thrombin receptor activating peptide. Biochem. Biophys. Res. Commun., 1992, 188, 604-610.

[390] Natarajan, S.; Riexinger, D.; Peluso, M.; Seiler, S.M. 'Tethered ligand' derived pentapeptide agonists of thrombin receptor: a study of side chain requirements for human platelet activation and GTPase stimulation. Int. J. Pept. Protein Res., 1995, 45, 145-151.

[391] Barry, G.D.; Le, G.T.; Fairlie, D.P. Agonists and antagonists of protease activated receptors (PARs). Curr. Med. Chem., 2006, 13, 243-265.

[392] Chackalamannil, S. Thrombin receptor (protease activated receptor-1) antagonists as potent antithrombotic agents with strong antiplatelet effects. J. Med. Chem., 2006, 49, 5389-5403

[393] Maryanoff, B.E.; Zhang, H.C.; Andrade-Gordon, P.; Derian, C.K. Discovery of potent peptide-mimetic antagonists for the human thrombin receptor, proteaseactivated receptor-1 (PAR-1). Curr. Med. Chem., 2003, 1, 13-36.

[394] Bernatowicz, M.S.; Klimas, C.E.; Hartl, K.S.; Peluso, M.; Allegretto, N.J.; Seiler, S.M. Development of potent thrombin receptor antagonist peptides. J. Med. Chem., 1996, 39, 4879-4887.

[395] Quinton, T.M.; Kim, S.; Derian, C.K.; Jin, J.; Kunapuli, S.P. Plasmin-mediated activation of platelets occurs by cleavage of protease-activated receptor 4. J. Biol. Chem., 2004, 279, 18434-18439

[396] Kahn, M.L.; Nakanishi-Matsui, M.; Shapiro, M.J. Ishihara, H.; Coughlin, S.R. Protease-activated receptors 1 and 4 mediate activation of human platelets by thrombin. $J$. Clin. Invest., 1999, 103, 879-887.

[397] Zhang, H.C.; Derian, C.K.; Andrade-Gordon, P.; Hoekstra, W.J.; McComsey, D.F.; White, K.B.; Poulter, B.L.; Addo, M.F.; Cheung, W.M.; Damiano, B.P.; Oksenberg, D.; Reynolds, E.E.; Pandey, A.; Scarborough, R.M.; Maryanoff, B.E. Discovery and optimization of a novel series of thrombin receptor (par-1) antagonists: potent, selective peptide mimetics based on indole and indazole templates. J. Med. Chem., 2001, 44, 1021-1024.

[398] Derian, C.K.; Maryanoff, B.E.; Andrade-Gordon, P.; Zhang, H.C. Design and evaluation of potent peptidemimetic PAR-1 antagonists. Drug Dev. Res., 2003, 59, 355-366

[399] Tsopanoglou, N.E.; Maragoudakis, M.E. Inhibition of angiogenesis by small-molecule antagonists of proteaseactivated receptor-1. Semin. Thromb. Hemost., 2007, 33, 680-687

[400] Valdivielso, A.M.; García-López, M.T.; Herranz, R. Improved synthesis of the PAR-1 thrombin receptor antagonist RWJ-58259. ARKIVOC 2008, 287-294.

[401] Damiano, B.P.; Derian, C.K.; Maryanoff, B.E.; Zhang, H.C.; Gordon, P.A. RWJ-58259: a selective antagonist of protease activated receptor-1. Cardiovasc. Drug Rev., 2003, 21, 313-326.

[402] Derian, C.K.; Damiano, B.P.; Addo, M.F.; Darrow, A.L.; D'Andrea, M.R.; Nedelman, M.; Zhang, H.C.; Maryanoff, B.E.; Andrade-Gordon, P. Blockade of the thrombin receptor protease-activated receptor-1 with a smallmolecule antagonist prevents thrombus formation and vascular occlusion in nonhuman primates. J. Pharmacol. Exp. Ther., 2003, 304, 855-861.

[403] Severino, B.; Fiorino, F.; Perissutti, E.; Frecentese, F.; Cirino, G.; Roviezzo, F.; Santagada, $V_{\text {.; }}$ Caliendo, G. Synthesis and pharmacological evaluation of peptidemimetic protease-activated receptor-1 antagonists containing novel heterocyclic scaffolds. Bioorg. Med. Chem., 2008, 16, 6009-6020

[404] Androutsou, M.E.; Saifeddine, M.; Hollenberg, M.D.; Matsoukas, J.; Agelis, G. Design, synthesis and biological evaluation of non-peptide PAR1 thrombin receptor antagonists based on small bifunctional templates: arginine and phenylalanine side chain groups are keys for receptor activity. Amino Acids, 2010, 38, 985-990.

[405] Ventosa-Andrés, P.; Valdivielso, A.M.; Pappos, I.; GarcíaLópez, M.T.; Tsopanoglou, N.E.; Herranz, R. Design, synthesis and biological evaluation of new peptide-based ureas and thioureas as potential antagonists of the thrombin receptor PAR1. Eur. J. Med. Chem., 2012, 58, 98-111.

[406] Valdivielso, A.M.; Ventosa-Andrés, P.; García-López, M.T.; Herranz, R.; Gutiérrez-Rodríguez, M. Synthesis and regioselective functionalization of piperazin-2-ones based on Phe-Gly pseudodipeptides. Eur. J. Org. Chem., 2013, 155-161.

[407] Valdivielso, A.M.; Ventosa-Andrés, P.; Tato, F.; Fernández-lbanez, M.A.; Pappos, I.; Tsopanoglou, N.E.; García-López, M.T.; Gutiérrez-Rodríguez, M.; Herranz, R. Highly functionalized 2-oxopiperazine-based 
peptidomimetics: An approach to PAR1 antagonists. Eur. J. Med. Chem., 2013, 70, 199-224.

[408] Valdivielso, A.M.; García-López, M.T.; GutiérrezRodríguez, M.; Herranz, R. Exploring the Phe-Gly dipeptide-derived piperazinone scaffold in the search for antagonists of the thrombin receptor PAR1. Molecules, $2014,19,4814-4846$.

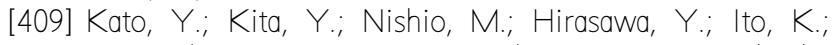
Yamanaka, T.; Motoyama, Y.; Seki, J. In vitro antiplatelet profile of FR171113, a novel non-peptide thrombin receptor antagonist. Eur. J. Pharmacol., 1999, 384, 197202.

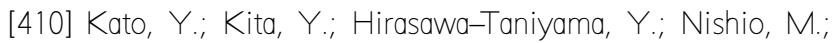
Mihara, K.; Ito, K.; Yamanaka, T.; Seki, J.; Miyata, S.; Mutoh, S. Inhibition of arterial thrombosis by a proteaseactivated receptor 1 antagonist, FR171113, in the guinea pig. Eur. J. Pharmacol., 2003, 473, 163-169.

[411] Barrow, J.C.; Nantermet, P.G.; Selnick, H.G.; Glass, K.L.; Ngo, P.L.; Young, M.B.; Pellicore, J.M.; Breslin, M.J.; Hutchinson, J.H.; Freidinger, R.M.; Condra, C.; Karczewski, J.; Bednar, R.A.; Gaul, S.L.; Stern, A.; Gould, R.; Connolly, T.M. Discovery and initial structure-activity relationships of trisubstituted ureas as thrombin receptor (PAR-1) antagonists. Bioorg Med Chem Lett, 2001, 11, 2691-2696

[412] Nantermet, P.G.; Barrow, J.C.; Lundell, G.F.; Pellicore, J.M.; Rittle, K.E.; Young, M.; Freidinger, R.M.; Connolly, T.M.; Condra, C.; Karczewski, J.; Bednar, R.A.; Gaul, S.L.; Gould, R.J .; Prendergast, K.; Selnick, H.G. Discovery of a nonpeptidic small molecule antagonist of the human platelet thrombin receptor (PAR-1). Bioorg. Med. Chem. Lett., 2002, 12, 319-323

[413] Suzuki, S.; Kotake, M.; Miyamoto, M.; Kawahara, T.; Kajiwara, A.; Hishinuma, I.; Okano, K.; Miyazawa, S.; Clark, R.; Ozaki, F.; Sato, N.; Shinoda, M.; Kamada, A.; Tsukada, I.; Matsuura, F.; Naoe, Y.; Terauchi, T.; Oohashi, Y.; Ito, O.; Tanaka, H.; Musya, T.; Kogushi, M.; Kawada, T.; Matsuoka, T.; Kobayashi, H.; Chiba, K.; Kimura, A.; Ono, N. Preparation of 2 -iminoimidazole derivatives as thrombin receptor antagonists PCT Int. Appl. WO 2002088092, 2002

[414] Suzuki, S.; Kotake, M.; Miyamoto, M.; Kawahara, T.; Kajiwara, A.; Hishinuma, I.; Okano, K.; Miyazawa, S.; Clark, R.; Ozaki, F.; al., e. Preparation of 2iminopyrrolidine derivatives as thrombin receptor antagonists PCT Int. Appl. WO 2002085855, 2002.

[415] Suzuki, S.; Kotake, M.; Miyamoto, M.; Kawahara, T.; Kajiwara, A.; Hishinuma, I.; Okano, K.; Miyazawa, S.; Clark, R.; Ozaki, F.; al., e. Preparation of cyclic amidine derivatives as thrombin receptor antagonists. PCT Int. Appl. WO 2002085850, 2002

[416] Safety and Tolerability of E5555 and Its Effects on Markers of Intravascular Inflammation in Subjects With Coronary Artery Disease http://clinicaltrials.gov/ct2/show/NCT00312052 (February 21, 2011),

[417] Ahn, H.S.; Arik, L.; Boykow, G.; Burnett, D.A.; Caplen, M.A.; Czarniecki, M.; Domalski, M.S.; Foster, C.; Manna, M.; Stamford, A.W.; Wu, Y. Structure-activity relationships of pyrroloquinazolines as thrombin receptor antagonists. Bioorg Med Chem Lett, 1999, 9, 2073-2078.

[418] Ahn, H.S.; Foster, C.; Boykow, G.; Stamford, A.; Manna, M.; Graziano, M. Inhibition of cellular action of thrombin by N3-cyclopropyl-7-[[4-(1-methylethyl)phenyl]methyl]7H-pyrrolo[3, 2-f]quinazoline-1,3-diamine (SCH 79797), a nonpeptide thrombin receptor antagonist. Biochem Pharmacol, 2000, 60, 1425-1434
[419] Ma, L.; Perini, R.; McKnight, W.; Dicay, M.; Klein, A.; Hollenberg, M.D.; Wallace, J.L. Proteinase-activated receptors 1 and 4 counter-regulate endostatin and VEGF release from human platelets. Proc Natl Acad Sci U S A, $2005,102,216-220$

[420] Strande, J.L.; Hsu, A.; Su, J.; Fu, X.; Gross, G.J.; Baker, J.E. SCH 79797, a selective PAR1 antagonist, limits myocardial ischemia/reperfusion injury in rat hearts. Basic Res Cardiol, 2007, 102, 350-358.

[421] Di Serio, C.; Pellerito, S.; Duarte, M.; Massi, D.; Naldini, A.; Cirino, G.; Prudovsky, I.; Santucci, M.; Geppetti, P.; Marchionni, N.; Masotti, G.; Tarantini, F. Proteaseactivated receptor 1-selective antagonist SCH79797 inhibits cell proliferation and induces apoptosis by a protease-activated receptor 1 -independent mechanism. Basic Clin Pharmacol Toxicol, 2007, 101, 63-69

[422] Chackalamannil, S.; Xia, Y.; Greenlee, W.J.; Clasby, M.; Doller, D.; Tsai, H.; Asberom, T.; Czarniecki, M.; Ahn, H.S.; Boykow, G.; Foster, C.; Agans-Fantuzzi, J.; Bryant, M.; Lau, J.; Chintala, M. Discovery of potent orally active thrombin receptor (protease activated receptor 1) antagonists as novel antithrombotic agents. J. Med. Chem., 2005, 48, 5884-5887

[423] Shinohara, Y.; Goto, S.; Doi, M.; Jensen, P. Safety of the novel protease-activated receptor-1 antagonist vorapaxar in Japanese patients with a history of ischemic stroke. J. Stroke Cerebrovasc. Dis., 2012, 21, 318-324.

[424] Morrow, D.A.; Braunwald, E.; Bonaca, M.P.; Ameriso, S.F.; Dalby, A.J.; Fish, M.P.; Fox, K.A.A.; Lipka, L.J.; Liu, X.; Nicolau, J.C.; Oude Ophuis, A.J.; Paolasso, E.; Scirica, B.M.; Spinar, J.; Theroux, P.; Wiviott, S.D.; Strony, J.; Murphy, S.A. Vorapaxar in the secondary prevention of atherothrombotic events. N. Engl. J. Med., 2012, 366, 1404-1413.

[425] Statkevich, P.; Kosoglou, T.; Preston, R.A.; Kumar, B.; Xuan, F.; Trusley, C.; Schiller, J.E.; Langdon, R.B.; Cutler, D.L. Pharmacokinetics of the novel PAR-1 antagonist vorapaxar in patients with hepatic impairment. Eur. J. Clin. Pharmacol., 2012, 68, 1501-1508.

[426] Whellan, D.J.; Tricoci, P.; Chen, E.; Huang, Z.; Leibowitz, D.; Vranckx, P.; Marhefka, G.D.; Held, C.; Nicolau, J.C.; Storey, R.F.; Ruzyllo, W.; Huber, K.; Sinnaeve, P.; Weiss, A.T.; Dery, J.P.; Moliterno, D.J.; Van de Werf, F.; Aylward, P.E.; White, H.D.; Armstrong, P.W.; Wallentin, L.; Strony, J.; Harrington, R.A.; Mahaffey, K.W. Vorapaxar in Acute Coronary Syndrome Patients Undergoing Coronary Artery Bypass Graft Surgery. J. Am. Coll. Cardiol., 2014, 63, 1048-1057.

[427] Zhang, C.; Srinivasan, Y.; Arlow, D.H.; Fung, J.J .; Palmer, D.; Zheng, Y.; Green, H.F.; Pandey, A.; Dror, R.O.; Shaw, D.E.; Weis, W.I.; Coughlin, S.R.; Kobilka, B.K. Highresolution crystal structure of human protease-activated receptor 1. Nature, 2012, 492, 387-392.

[428] Chelliah, M.V.; Eagen, K.; Guo, Z.; Chackalamannil, S.; Xia, Y.; Tsai, H.; Greenlee, W.J.; Ahn, H.S.; Kurowski, S.; Boykow, G.; Hsieh, Y.; Chintala, M. HimbacineDerived Thrombin Receptor Antagonists: C7-Spirocyclic Analogues of Vorapaxar. ACS Med. Chem. Lett., 2014, 5, $561-565$

[429] Kakarala, K.K.; Jamil, K. Screening of phytochemicals against protease activated receptor 1 (PAR1), a promising target for cancer. J. Recept. Signal Transduct. Res., 2014, $1-20$.

[430] Lee, S.; Song, J.H.; Park, C.M.; Kim, J.-S.; Jeong, J.-H.; Cho, W.-Y.; Lim, D.-C. Discovery of Octahydroindenes as PAR1 Antagonists. ACS Med. Chem. Lett., 2013, 4, 10541058. 
[431] Rilatt, I.; Mirabel, E.; Le Grand, B.; Perez, M. Discovery and SAR of small molecule PAR1 antagonists. Bioorg. Med. Chem. Lett., 2010, 20,903-906.

[432] Planty, B.; Pujol, C.; Lamothe, M.; Maraval, C.; Horn, C.; Le Grand, B.; Perez, M. Exploration of a new series of PAR1 antagonists. Bioorg. Med. Chem. Lett., 2010, 20, 1735-1739.

[433] Perez, M.; Lamothe, M.; Maraval, C.; Mirabel, E.; Loubat, C.; Planty, B.; Horn, C.; Michaux, J.; Marrot, S.; Letienne, R.; Pignier, C.; Bocquet, A.; Nadal-Wollbold, F.; Cussac, D.; de Vries, L.; Le Grand, B. Discovery of Novel Protease Activated Receptors 1 Antagonists with Potent Antithrombotic Activity in Vivo. J. Med. Chem., 2009, 52, $5826-5836$

[434] Letienne, R.; Leparq-Panissie, A.; Calmettes, Y.; NadalWollbold, F.; Perez, M.; Le Grand, B. Antithrombotic activity of $F$ 16618, a new PAR1 antagonist evaluated in extracorporeal arterio-venous shunt in the rat. Biochem. Pharmacol., 2010, 79, 1616-1621.

[435] Chieng-Yane, P.; Bocquet, A.; Letienne, R.; Bourbon, T.; Sablayrolles, S.; Perez, M.; Hatem, S.N.; Lompre, A. M.; Le Grand, B.; David-Dufilho, M. Protease-activated receptor-l antagonist $F 16618$ reduces arterial restenosis by down-regulation of tumor necrosis factor $\alpha$ and matrix metalloproteinase 7 expression, migration, and proliferation of vascular smooth muscle cells. J. Pharmacol. Exp. Ther., 2011, 336, 643-651.

[436] Dumas, M.; Nadal-Wollbold, F.; Gaussem, P.; Perez, M.; Mirault, T.; Letienne, R.; Bourbon, T.; Grelac, F.; Le Grand, B.; BachelotŁoza, C. Antiplatelet and antithrombotic effect of $F$ 16618, a new thrombin proteinase-activated receptor-1 (PAR1) antagonist. Br. J. Pharmacol., 2012, 165, 1827-1835.

[437] Asteriti, S.; Daniele, S.; Porchia, F.; Dell'Anno, M.T.; Fazzini, A.; Pugliesi, I.; Trincavelli, M.L.; Taliani, S.; Martini, C.; Mazzoni, M.R.; Gilchrist, A. Modulation of PAR1 signalling by benzimidazole compounds. Br. J. Pharmacol., 2012, 167, 80-94.

[438] Zhang, P.; Gruber, A.; Kasuda, S.; Kimmelstiel, C.; O'Callaghan, K.; Cox, D.H.; Bohm, A.; Baleja, J.D.; Covic, L.; Kuliopulos, A. Suppression of Arterial Thrombosis Without Affecting Hemostatic Parameters With a Cell-Penetrating PAR1 Pepducin. Circulation, 2012, 126, 83-91.

[439] Tressel, S.L.; Koukos, G.; Tchernychev, B.; Jacques, S.L.; Covic, L.; Kuliopulos, A. Pharmacology, biodistribution, and efficacy of GPCR-based pepducins in disease models. In Methods Mol. Biol. Langel, Ü., Ed.; Springer, 2011; Vol. 683, pp 259-275

[440] Covic, L.; Misra, M.; Badar, J.; Singh, C.; Kuliopulos, A. Pepducin-based intervention of thrombin-receptor signaling and systemic platelet activation. Nat. Med., 2002, 8, 1161-1165.

[441] Kostenis, E.; Conklin, B.R.; Wess, J. Molecular basis of receptor/G protein coupling selectivity studied by coexpression of wild type and mutant m2 muscarinic receptors with mutant $\mathrm{G}$ alpha(q) subunits. Biochemistry, 1997, 36, 1487-1495.

[442] Yang, E.; Boire, A.; Agarwal, A.; Nguyen, N.; O'Callaghan, K.; Tu, P.; Kuliopulos, A.; Covic, L. Blockade of PAR1 Signaling with Cell-Penetrating Pepducins Inhibits Akt Survival Pathways in Breast Cancer Cells and Suppresses Tumor Survival and Metastasis. Cancer Res., 2009, 69, 6223-6231.

[443] Cisowski, J.; O'Callaghan, K.; Kuliopulos, A.; Yang, J.; Nguyen, N.; Deng, Q.; Yang, E.; Fogel, M.; Tressel, S.; Foley, C.; Agarwal, A.; Hunt, S.W., 3rd; McMurry, T.;
Brinckerhoff, L.; Covic, L. Targeting protease-activated receptor-1 with cell-penetrating pepducins in lung cancer. Am. J. Pathol., 2011, 179, 513-523. 